\title{
Impact of a Hanford Nuclear Energy Center on Ground Level Fog and Humidity
}

by

J. V. Ramsdell

Atmospheric Sciences Department

March 1977

Prepared for the Energy Research and Development Administration under Contract EY-76-C-06-1830 
NOTICE

This report was prepared as an account of work sponsored by the United States Government. Neither the United States nor the Energy Research and Developmen: Administration, nor any of their employees, nor any of their contractors, subcontractors, or their employees, makes any warranty, express or implied, or assumes any legal liability or responsibility for the accuracy, completeness or usefulness of any information, apparatus, product or process disclosed, or represents that its use would not infringe privately owned rights.

\author{
PACIFIC NORTHWEST LABORATORY \\ operated by \\ BATTELLE \\ for the \\ ENERCY RESEARCH AND DEVELOPMENT ADMINISTRATION \\ Under Contract EY-76-C-06-1830
}

\begin{tabular}{|c|c|}
\hline \multirow{2}{*}{\multicolumn{2}{|c|}{$\begin{array}{l}\text { Printed in the Linited States of Amt } \\
\text { Available from } \\
\text { Natianal Tethnica: Information Ser } \\
\text { L.S. Qesartment of Commerce } \\
5285 \text { Port Royal Road } \\
\text { Springfield. Virginia } 22151\end{array}$}} \\
\hline & \\
\hline -Pages & $\begin{array}{c}\text { NTIS } \\
\text { Selling Price }\end{array}$ \\
\hline $001-025$ & 54.50 \\
\hline $026-050$ & 55.00 \\
\hline $051-075$ & $\$ 5.50$ \\
\hline $076-100$ & $\$ 6.00$ \\
\hline $101-125$ & $\$ 6.50$ \\
\hline $126-150$ & 57.00 \\
\hline $151-175$ & 57.75 \\
\hline $176-200$ & $\$ 8.50$ \\
\hline $201-225$ & $\$ 8.75$ \\
\hline $226-250$ & $\$ 9.00$ \\
\hline $257-275$ & $\$ 10.00$ \\
\hline $276-360$ & 510.25 \\
\hline
\end{tabular}




\section{4}

IMPAC'T OF A HANFORD NUCLEAR ENERGY CENTER ON GROUND LEVEL FOG AND HUMIDITY

by

J. V. Ramsdel1

Atmospheric Sciences Department

March 1977

BATTELLE

Pacific Northwest Laboratories

Richland, Washington 99352 


\section{CONTENTS}

TABLES . iii

FIGURES

INTRODUCTION .

ATMOSPHERIC MODEL • • • • • • • • • • • • • • • • • . 6

Main Program BATMAN. . . . . . . . . . . . . . . 8

Subroutine PRISE . . . . . . . . . . . . . . . . . . 11

Subroutine RCPTOR. . . . . . . . . . . . . . . . 12

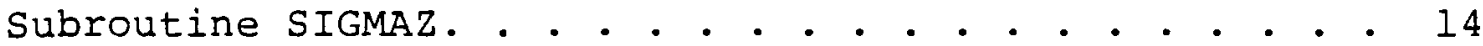

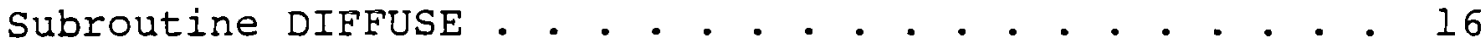

Model Output . . . . . . . . . . . . . . . . . 19

Output Interpretation. . . . . . . . . . . . . . . . 24

THE HNEC MODEL. • . . . . . . . . . . . . . . . . . . . . . 27

Cluster Locations. . . . . . . . . . . . . . . 28

Cooling System Models. . . . . . . . . . . . . . 30

Heat Sink Management Simulations . . . . . . . . . . 32

THE HANFORD CLIMATE - . . . . . . . . . . . . . . . . . . 36

General Climatology. • • • • • • • • • • • • • . 36

Diffusion Climatology. . . . . . . . . . . . . . . . 49

HNEC SIMULATION RESULTS • • • • • • • • • • . . • . . 52

The Predicted Increase in Hours of Fog . . . . . . . . 55

The Influence of Site Location on Fog Increases. . . . 57

The Influence of Cooling system Type on Fog Increases. 58

The Reduction of Visibility in the Tri-Cities. . . . . 61

The Statistical Significance of the Predicted

Increases. . . . . . . . . . . . . . . . . . 62

The Impact on Summer Humidity. . . . . . . . . . . 66

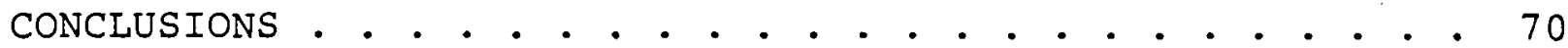

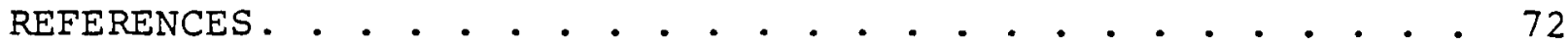
APPENDIX A - BATMAN USER'S GUIDE AND COMPUTER CODE. . . . . A-1 


\section{TABLES}

1 Relationships Between $\sigma_{z}$, Atmospheric Stability and Distance Between the Receptor and Virtual Point Source. . . . . . . . . . . . . . . . . 16

2 Positions of the 4 Reactor clusters for the HNEC Simulations. . . . . . . . . . . . . . . 30

3 Characteristic Cooling System Dimensions. . . . . . . 33

4 Cooling System Thermal Characteristics. . . . . . . 33

5 Site and cooling System Combinations Simulated. . . 35

6 Averages and Extremes of Climatic Elements at Hanford. . . . . . . . . . . . . . . . . . 38

7 Total Duration and Maximum Persistence of Fog Tabulated in Hours for Hanford for the Period 1945-1970 . . . . . . . . . . . . . . . . . . 46

8 Joint Probability of Wind Direction, Wind Speed and Atmospheric Stability at 200' for Hanford . . . . . 51

9 Predicted Increases in Hours of Fog in Selected Areas . . . . . . . . . . . . . . . . 56

10 Predicted Increases in Hours of Reduced Visibility in the Tri-Cities . . . . . . . . . . . . 63

11 Predicted Fog conditions in the Tri-Cities with an HNEC (Current Conditions + Predicted Increases). .

12 Minimum Statistically Significant Increases in Fog in the Tri-Cities . . . . . . . . . . . . . . . . . 


\section{FIGURES}

1 The Hanford Reservation Location. . . . . . . . 3

2 Plume Source and Receptor Geometry. . . . . . . . 13

3 Sigma 2 Curves. . . . . . . . . . . . . . 15

4 Sample Computer Output of Increased Water Vapor

Density (l Cluster). . . . . . . . . . . 20

5 Sample Computer Output of Increased Water Vapor Density (5 Clusters). . . . . . . . . . . . 21

6 Sample Computer Output of Increased Hours of Water Vapor Density Exceeding a Fixed Value $\left(1 \mathrm{~g} / \mathrm{m}^{3}\right) \cdot$. 23

7 Sample Computer Output for Predicted Increase in Hours of Saturation (Fog). . . . . . . . . . 25

8 Relationship Between Relative Humidity Increase and Temperature for an Increase in Water Vapor Density of $1 \mathrm{~g} / \mathrm{m}^{3}$. . . . . . . . . . . . . . . 26

9 The HNEC Cluster Locations in the BATMAN Grid system. . . . . . . . . . . . . . . . . . 29

10 The Diurnal Cycles of Temperature, Relative Humidity and Wind Speed for January at Hanford. . . . . . 40

11 The Diurnal Cycles of Temperature, Relative Humidity and Wind Speed for July at Hanford. . . . . . . . 41

12 The Diurnal and Annual Variation of Average Saturation Deficit $\left(\mathrm{g} / \mathrm{m}^{3}\right)$ at Hanford. . . . . . . 43

13 Cumulative Frequency Distributions for Saturation Deficits at Hanford. . . . . . . . . . . . . . 44

14 Percent Probability of Exceeding a Given Number of Hours of Fog at Hanford. . . . . . . . . . . 47

15 Cumulative Frequency Distributions for Visibility During Fog at Hanford. . . . . . . . . . . . 48

16 Wind Roses by Atmospheric Stability for Hanford. . . 50 
17 Surface Wind Roses for Various Locations on and Surrounding the Hanford Site. (The points of the rose represent the directions from which the winds come). . . . . . . . . . . . . . . . . 53

18 Wind Roses for the FFTF and WNP-2 Sites. . . . . . 54

19 Relationship Between Increased Hours of Fog for an HNEC Using Hybrid Wet/Dry Cooling systems and the Percent wet Cooling. . . . . . . . . . . . 60

20 Hours of Water Vapor Density Increase Exceeding $1 \mathrm{~g} / \mathrm{m}^{3}$ During summer Months for a Single Cluster at Hanford . . . . . . . . . . . . . . . 67

21 Hours of Water Vapor Density Increase Exceeding $1 \mathrm{~g} / \mathrm{m}^{3}$ During Summer Months for a 20 Reactor Energy Center at Hanford. . . . . . . . . . . . . 68

22 Hours of Water Vapor Density Increase Exceeding $1 \mathrm{~g} / \mathrm{m}^{3}$ During Summer Months for a 40 Reactor Energy Center at Hanford. . . . . . . . . . . . . 69

Al Input statements and Formats for BATMAN. . . . . . . A-2

A2 A Sample Input Data Deck for Computation of Increases in Water Vapor Density . . . . . . . . A-6

A3 A Sample Input Data Deck for Computation of Increases in Fog . . . . . . . . . . . . . . A-7

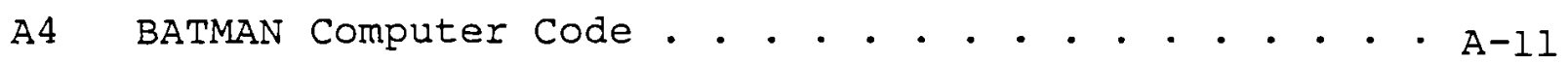


IMPACT OF A HANFORD NUCLEAR ENERGY CENTER

ON GROUND IEVEL FOG AND HUMIDITY

\section{INTRODUCTION}

Battelle, Pacific Northwest Laboratory is currently involved in the evaluation of the nuclear energy center concept as it might be applied to development of the Energy Research and Development Administration's Hanford Reservation. In that study a number of subjects have been examined in detail and the results presented in technical reports $(1-4)$; the over-all results have been summarized in an interim report ${ }^{(5)}$. During the past year the examination of various heat sink management options has continued in greater depth. The results of this work are contained in Selection of Heat Disposal Methods for a Hanford Nuclear Energy Center ${ }^{(6)}$. This document presents the details of a study of the atmospheric impacts of an Hanford Nuclear Energy Center (HNEC) that might result from the use of evaporative cooling alternatives. Specific cooling systems considered. include once-through river cooling, cooling ponds, cooling towers, helper cooling ponds and towers and hybrid wet/dry cooling towers. The specific impacts evaluated are increases in fog and relative humidity.

The energy center concept generally involves the grouping of 10 to 40 power plants on a common site. The center may contain supporting fuel cycle facilities, however the major heat releases and atmospheric effects are expected to be associated directly with power generation. A summary of the postulated atmospheric effects of heat rejection from nuclear energy centers is presented in Reference 7. These effects have been postulated on the basis of theory, models, analogy and speculation. Unfortunately some of the more spectacular 
effects are primarily the result of the last two processes. While a complete listing is not particularly important here, typical effects include: increases in humidity, cloudiness and fog, enhancement of precipitation and modification of precipitation patterns, triggering of severe weather such as thunderstorms, and the concentration of vorticity resulting in the formation of large dust devils.

The specific atmospheric effects which might be associated with a particular energy center are generally related to the form of heat rejection, the flux density and area of heat rejection, and the climate of the energy center site. For example fog and humidity increases are associated with low level wet cooling systems, while more spectacular effects such as concentration of vorticity are postulated for closely spaced cooling systems with a high energy flux.

The conceptual center being evaluated for Hanford (HNEC), which is located in South-central Washington state is shown in Figure 1, consists of 20 to 40 power plants with associated switching and transmission facilities, a fuel fabrication plant, two fuel reprocessing plants and a waste storage facility (5). Each of the reactors is assumed to be rated at $1250 \mathrm{MW}_{\mathrm{e}}$, so that total heat rejection from a 40 reactor energy center is approximately $10^{5}$ MW. Specific locations for the individual power plants have not been established, however it has been assumed that they will be grouped in clusters of 4 with each cluster covering approximately $1 \mathrm{sq}$. mi. Preliminary site evaluation indicates that the total area covered by the energy center will be between 100 and 300 sq. mi. with the larger value representing the full 40 reactor case. These values are in contrast to the $75 \mathrm{sq}$. $\mathrm{mi}$. assumed for 40 reactor nuclear energy centers in the NECSS study. 


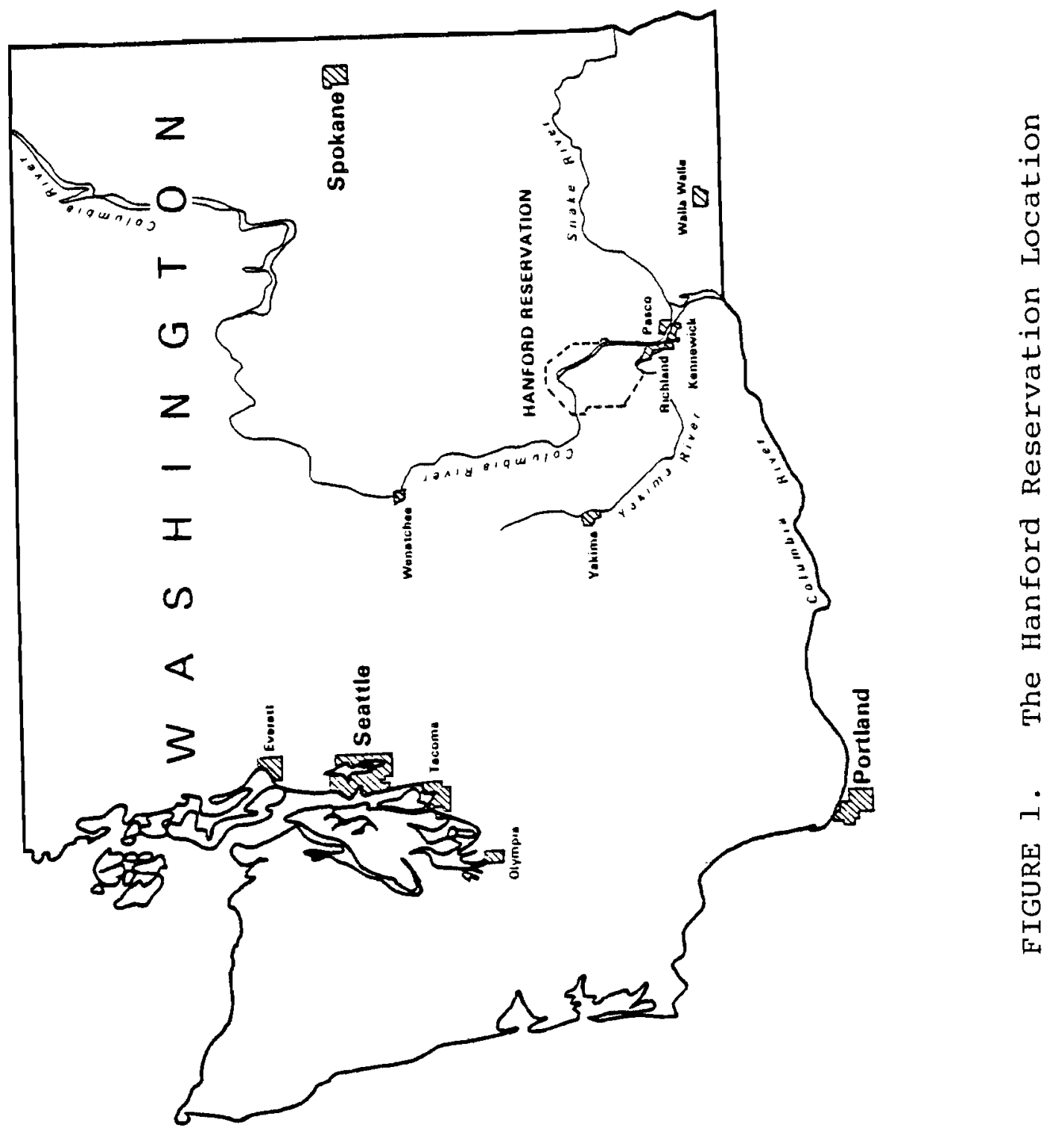


A preliminary study of heat sink management for the HNEC $^{(4)}$ has indicated that, from an engineering standpoint, a variety of cooling systems are potentially suitable for handling the heat dissipation. These systems range from once through cooling to dry cooling towers and include several hybrid systems. The selection of the cooling system mix to be assumed in evaluation of the HNEC concept has been a matter of some concern along with selection of specific locations for the clusters. An attempt has been made to resolve both issues through the development of a comprehensive heat sink management plan that would result in the most favorable balance between resource utilization, economics and environmental impact. In this effort it has been necessary to evaluate the effects of heat dissipation so that their significance could be rationally assessed.

Rational evaluation of the significance of any effect of heat rejection requires that the extent and timing of the effect be estimated quantitatively, and that significance be defined in meaningful terms. Each of the effects postulated in the NECSS report ${ }^{(7)}$ has been considered in a cursory manner to screen out improbable impacts and those which can not be adequately evaluated at this time.

Concentration of vorticity has been related to high density of the rejected heat and relatively large areas. This was a major concern for the energy centers considered in the NECSS where the flux density was about .5 KW/M ${ }^{2}$. The flux density for the HNEC would be between .1 and $.3 \mathrm{~kW} / \mathrm{M}^{2}$. There are no simple methods for quantifying the frequency, magnitude or effect of vortices which might be generated. As a result, detailed consideration of vorticity concentration has been postponed until better tools are developed. 
The status with respect to modification of precipitation patterns and the triggering of storms is somewhat better. Theory and numerical models exist which can provide insight into these postulated effects. Several investigators are currently pursuing this avenue of research. When suitable results are achieved they will be applied to HNEC, although recently publicized problems in the National Hail Research Experiment ${ }^{(8)}$ raise questions about the reliability of quantitative estimates in this area.

The only atmospheric effects that are most amenable to treatment at this time are those associated with the addition of moisture to atmosphere. Even in this case the treatment is semi-quantitative at best. The effects of cooling systems on fog and humidity are the atmospheric impacts of heat rejection that have been used in selection of a overall HNEC heat sink management plan.

At the outset of the evaluation it was assumed that the addition of heat and moisture were not, in themselves, significant. Similarly it was assumed that a postulated small change in any naturally occurring atmospheric phenomenon would not be significant. Rather, significance must be achieved by meeting some specific criteria. Four possible areas for criteria have been identified. These include: a statistically significant change in a meteorological variable, substantial adverse economic impact of a postulated change, initiation of an ecological change, and adverse public reaction. The criteria other than that of statistical significance are still not satisfactorily defined, but the general areas provide guidance on the detail required in specification of a postulated impact. 


\section{ATMOSPHERIC MODEL}

The introductory remarks above contain the seeds of the atmospheric modeling requirements for input to selection of an optimum heat sink management scheme. The number of combinations of reactor locations and cooling systems, plus the need to evaluate each combination under a variety of meteorological conditions indicate that a flexible, inexpensive model be used in the evaluation. Further the need to differentiate between the atmospheric impacts of various cooling system mixes indicates that the model should be as realistic and as sensitive to differences between cooling systems as possible.

With these requirements as a background, BATMAN a Battelle Atmospheric Management computer code was developed. Specifically the code was designed to assist in the selection of viable heat sink management options for the HNEC by providing estimates of the impact of evaporative cooling systems. To accomplish this objective, the code is capable of computing the diffusion of moisture released in the cooling of 1 to 20 arbitrarily placed reactor clusters. The number of reactors in each cluster is limited only in the sense that all reactors in the cluster must utilize the same type cooling system. A mixture of cooling systems within a cluster can be simulated by superpositioning 2 or more clusters with different systems. In reality, BATMAN is a computer code that provides "back of the envelope", computations for up to 20 simultaneous energy releases and 144 receptor locations.

The economy and flexibility needed to examine the many possible HNEC scenarios are incorporated in BATMAN through the use of climatological data input and a modified sectoraveraged Gaussian plume diffusion model. Reactor cluster locations and cooling system emission characteristics are input at the time of program execution. The cluster locations 
are identified with respect to a receptor grid; it is not necessary that they be on the grid. The receptor grid is a $12 \times 12$ matrix of surface points for which increases in water vapor density are computed. This increase may be computed at several levels above the surface for each grid point, if desired. The spacing between grid points may be adjusted with the north-south spacing independent of the east-west spacing.

Currently BATMAN can be run in two modes. In the first mode a specific scenario is examined (i.e., a fixed set of reactor clusters, a specified wind direction and speed, and a single atmospheric stability). BATMAN then provides estimates of increased density of atmospheric water vapor. An estimate of the frequency of occurrence of the scenario can be made if sufficient climatological information is available. The second mode uses climatological input in the form of a joint frequency distribution of occurrence of wind speed, wind direction and atmospheric stability. The number of hours per year that increases in vapor density can be expected to fall within selected ranges is estimated. If additional climatological data on the frequency of occurrence of saturation deficits (in terms of vapor density) are available, BATMAN can produce direct estimates of the increase in hours of fog at each receptor location.

Economy of operation of BATMAN is enhanced by computing diffusion estimates only if a receptor is in the plume from a given cluster. After all receptor locations are considered for one cluster the process is repeated for successive clusters until all have been treated. The change in water vapor density at each receptor location is the sum of the contributions from all clusters. 
In the following sections the details and features of BATMAN are described. The computer code and a short users guide are presented in Appendix $A$ at the end of this document.

\section{Main Program BATMAN}

BATMAN performs the typical function of a main program. It controls the flow of information by handing input and output, and by calling subroutines which perform most of the actual computations. In addition to these functions BATMAN computes the source term for each reactor cluster, determines the appropriate virtual source as a function of wind direction, and combines the results of the individual cluster impacts to estimate the impact of the energy center.

The moisture source term is determined from input data on number of reactors in a cluster, rates electrical power output and cooling system type. Additional inputs required in the source term evaluation are overall thermal efficiency of the power plant and the fraction of the waste heat which is rejected in the latent form. The remaining waste heat is assumed to be sensible (increased temperature). Radiative heat transfer is neglected. The total latent heat release is then used to compute a rate of evaporation. The thermal efficiencies and latent heat fraction are functions of cooling system type and atmospheric conditions. The relationships between efficiency and atmospheric conditions are summarily treated by use of seasonal or annual values. More detailed treatment of these relationships is not warranted because of the nature of the basic model.

The fundamental climatological data input to BATMAN consists of information on wind direction, wind speed, atmospheric stability, temperature, plume width and mixing depths. With these data and a moisture source term the model can compute 
increases in water vapor density and the frequency of occurrence of increases within specified ranges. If the model is to convert the water vapor increase to frequency of occurrence of fog, additional climatological input is required. This information includes the number of hours being considered and the distribution of water vapor saturation deficits.

Wind direction must be specified in terms of sectors starting with sector 1 as the first sector east of north and increasing in a clockwise direction. The number of sectors is limited only by dimensions of the program. Currently the program is set for 16 sectors. Calm and variable winds should be distributed among the sectors. The distribution of these winds in proportion to the frequency of occurrence of directions during the remainder of the time should be conservative.

As with wind direction, the number of wind speed categories is limited by the program dimensions. The limitation is on the product of wind speed and direction classes and is currently set at 96. Thus, with 16 wind direction sectors, the number of wind speed classes is limited to 6 .

The limitation on the product can easily be increased to accommodate more wind direction and/or speed classes. However, an increase in the number of classes rapidly increases computer storage requirements. For instance, increasing the number of direction classes to 36 and speed classes to 10 would increase storage requirements by almost 3200 words.

BATMAN will accept atmospheric stability data in the 4 category Hanford stability classification scheme or in either the 6 or 7 category Pasquill-Gifford scheme (9). The stability classification scheme is specified by indicating the number of categories, with categories numbered in order of increasing stability. 
A temperature input is required for plume rise computations if cooling towers are specified in the source description. The model is not particularly sensitive to the temperature input, therefore, a seasonal or annual average is adequate.

The diffusion model is used in a sector-averaged model, thus it is necessary to define the width of the sector occupied by the plume. There are no mathematical restrictions on the width of this sector, however, common sense would indicate that it should be at least as wide as the wind direction sectors.

The final climatological input required in all modes of operation for BATMAN is the sepcification of a mixing depth. The mixing depth is the upper limit to the vertical spread of the moisture plumes. As moisture reaches this level, it is reflected. If the mixing level is specified as zero, vertical diffusion of the plumes is unbounded.

Additional climatological data on the water vapor saturation deficit must be provided if the frequency of occurrence of fog is to be computed. This information is the expected number of hours of saturation deficit within ranges which may be specified. The model is currently limited to 10 ranges, but again that limit can be increased if necessary.

Finally, it is necessary to specify several physical parameters in addition to the source term, and climatology. These parameters include the grid spacing; the number of levels of interest and their heights; the type cooling systems, their dimensions and release heights, and a critical wind speed if cooling towers are specified. The critical wind speed is used in conjunction with ambient wind speed to determine when plume rise should be limited by downwash and when building wake effects should be considered. 
The number of levels which can be considered is limited to a maximum of 10 , but is also limited by the number of saturation deficit classes. The product of saturation deficit classes and levels must be less than 20. The grid spacing is restricted only by the cooling system dimensions. The model is not meant for a fine scale examination of effects near the sources. Thus the grid spacing should be larger than the characteristic horizontal dimensions of the cooling system. North-south and east-west grid spacings need not be the same.

\section{Subroutine PRISE}

Subroutine PRISE computes the plume rise for cooling tower releases. Prior to calling PRISE, BATMAN checks the wind speed. If the wind speed is equal to or greater than the critical speed, the plume rise is assumed to be zero and the effective release height is set equal to the actual release height. Otherwise, PRISE is called and the plume rise is computed. Following the plume rise computation the effective release height is determined. If it is above the mixing layer and the actual release height is below the lid, plume rise is reduced to make the effective release height equal to the top of the mixing layer.

Computation of plume rise is based on Briggs' formulae for final plume rise ${ }^{(10)}$. In these formulae, plume rise is a function of the sensible heat flux, the wind speed, atmospheric stability, atmospheric temperature and actual release height. The formulae do not account for latent heat flux, which in cooling towers may be several times the sensible heat flux. As a cooling tower plume condenses this latent heat contributes to additional plume rise. Therefore, provision has been made for inclusion of a latent heat correction factor. 
In these formulae it is not appropriate to allow the wind speed to approach zero too closely. Thus, for wind speeds less than $1 \mathrm{~m} / \mathrm{s}$, the following assumptions were made: for stable atmospheric conditions the calm formulation was used, and for neutral and unstable conditions the wind speed was assumed to be $0.5 \mathrm{~m} / \mathrm{s}$.

The use of final plume rise formulae reduced the number of required plume use computations and is generally justifiable because of coarse grid spacing. Had plume rise been treated as a function of distance from the source the number of plume rise computations would have been several times as large.

Subroutine RCPTOR

The function of subroutine RCPTOR is to determine whether a receptor is within the plume from a cluster or not, and if it is to determine the distance from the virtual point source to the receptor.

The problem solved by RCPTOR is shown schematically in Figure 2. Position $A$ is the location of the cooling system which is specified in the cooling system description along with a typical horizontal dimension for the system. Position $B$ is the virtual point source. It is computed from the cooling system width, the angular width of the plume and the wind direction. The distance between $A$ and $B$ is constant once the source and plume widths are specified. Position $C$ is a known point in the grid. Thus the positions of three vertices of a triangle are known.

From this information the remaining sides of the triangle, the distances between the actual and virtual sources and the receptor, can be computed. If the distance between the virtual source and the receptor is less than either of the other sides of the triangle, the receptor is not in the plume 


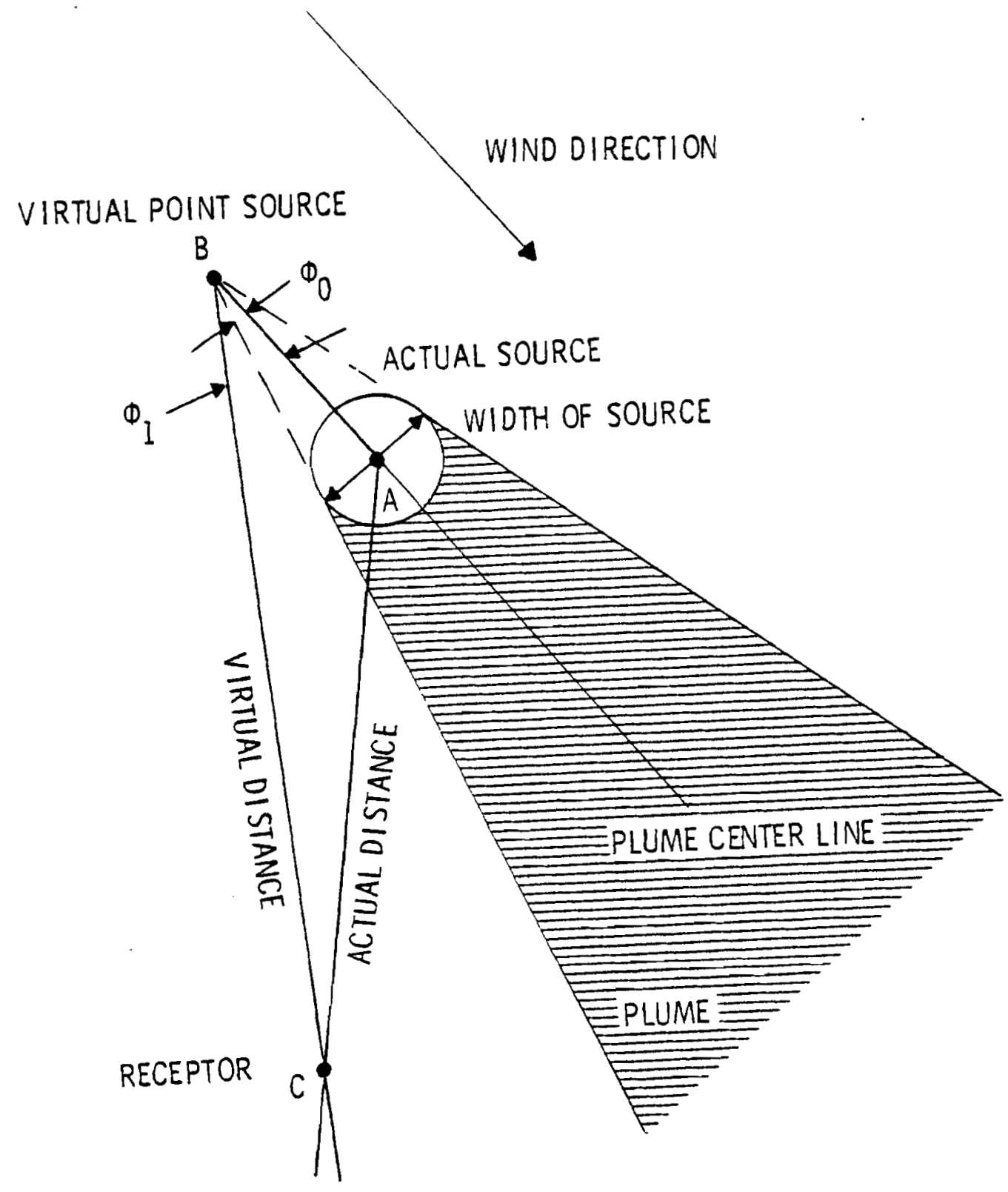

FIGURE 2. Plume Source and Receptor Geometry 
and RCPTOR returns to the main program to start consideration of the next receptor. If this virtual distance is the longest side of the triangle, the angle at $B$, labeled $\phi_{1}$ is compared with $1 / 2$ the plume angular width, $\phi_{0} \cdot$ When $\phi_{1}$ is less than or equal to $\phi_{O}$, RCPTOR initiates the diffusion computation. Otherwise the return from RCPTOR initiates consideration of the next receptor.

\section{Subroutine SIGMAZ}

The first step in the diffusion computation is the computation of the vertical dispersion parameter $\sigma_{z}$. Under normal conditions $\sigma_{z}$ is a function of atmospheric stability and distance from the source. In BATMAN the distance between the receptor and virtual point source is used. When wind speeds are above the critical wind speed and low-level mechanical draft cooling towers are used, the value of $\sigma_{z}$ is corrected for wake effects.

The basic formulations used for the relationships between stability, distance and $\sigma_{z}$ are those suggested by Briggs (11). A seventh relationship has been added to treat the PasquillGifford $G$ stability class. The relationships are given in Table 1 and shown in Figure 3. Table 1 also serves to show the relationship between the Pasquill-Gifford and Hanford stability classes. The existence of the G stability class is in doubt and is currently an issue receiving attention.

Plumes from low-level, mechanical draft cooling towers are assumed to downwash and enter the wake behind the tower when the wind speed exceeds the critical speed. In these cases, the plume undergoes a rapid initial vertical dispersion due to the cooling tower wake. This effect is accounted for in subroutine SIGMAZ. 
BRIGG'S SIGMA Z CURVES

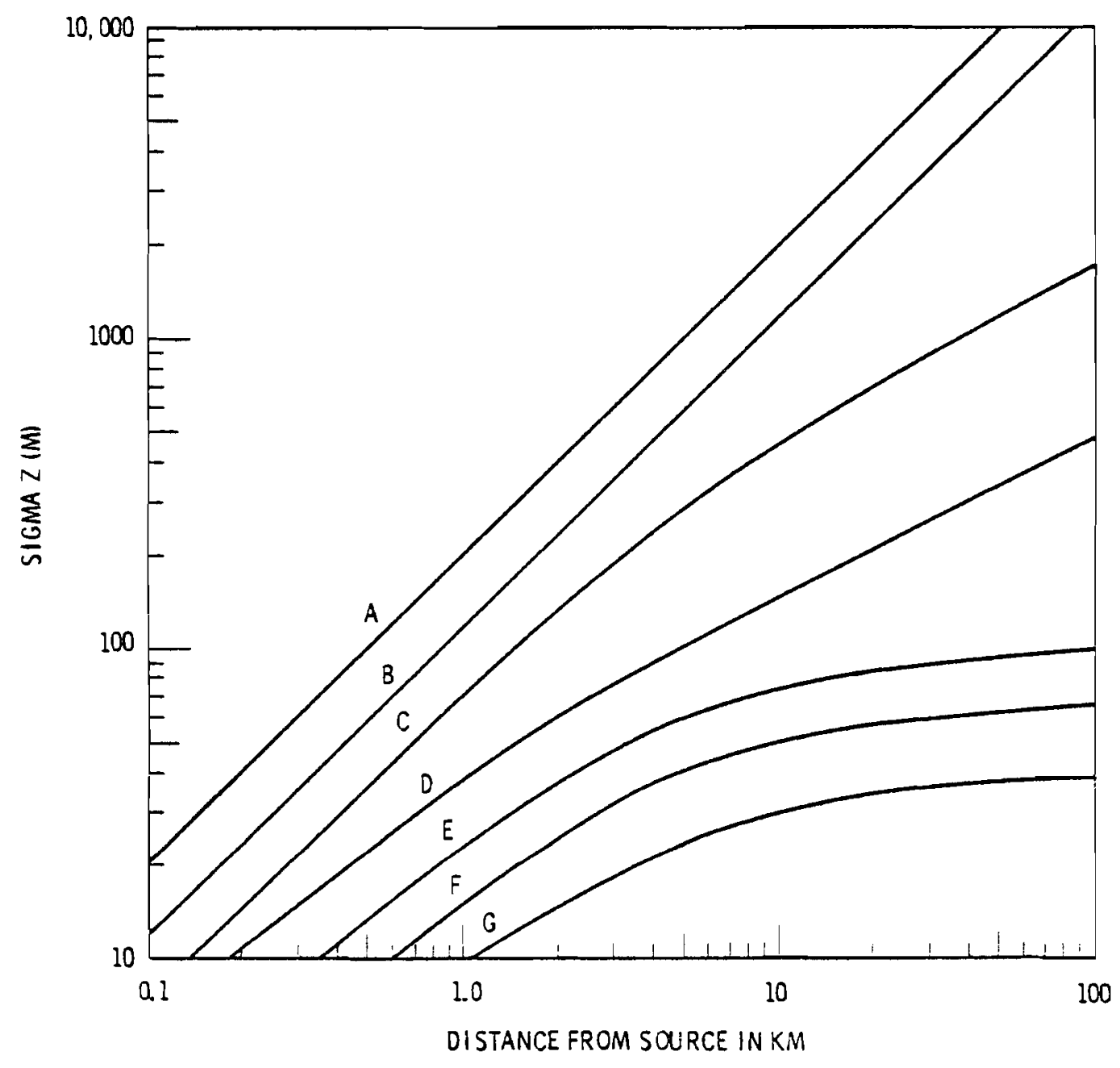

FIGURE 3. Sigma $Z$ Curves 
TABLE 1. Relationships Between $\sigma_{z}$, Atmospheric Stability and Distance Between the Receptor and Virtual point Source

Stability Class

\section{Pasquill-Gifford}

A

B

$\mathrm{C}$

D

E

F

G
Hanford

Unstable
Neutral
Slightly stable
Moderately stable

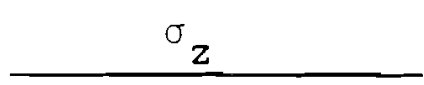

$.20 \mathrm{x}$

$.12 \mathrm{x}$

$.08 x /(1+.0002 x)^{\frac{1}{2}}$

$.06 x /(1+.0015 x)^{\frac{1}{2}}$

$.03 x /(1+.0003 x)$

$.02 x /(1+.0003 x)$

$.012 x /(1+.0003 x)$

A corrected estimate of $\sigma_{z}$ is computed using the relationship

$$
\sigma_{\mathrm{zC}}^{2}=\sigma_{\mathrm{zi}}^{2}+\mathrm{H}^{2} / 2 \pi
$$

where $\sigma_{z c}$ is the corrected value, $\sigma_{z i}$ is the initial uncorrected value and $\mathrm{H}$ is the height of the cooling tower. In cases where the source is a cluster of cooling towers with a large width, the net effect of this correction is generally small.

\section{Subroutine DIFFUSE}

The last subroutine used by BATMAN is DIFFUSE. It calls SIGMAZ and then uses the result to compute the water vapor density increase at the receptor. DIFFUSE is by far the longest and most complex subroutine.

The diffusion computations in DIFFUSE use a sectoraveraged Gaussian plume model with complete reflection at the ground and an optional reflecting lid. The basic sector- 
averaged model is described in Section 3.3 of Meteorology and ${\text { Atomic Energy - } 1968^{(9)}}^{(9)}$ while the treatment of the reflecting Iid is based upon Section 6.6 of Csanady's Turbulent Diffusion in the Environment ${ }^{(12)}$.

The model that was derived from these sources is:

$$
\left(\Delta \rho_{v}\right)_{k i}=\frac{Q_{i} \hat{n}}{(2 \pi)^{3 / 2} \sigma_{z} \overline{u x}} \sum_{j=-\infty}^{\infty}\left\{\exp \left[\frac{\left(z-h_{j}+2 j H\right)^{2}}{-2 \sigma_{z}^{2}}\right]+\exp \left[\frac{\left(z+h_{j}+2 j H\right)^{2}}{-2 \sigma_{z}{ }^{2}}\right]\right\}
$$

where: $\left(\Delta \rho_{\mathrm{v}}\right)_{\mathrm{ki}}$ is the increase in water vapor density at receptor $k$ due to source $i$,

$Q_{i} \quad$ is the water vapor release rate of source $i$,

$\hat{\mathrm{n}} \quad$ is related to the assumed plume width, $\phi_{0^{\prime}}$ by $\hat{n}=\pi / \phi_{0}$ when $\phi_{0}$ is in radius,

$\phi_{z} \quad$ is the vertical dispersion parameter,

$\overline{\mathrm{u}} \quad$ is the wind speed,

$\mathrm{x} \quad$ is the distance between the receptor and virtual point source,

$z$ is the height above the ground,

$h_{i} \quad$ is the effective release height for source $i$, and

$\mathrm{H} \quad$ is the height of the reflecting lid.

Equation 2 can be simplified if any or all of $z, h_{i}$ and $\mathrm{H}$ are zero. The greatest simplification occurs if $\mathrm{H}$ is zero. In that case the infinite sum is eliminated. If either $h_{i}$ is zero the two exponential terms can be combined. If $z=0$ the infinite sum is twice the sum from $\circ$ to $\infty$. Finally, if all three are zero, the infinite sum and the exponential terms are eliminated. 
DIFFUSE computes the relative water vapor increase $\left(\Delta \rho_{\mathrm{v}}\right)_{\mathrm{ki}} / Q_{\mathrm{i}}$ by first calculating

$$
\frac{\hat{n}}{(2 \pi)^{3 / 2} \sigma_{z} \overline{u x}}
$$

and the denominator in the exponential terms. It then determines what simplifications can be made in the infinite sum. If there is no lid, the infinite sum reduces to the sum of the two exponential terms with $j=0$ and a check is made to see if the exponential terms may be combined or eliminated. In all cases where $\mathrm{H}=0$ the computations are straight foreward.

If the model cannot be simplified because $\mathrm{H}=0$, DIFFUSE checks the ratio of $\mathrm{H} / \sigma_{z}$. In the limit of $\sigma_{z}$ becomes large, the vertical profile of the water vapor increase becomes a uniform distribution, and (2) reduces to

$$
\frac{\left(\Delta \rho_{V}\right)_{k i}}{Q_{i}}=\frac{\hat{n}}{2 \pi H \bar{u} x}
$$

A uniform distribution can be assumed with an error of less than $0.25 \%$ if the ratio $\mathrm{H} / \sigma_{z}$ is less than 1.5 .

When a uniform concentration cannot be assumed with this accuracy, the summation is carried out between $j=-2$ and $j=+2$. In this process, all reflection terms that are less than $0.25 \%$ of the value of the term when $j=0$ are neglected. The terms to be neglected can be identified by examination of ratios between $z, h_{i}, H$ and $\sigma_{z}$.

Finally DIFFUSE computes $\left(\Delta \rho_{\mathrm{V}}\right)_{\mathrm{ki}}$ according to 


$$
\left(\Delta \rho_{v}\right)_{k i}=Q_{i}\left[\frac{\left(\Delta \rho_{v}\right)_{k i}}{Q_{i}}\right] \text {. }
$$

The combination of the increases in water vapor density from all of the sources to estimate the total increase is accomplished in BATMAN. The next section describes this process and the treatment of the computational results.

Model Output

BATMAN has the flexibility to examine increases in water vapor content for both special cases and on a climatological basis. This section describes the output for both operational modes and discusses the interpretation of the output.

In both modes BATMAN computes the total increase in water vapor density at each grid point assuming that the contributions of the individual plumes are additive. Thus, the total increase is given by

$$
\left(\Delta \rho_{v}\right)_{k}=\sum_{i=1}^{N}\left(\Delta \rho_{v}\right)_{k i}
$$

where $\mathrm{N}$ is the number of sources (clusters).

If the effects of a single set of atmospheric conditions (wind speed, direction, stability and mixing depth) are being examined, this information can be obtained. Figure 4 shows a sample of the output of $\Delta p_{\mathrm{V}}$ for the case of WNW winds at $6.93 \mathrm{~m} / \mathrm{s}$ during moderately stable atmospheric conditions for a single 4 reactor cluster with mechanical draft cooling towers located at grid position 6.1, 7.5. These atmospheric conditions occur approximately 3.45\% of the time. Figure 5 shows the impact of 20 reactors divided among 5 clusters under the 


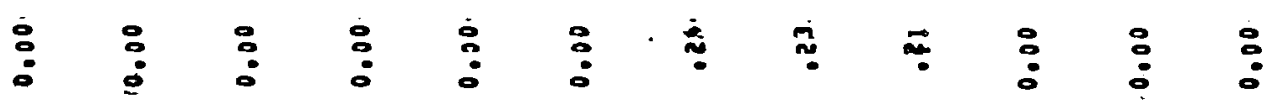

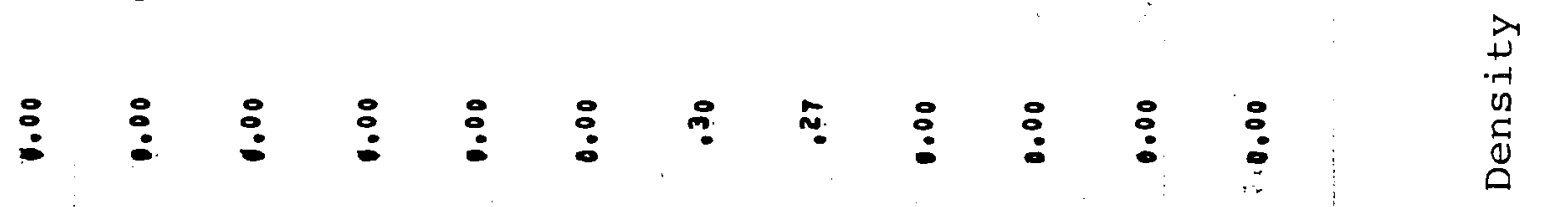
๕

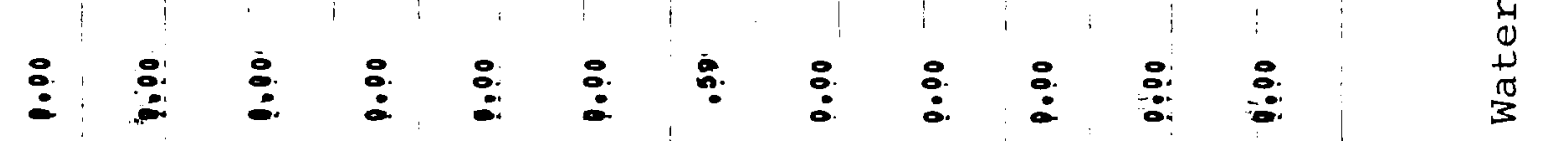

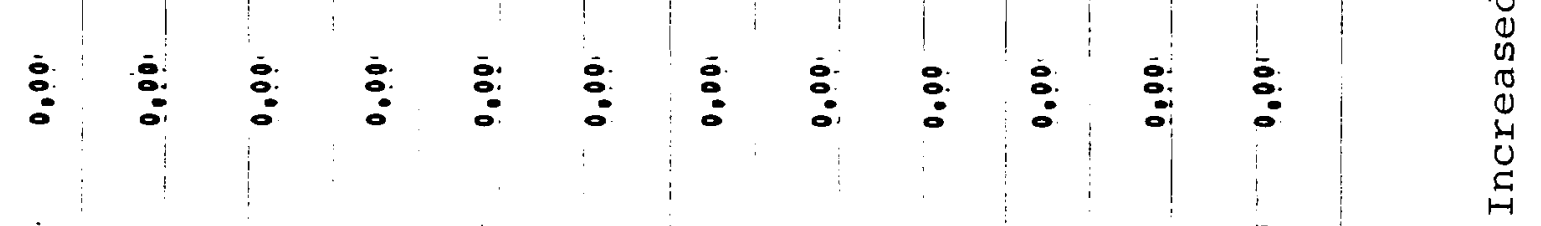

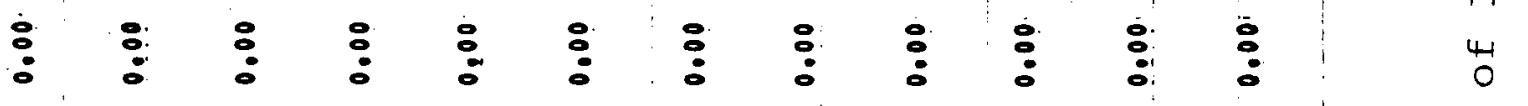

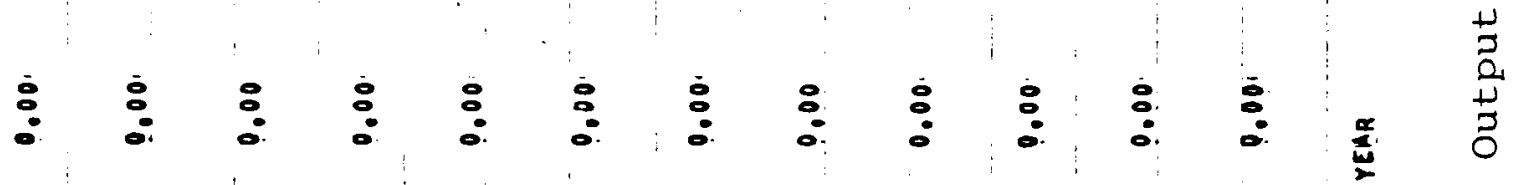

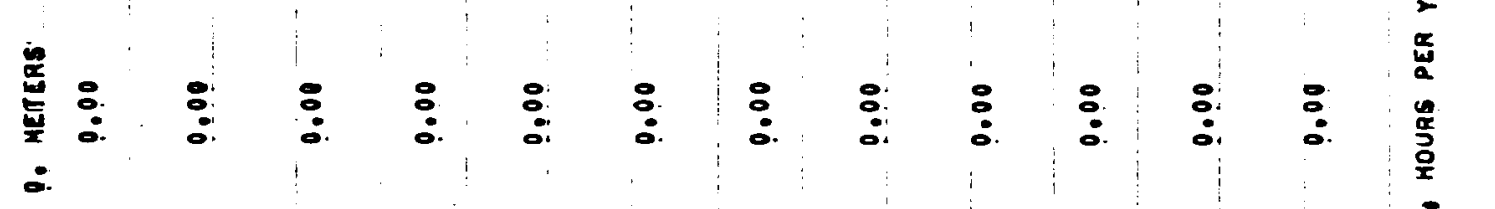
.

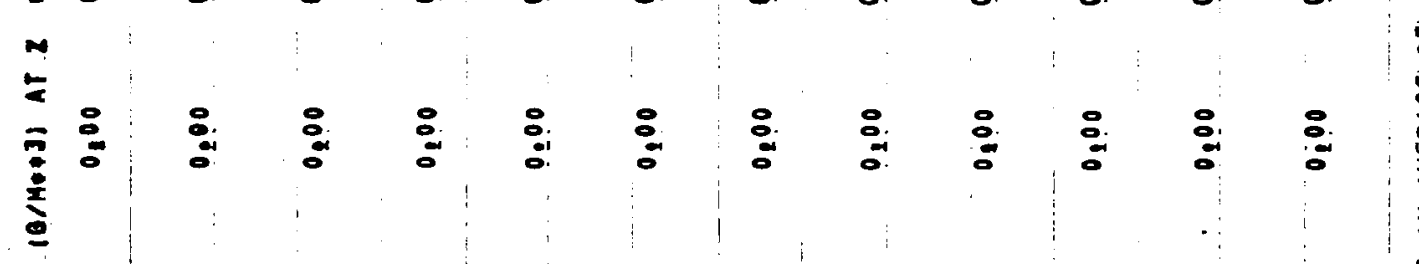

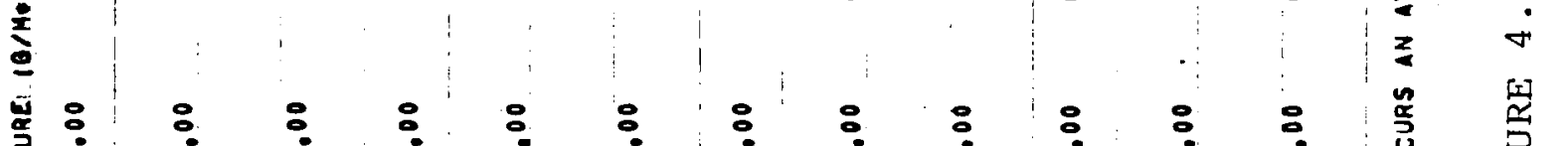

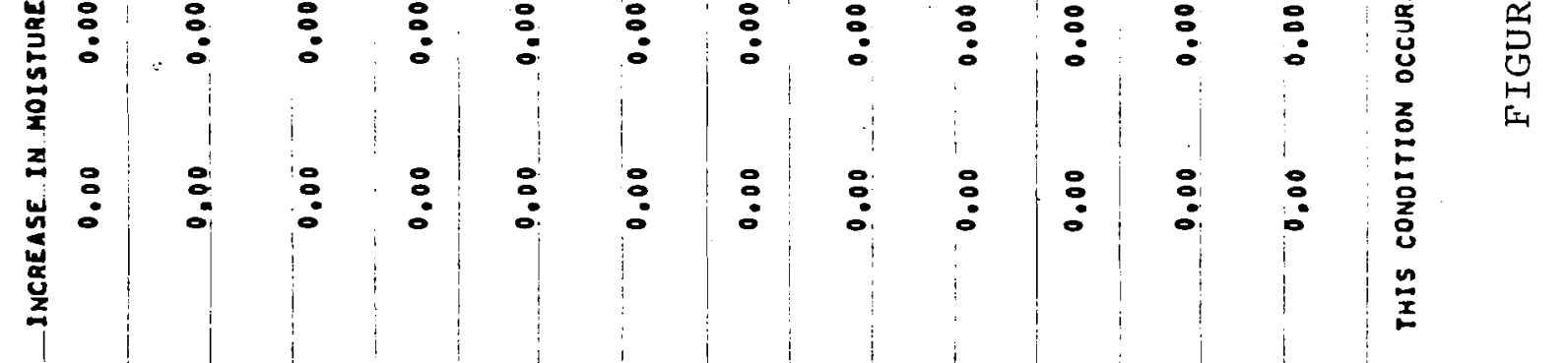




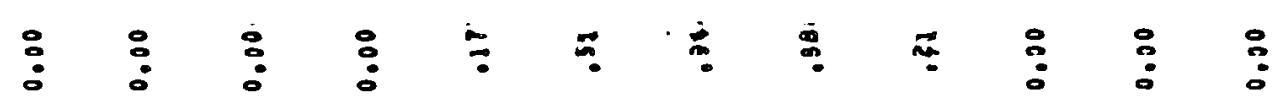

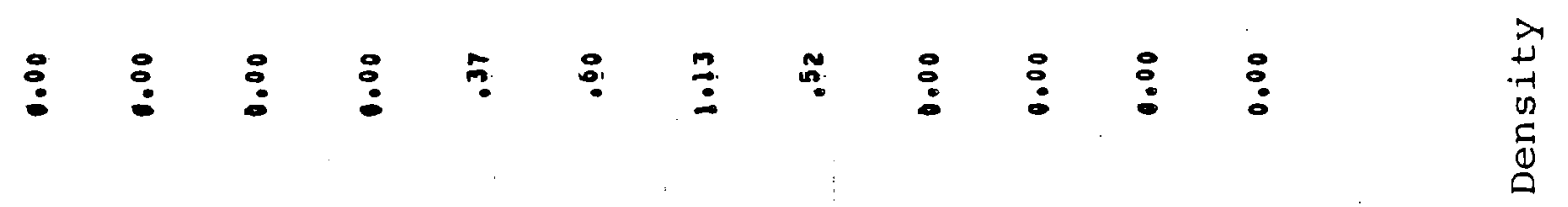

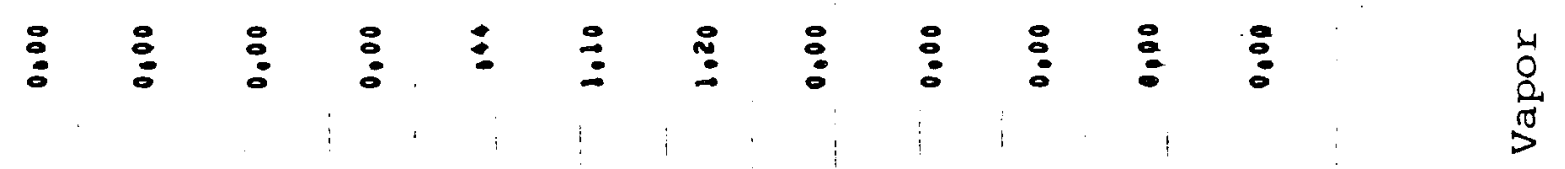

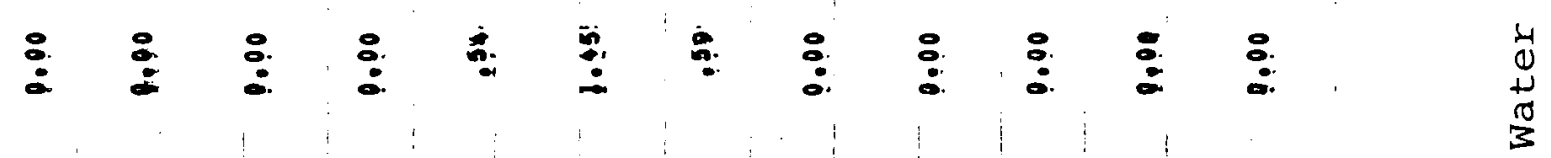

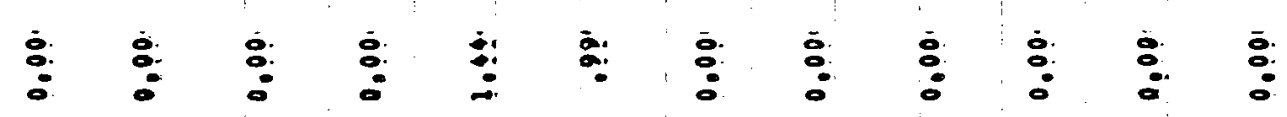
ఏั

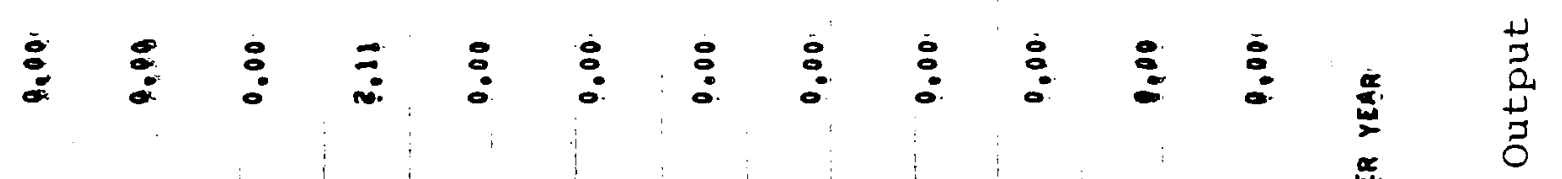

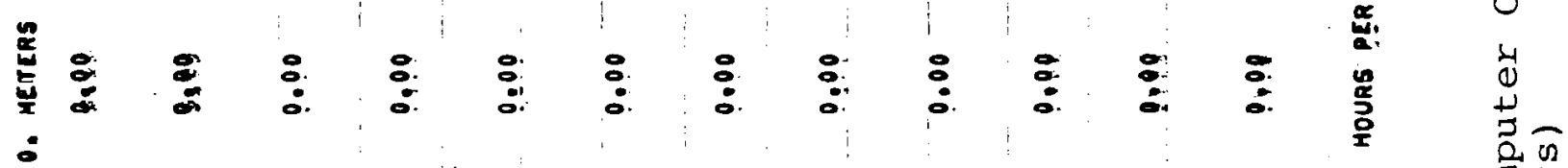
.

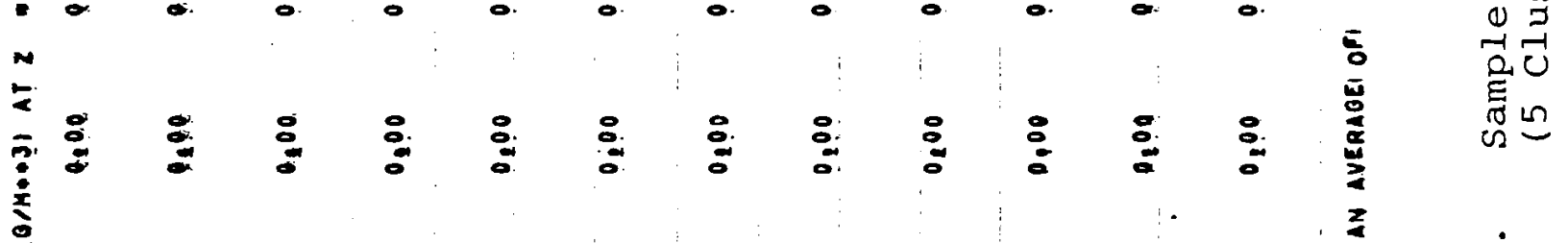

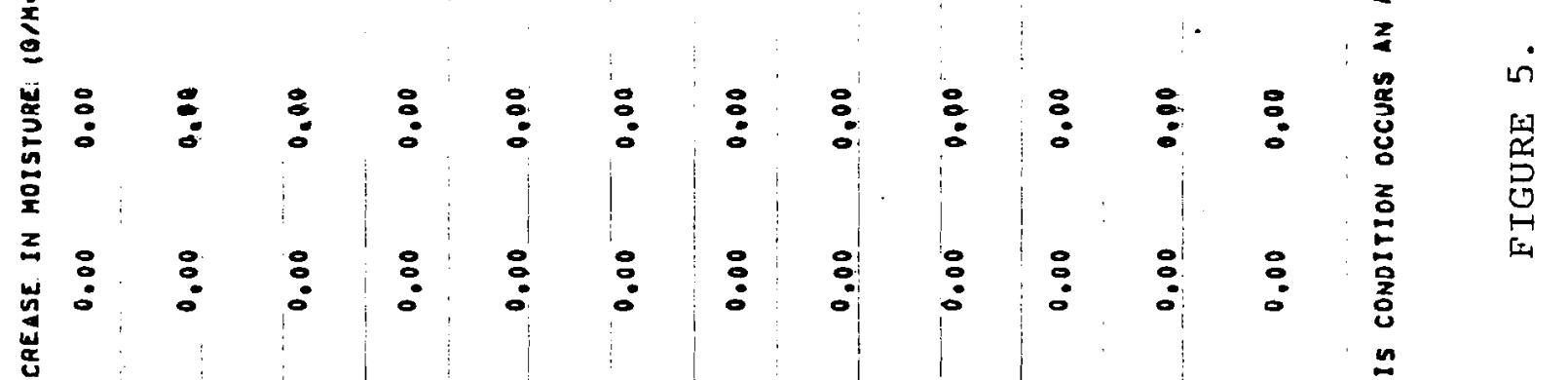


the same climatic conditions. The grid locations for the 4 additional clusters in Figure 5 were at $5.5,7.2 ; 4.7,6.7$; $3.7,5.4$ and $3.7,4.9$. Mechanical draft cooling systems were assumed for all clusters.

If a climatological output is desired, BATMAN can compute the number of hours of water vapor density increase within each specified range. In this case the number of hours of increase is computed as

$$
H_{o}\left(\Delta \rho_{v} \geq a\right)_{k}=\sum_{n} \sum_{u} \sum_{s}\left[8766 P\left(n, u, s \mid \Delta \rho_{v} \geq a\right)_{k}\right]
$$

where $H_{0}\left(\Delta \rho_{v} \geq a\right)_{k}$ is the number of hours that the water vapor density increase is greater than a at receptor $k$; the summations are over wind direction, speed and atmospheric stability; 8766 is the average number of hours per year; and $P\left(n, u, s \mid \Delta \rho_{v} \geq a\right) k$ is the joint frequency of occurrence of wind direction, speed and atmospheric stability that result in a water vapor density increase greater than a at receptor $k$. As many as 10 values for a can be used in any single simulation. A sample of the output is given in Figure 6 using the same 5 clusters used for Figure 5. This output is of value in determining the effects of moisture releases on relative humidity and wet-bulb temperature, but further computations are required to estimate the effect on fog.

If the impact of moisture releases on fog is to be estimated additional climatological information is required. That information describes the probability distribution of atmospheric water vapor saturation deficits, (i.e., the difference between the density of water vapor when air would be saturated and the actual vapor density). The increased number of hours of atmospheric saturation is given by 
3
0
0
0

Iㄴ

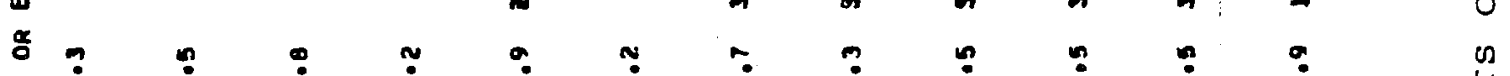

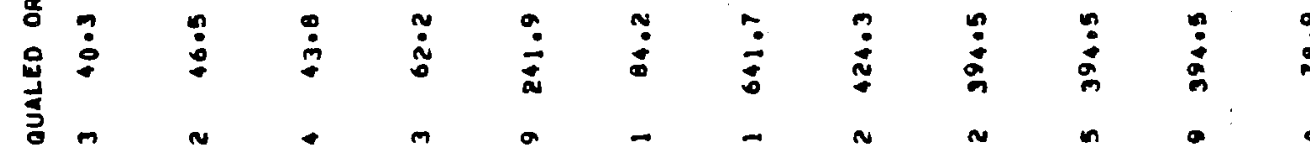

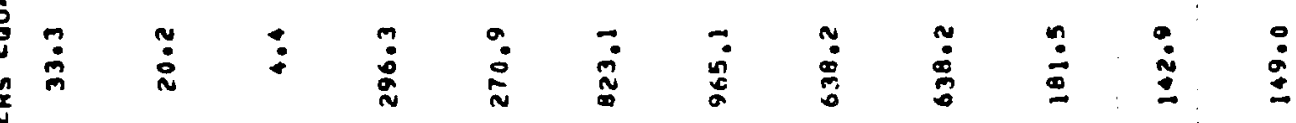

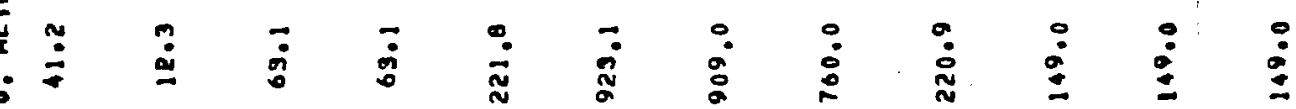

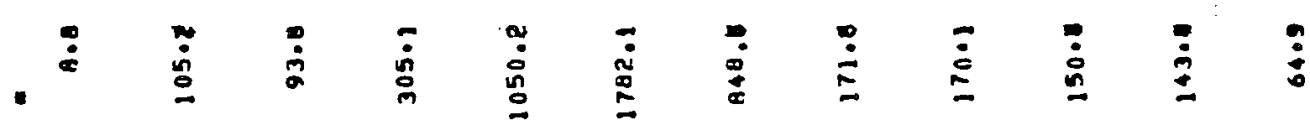

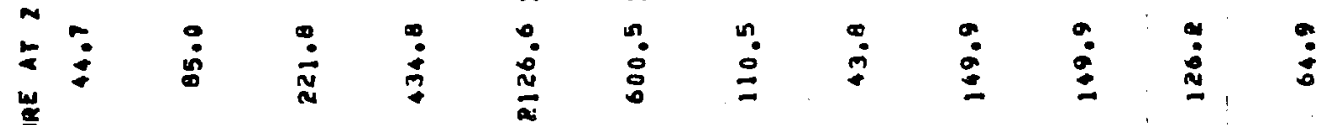

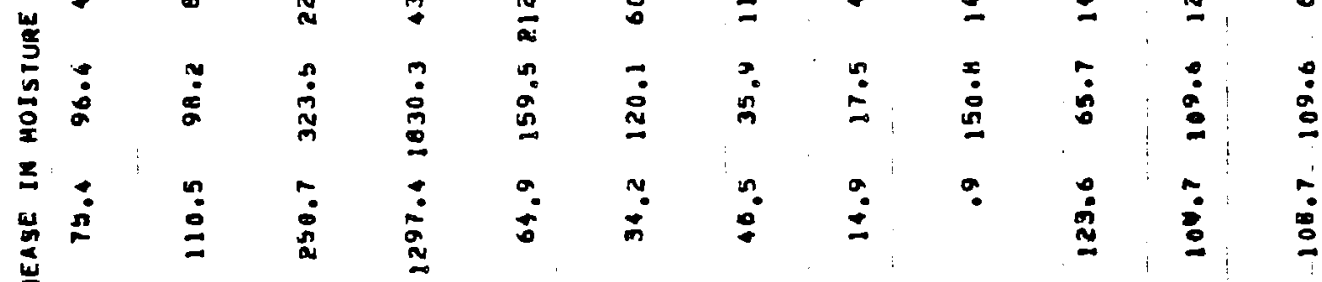

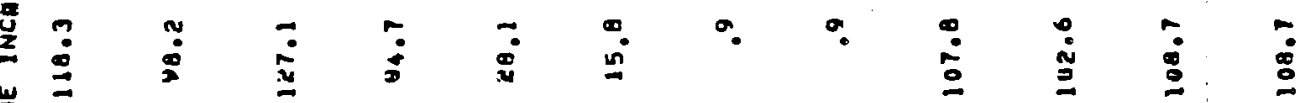

ข้อง

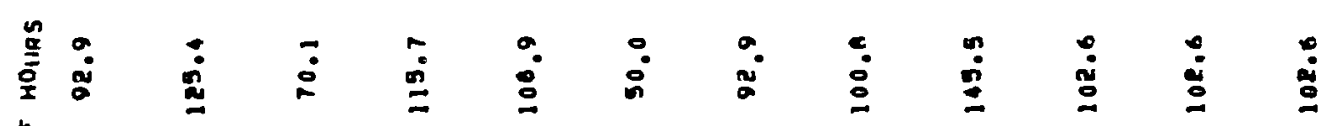

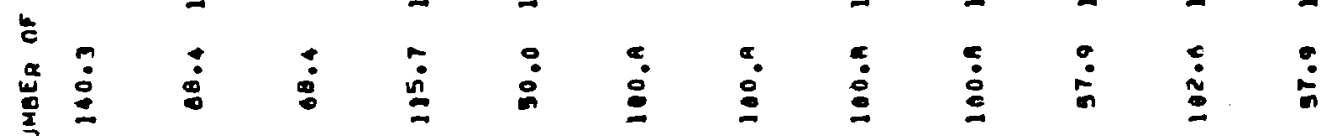

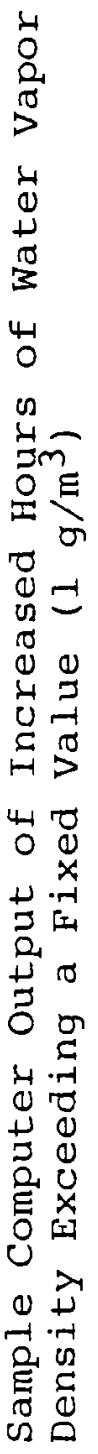

$\sum_{2}^{2} \rightarrow-7 \rightarrow-\infty$ 


$$
\left(\mathrm{H}_{\mathrm{f}}\right)_{\mathrm{k}}=\sum_{m=1}^{\mathrm{M}}\left\{\mathrm{H}_{\mathrm{o}}\left(\Delta \rho_{\mathrm{v}} \geq \mathrm{a}_{\mathrm{m}}\right)_{\mathrm{k}} \mathrm{P}\left(\mathrm{a}_{\mathrm{m}-1} \leq \mathrm{d}_{<\mathrm{m}}\right)\right\}
$$

where $\left(\mathrm{H}_{f}\right)_{k}$ is the increase in hours of saturation at $k, M$ is the number of density increase categories and $P\left(a_{m-1}<d<a_{m}\right)$ is the probability that the saturation deficit is between $a_{m}-1$ and $a_{m}$. Figure 7 shows a sample of the computer output of this information for the same 5 clusters used for previous figures. In this case the increased number of hours of saturation have been interpreted as an increased number of hours of fog.

\section{Output Interpretation}

Prior to closing the discussion of the atmospheric model and the model output, some discussion of interpretation of the model output is appropriate. The first two forms of model output describe the increase in moisture content in terms of grams of water vapor per cubic meter of air. This can be related to other measures of humidity such as relative humidity and wet bulb temperature.

The relationship between increase in water vapor density and increase in relative humidity is a function of the temperature of the air. This relationship is shown in Figure 8 , where the increase in relative humidity for a $1 \mathrm{~g} / \mathrm{m}^{3}$ increase in water vapor density is given as a function of temperature. Two striking features are evident in the Figure. The first is that at low temperatures a small increase in vapor density will cause a large increase in relative humidity, and the second is that at high temperatures small increases in water vapor have little effect on relative humidity. These features indicate that the greatest direct impacts of moisture releases should occur in the winter and in cool or cold climates. 


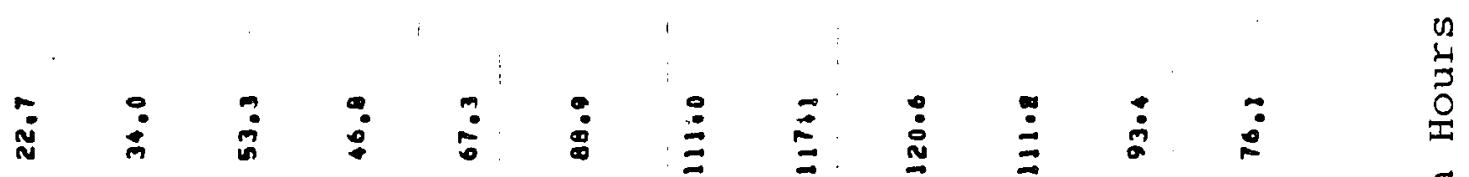

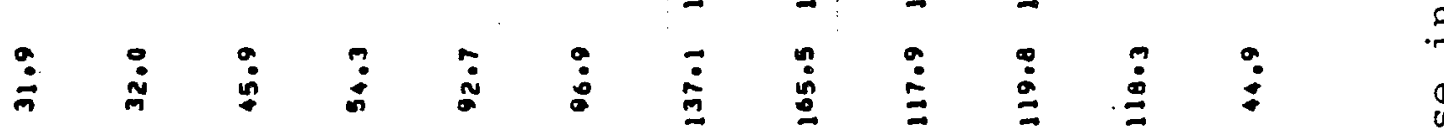

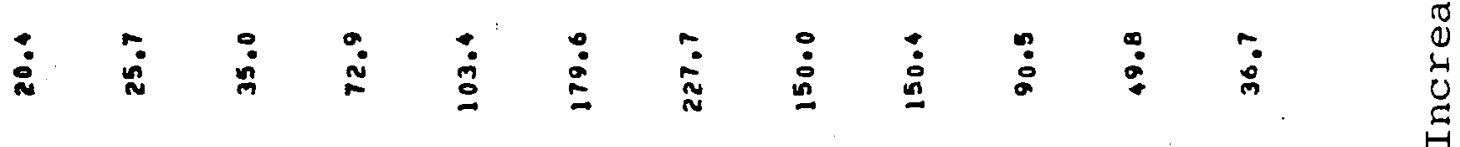

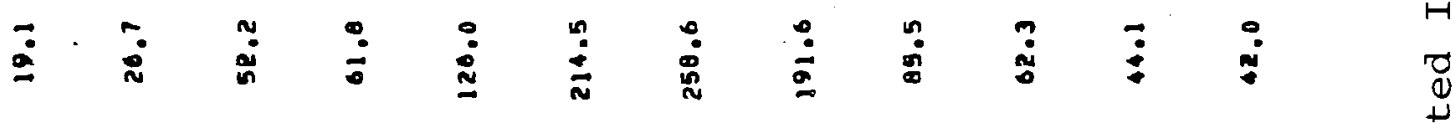

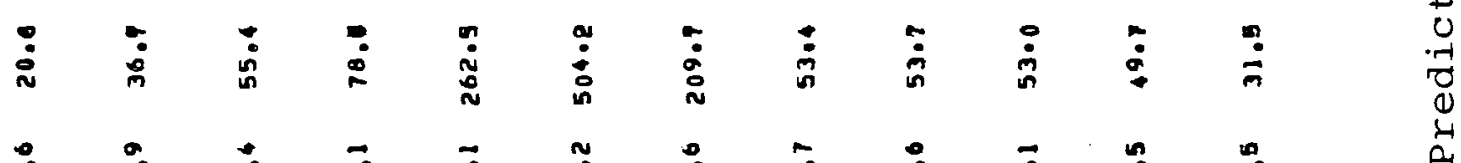

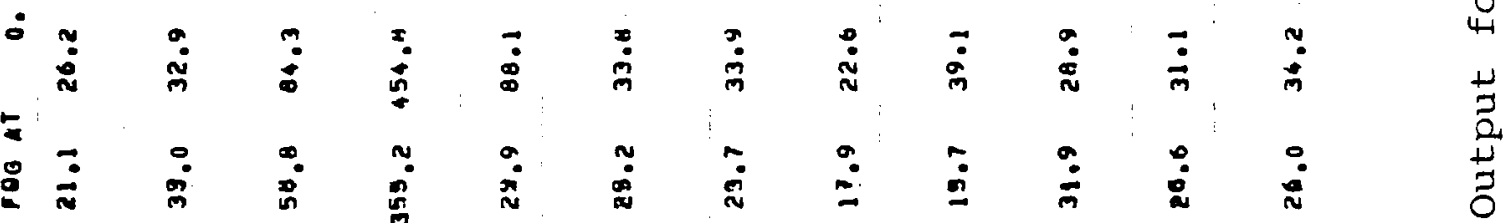

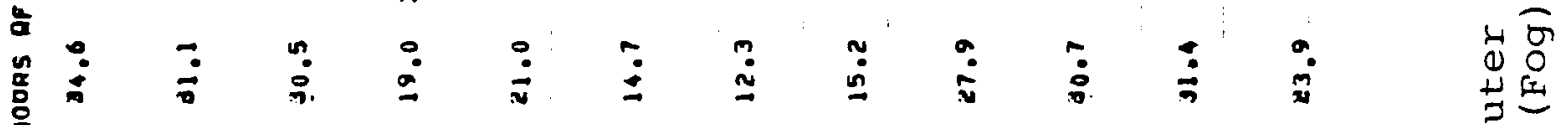

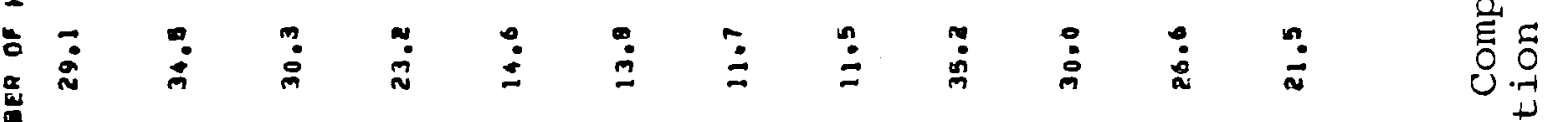

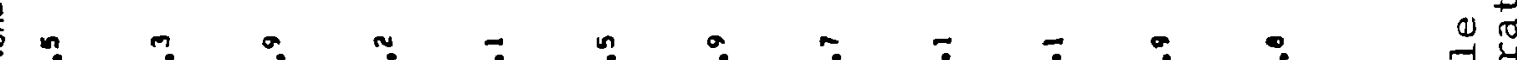

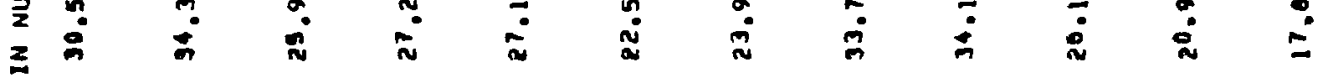

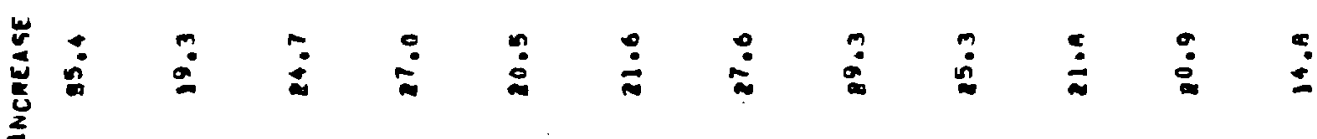

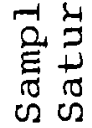
兽 


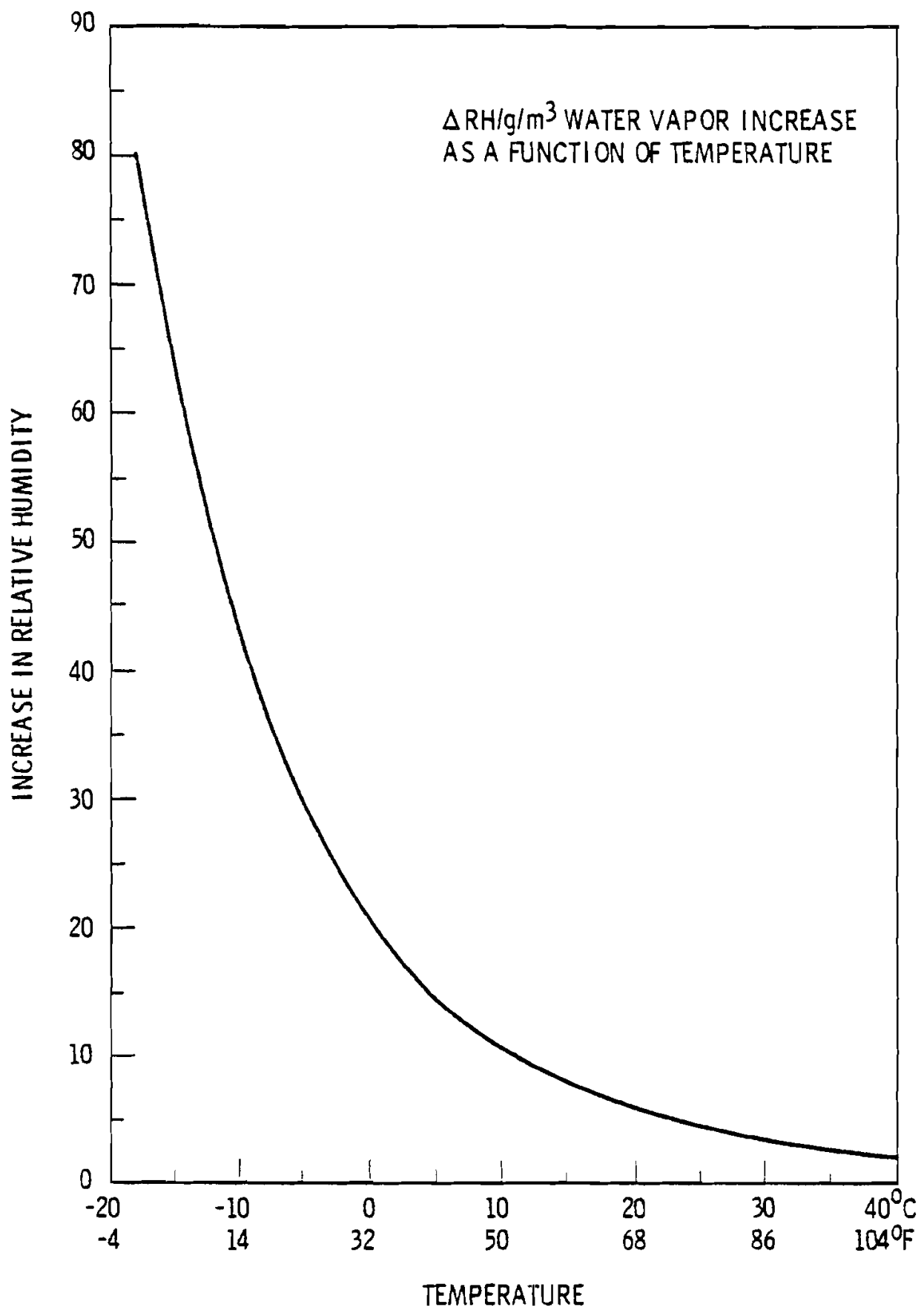

FIGURE 8. Relationship Between Relative Humidity Increase and Temperature for an Increase in Water Vapor Density of $1 \mathrm{~g} / \mathrm{m}^{3}$ 
Wet-bulb temperature is of interest in the evaluation of the performance of evaporative cooling systems. The performance of these systems decreased as the wet-bulb temperature increases. Addition of moisture raises the atmospheric wet-bulb temperature. The rate of increase in a slowly varying function of temperature, however, in the normal range of atmospheric temperatures it is approximately $1 \mathrm{C}^{\circ}$ for each gram per cubic meter of moisture increase.

The interpretation of increased hours of saturation was briefly discussed earlier. This interpretation requires some clarification. If the probability in (7) is the probability of saturation deficit during periods without fog then the result is properly interpreted as an increase in the number of hours of fog. But, if the probability covers all hours including those with fog, the output should be interpreted as total hours of fog.

It should also be noted that this interpretation assumes that saturation of the atmosphere is synonymous with fog, when in fact it is not. Fog is defined as a restriction to visibility which is associated with high humidities and water droplets. Fog frequently forms and persists at humidities slightly below saturation and the atmosphere may be very near or at saturation without the formation of fog. Thus, the modeling definition of fog as saturation of the atmosphere is only approximately correct.

THE HNEC MODEL

The evaluation of impacts of moisture releases for an HNEC required that release characteristics be assumed for a variety of potential HNEC configurations. An initial configuration was suggested in Reference 5. However other configurations were considered to estimate effects of changes in the configuration 
on the total impact of the moisture release. This section describes the spatial and cooling system configurations evaluated.

In all cases, the HNEC was assumed to consist of discrete clusters with 4 reactors rated at $1250 \mathrm{MW}$ in each cluster. In addition, all reactors within a cluster were assumed to use the same type cooling system.

\section{Cluster Locations}

During the course of the modeling program, reactor clusters were located at 14 different sites within the Hanford Reservation. Figure 9 depicts the Hanford Reservation (enclosed by dashed lines) and cluster locations within the BATMAN grid system. Exact locations of the clusters are given in Table 2. The Figure also shows the major roads and population centers in the area. The climatological data used for the model simulations were obtained at the Hanford Meteorology Station. The grid system, itself, is oriented North-South with $8 \mathrm{~km}$ (5 mi) spacing.

Major topographic features not shown in Figure 9 include Rattlesnake Mountain, the Saddle Mountains and the Horse Heaven Hills. Rattlesnake Mountain runs along the southwest boundary of the Hanford Reservation and effectively blocks the movement of air from Hanford toward the area of Sunnyside, Grandview and Prosser. The Horse Heaven Hills lie to the south of Highway 12 and tend to force air to the southeast to follow the Columbia River. Finally, to the north of the Reservation the saddle Mountains tend to force airflow from the south through the Columbia River gap near Beverly or deflect it toward the east. These airflow perturbations are not fully reflected in the climatology and cannot be treated by BATMAN. 


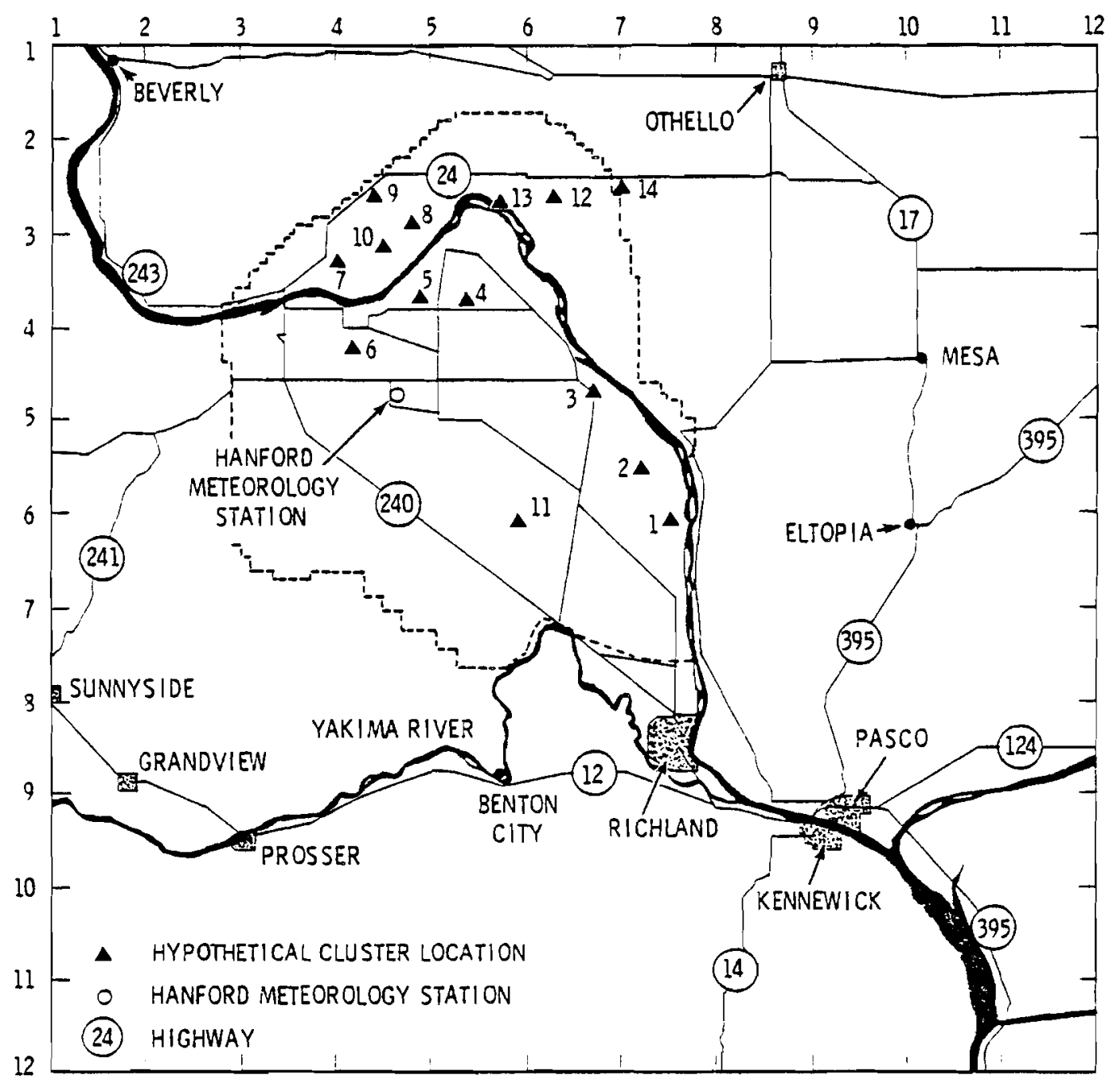

FIGURE 9. The HNEC Cluster Locations in the BATMAN Grid System 
Table 2. Positions of the 4 Reactor Clusters for the HNEC Simulations

\begin{tabular}{ccc} 
Cluster & $\begin{array}{c}\text { North-South } \\
\text { Coordinate }\end{array}$ & $\begin{array}{c}\text { East-West } \\
\text { Coordinate }\end{array}$ \\
\cline { 1 - 2 } 1 & 6.10 & 7.50 \\
2 & 5.50 & 7.20 \\
3 & 4.70 & 6.70 \\
4 & 3.70 & 5.40 \\
5 & 3.70 & 4.90 \\
6 & 4.20 & 4.20 \\
7 & 3.30 & 4.00 \\
8 & 2.90 & 4.80 \\
9 & 2.60 & 4.40 \\
10 & 3.10 & 4.50 \\
11 & 6.10 & 5.90 \\
12 & 2.60 & 6.30 \\
13 & 2.70 & 5.80 \\
14 & 2.50 & 7.00
\end{tabular}

Cooling System Models

The original problem which led to this modeling effort was one of heat sink management. Evaluation of cooling system types and locations are included within that problem. As a result a set of rudimentary cooling system models has been included in BATMAN. The cooling system models are not detailed and do not consider many of the physical processes that take place within cooling systems. Rather, the cooling system models provide a means to vary moisture release rates, release heights and horizontal scales. Seven different cooling systems have been simulated, however, there are only three different models. The basic models and their variation are described in this section. 
The primary cooling system model in BATMAN is the lowlevel, mechanical draft cooling tower. This model assumes that the overall efficiency of the energy conversion is $33 \%$ and that $80 \%$ of the energy rejected will be released as latent heat of vaporization. With these assumptions a moisture source term is computed. The release height of mechanical draft cooling towers is assumed to be $25 \mathrm{~m}$, further a characteristic horizontal dimension for the combined cooling systems in a cluster is assumed to be $1609 \mathrm{~m}(1 \mathrm{mi})$. In essence, the plumes from the individual cooling systems within a cluster are assumed to merge immediately.

The mechanical draft cooling tower model is altered to simulate a helper cooling tower on a once through cooling system by reducing the latent heat fraction from .80 to .60 . Similarly, to simulate a hybrid, wet/dry cooling tower, the final moisture source term is multiplied by the wet cooling fraction. A tall natural draft cooling tower cluster is simulated by increasing the release height and decreasing the horizontal scale length to 154 and $400 \mathrm{~m}$, respectively. Natural draft cooling towers may not be viable at Hanford, but mechanically assisted cooling towers of the same size may be.

The basic cooling model is simply a ground level, area source model. The pond for a 4 reactor cluster is assumed to be circular with a diameter of $9260 \mathrm{~m}$. The total system efficiency is assumed to be $32 \%$. Unlike the cooling tower model, in which the latent heat fraction was constant, the latent heat fraction in the cooling pond model is highly seasonal. It varies from a low of $56 \%$ in the winter to a high of over $200 \%$ in the summer. The latent heat release considers evaporation increases caused by construction of a pond on previously dry land. This is the cause of the high summer release rates. The modification of the basic cooling pond model to simulate helper ponds is accomplished by reducing the latent 
heat release fraction. Background information on which the latent heat release fraction were based was supplied by the PNL Land Water Resources Department.

Although spray cooling ponds were not simulated, the basic cooling pond model with reduction of the horizontal scale length is the approach that would be taken.

The final cooling system simulated, and in many ways the least satisfactory, was once through cooling using the Columbia River. The approach taken was to assume that the river could be simulated by 5 circular areas that increased in size with distance from the source. The temperature increase in each area was computed assuming that the reactor effluent was thoroughly mixed with the river. The evaporation rate was then computed using the evaporation relationship in the COLHEAT river model (13), the average river temperature, the clausiusclapeyron equation, and wind speed. In short, the whole process is both cumbersome and tedious. The results using this approach were not encouraging although they were intuitively reasonable.

The basic parameters of the cooling system models (cooling tower and pond) are given in Tables 3 and 4 . Table 3 summarizes the horizontal scales and release heights for these systems, while Table 4 summarizes the overall efficiency and latent heat fractions. The annual average water consumption per reactor for each cooling system is also given in Table 4 . It is interesting to note that a lower consumptive use of water is achieved with cooling towers than with cooling ponds.

\section{Heat Sink Management Simulations}

The various cooling system models and cluster locations were combined to give 27 cases for evaluation. Initial evaluations indicated that approximately the same results were 

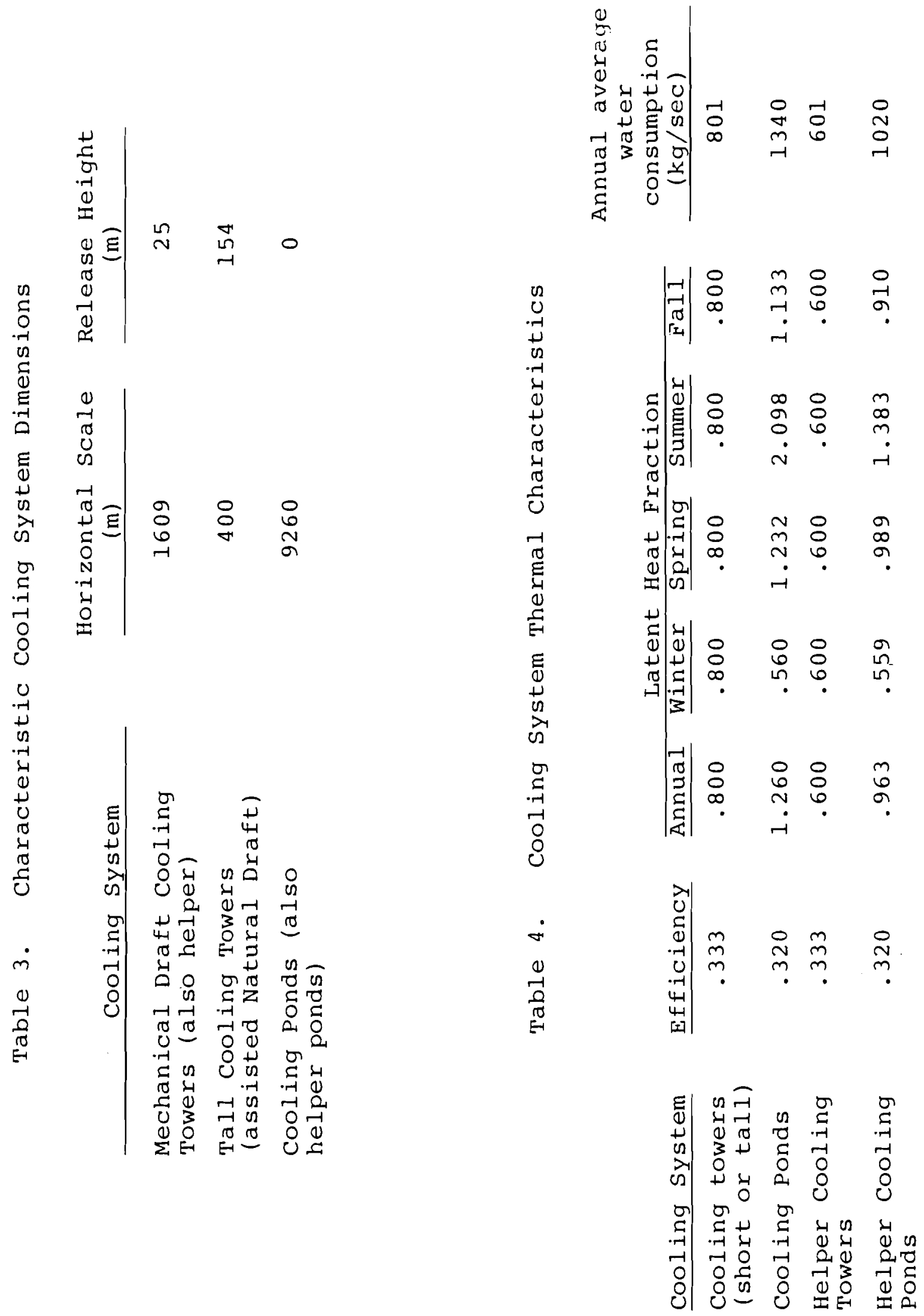
achieved when annual climatological data were used as when the results of simulations using seasonal data were combined. As a result most simulations were made using annual data. In two cases summer climatological data were used to examine the increases in humidity more closely.

The test cases that were used to evaluate the impact of the potential HNEC moisture releases are described in Table 5 . The cooling systems and locations simulated in each case are denoted by the small letters in the Table. In case 1 a single cluster of 4 reactors using mechanical draft cooling towers was examined. This is generally considered to represent the future conditions at Hanford because Site 1 is located near the area in which the washington Public Power supply system is constructing 3 reactors. However this was not an attempt to model the wPPSS cooling systems or evaluate their effects. Each of the remaining cases includes a cluster with mechanical draft towers at site 1 .

Cases 2 through 6 were used to examine the effect of cluster location on the population centers and roads in the area. These cases include grouping the clusters near both the north and south sides of the Hanford Reservation, aligning the clusters both perpendicular and parallel to the prevailing wind direction, and spreading them as widely as possible. These cases were selected without regard to other probable siting considerations.

Cases 7 through 11 examine the effects of a 5 cluster HNEC with clusters sited using criteria such as water availability, potential pond sites and distance from population centers. They also provide information on the relative effects of the various cooling systems. The simulations in cases 12 through 14 extended this evaluation to the full 10 cluster ( 40 reactor) HNEC . 
Table 5. Site and Cooling system Combinations Simulated

\begin{tabular}{|c|c|c|c|c|c|c|c|c|c|c|c|c|c|}
\hline \multirow{2}{*}{ Case } & \multicolumn{12}{|c|}{ Site } & \multirow[b]{2}{*}{ Climatology } \\
\hline & $\bar{I}$ & 2 & 3 & 4 & 5 & 6 & 78 & 9 & 10 & $11 \quad 12$ & 13 & $\overline{14}$ & \\
\hline 1 & a & & & & & & & & & & & & annual \\
\hline 2 & a & a & $a$ & a & a & & & & & & & & annual \\
\hline 3 & a & & & a & & $\mathbf{a}$ & & & & & a & a & annual \\
\hline 4 & $a$ & & & & & a & & $a$ & & $a$ & & a & annual \\
\hline 5 & a & & & a & & a & a & a & & & & & annual \\
\hline 6 & a & a & a & a & & & & & & a & & & annual \\
\hline 7 & a & & & b & & $b$ & b & b & & & & & annual \\
\hline 8 & a & & & e & & e & e & e & & & & & annual \\
\hline 9 & a & & & d & & d & d & d & & & & & annual \\
\hline 10 & a & $c$ & c & $c$ & c & & & & & & & & annual \\
\hline 11 & a & c & c & & & & e & e & & & & & annual \\
\hline 12 & a & a & a & a & a & a & a & $a$ & a & a & & & annual \\
\hline 13 & a & c & c & c & c & c & c & c & c & c & & & annual \\
\hline 14 & a & c & c & e & c & e & e & e & e & c & & & annual \\
\hline 15 & a & $a$ * & $a^{*}$ & $a^{*}$ & $a *$ & & & & & & & & annual \\
\hline 16 & a & $a^{+}$ & $a^{+}$ & $a^{+}$ & $a^{+}$ & & & & & & & & annual \\
\hline 17 & a & $a^{\circ}$ & $a^{\circ}$ & $a^{\circ}$ & $a^{0}$ & & & & & & & & annual \\
\hline 18 & a & $a^{*}$ & $a^{*}$ & $a^{*}$ & $a^{*}$ & $a^{*}$ & $a^{\star}$ & $a^{*}$ & $a^{*}$ & $a^{\star}$ & & & annual \\
\hline 19 & a & $a^{+}$ & $a^{+}$ & $a^{+}$ & $a^{+}$ & $a^{+}$ & $a^{+}$ & $a^{+}$ & $a^{+}$ & $a^{+}$ & & & annual \\
\hline 20 & a & $a^{\circ}$ & $a^{\circ}$ & $a^{\circ}$ & $a^{0}$ & $a^{\circ}$ & $a^{0}$ & $a^{\circ}$ & $a^{\circ}$ & $a^{\circ}$ & & & annual \\
\hline 21 & $a$ & a & $a$ & $a$ & $a$ & & & & & & & & annual \\
\hline 22 & $a$ & a & a & $a$ & $a$ & a & a & $a$ & $a$ & $a$ & & & annual \\
\hline 23 & $a$ & c & c & & & & d & d & & & & & annual \\
\hline 24 & a & c & c & d & c & $d$ & $d$ & $d$ & $d$ & c & & - & annual \\
\hline 25 & a & c & c & c & & & $f$ & & & & & & annual \\
\hline 26 & a & $c$ & c & & & & $f$ & & & & $E$ & & annual \\
\hline 27 & $a$ & c & $c$ & $c$ & $c$ & c & $\mathrm{f}$ & c & & c & $f$ & & annual \\
\hline & & $\mathrm{COC}$ & lin & & syst & & types & & $\begin{array}{l}\text { ow to } \\
\text { polir } \\
\text { all t } \\
\text { elper } \\
\text { elper } \\
\text { iver }\end{array}$ & $\begin{array}{l}\text { ower } \\
\text { ng pond } \\
\text { tower } \\
r \text { tower } \\
r \text { pond }\end{array}$ & $\begin{array}{l}a \\
b \\
c \\
d \\
e \\
f\end{array}$ & & \\
\hline
\end{tabular}


The remaining simulations, except for cases 21 and 22 , were done to identify those heat sink management options which minimize the potential impact of the HNEC moisture releases. Test cases 15 through 20 were directed toward the evaluation of hybrid wet/dry cooling systems, while those from 23 through 27 examined combinations of more conventional cooling systems.

The detailed results of the HNEC simulations will be discussed following a description of the Hanford climate.

\section{THE HANFORD CLIMATE}

Any evaluation of the impact of heat sink management alternatives on the environment must consider the climate of the region under consideration. Thus it is appropriate to describe the climate of the Hanford area in some detail. The basic reference on Hanford Climate is the Climatography of the Hanford Area prepared in 1972 by Stone, Jenne and Thorp (14). The temperature and precipitation data in this work indicate that the Hanford area borders between a steppe (BS) and desert (BW) climate using the Koppen classification scheme ${ }^{(15)}$. This classification is confirmed by the vegetation types that occupy nost of the Hanford Reservation.

General Climatology

Meteorological observations have been made at numerous locations in the Hanford vicinity, but the only extensive records for a single location are those for the Hanford Meteorological Station (HMS). The HMS is located on a plateau at about $750 \mathrm{ft}$ MSI and is about $300 \mathrm{ft}$ above the columbia River which flows through the reservation to the north and east. There are several significant topographic features within 20 miles of the HMS that affect some aspects of the Hanford climatology including wind. 
Prior to the establishment of the HMS in December 1944 , meteorological measurements were made by U. S. Weather Bureau cooperative observers between 1912 and 1943 and by the U. S. Weather Bureau in Richland for a short period at the end of 1943 and beginning of 1944 .

The climatological data from these sources are summarized in Table 6 . This summary gives both monthly and annual statistics for a large number of climatological variables and includes extreme values as well as means. Since 1975, the last year for which data are included in the table, several new records have been set, but there has been little variation in the climatological averages.

In addition to the month to month variation of climatological statistics presented in Table 6 , there are distinct daily cycles which are superimposed on the seasonal variation. These daily cycles are most evident in temperature, humidity, and wind speed. The daily temperature cycle is familiar to all. The amplitude of this cycle at Hanford ranges from about $13 \mathrm{~F}^{\circ}$ in December to about $30 \mathrm{~F}^{\circ}$ in July and August. The daily cycle of relative humidity should also be familiar. It is related to the temperature cycle but out of phase, that is when the temperature decreases the humidity increases and conversely when the temperature increases the relative humidity decreases. The magnitude of the daily relative humidity variation at Hanford is about $25 \%$ throughout most of the year. However it decreases to about $10 \%$ in December and January. The daily wind speed cycle has a minimum during the morning hours and increases during the afternoon hours until it reached a maximum near sunset. It is most pronounced during the summer and almost imperceptible during the months of December and January. Figures 10 and 11 show these daily cycles for the months of January and July respectively. 

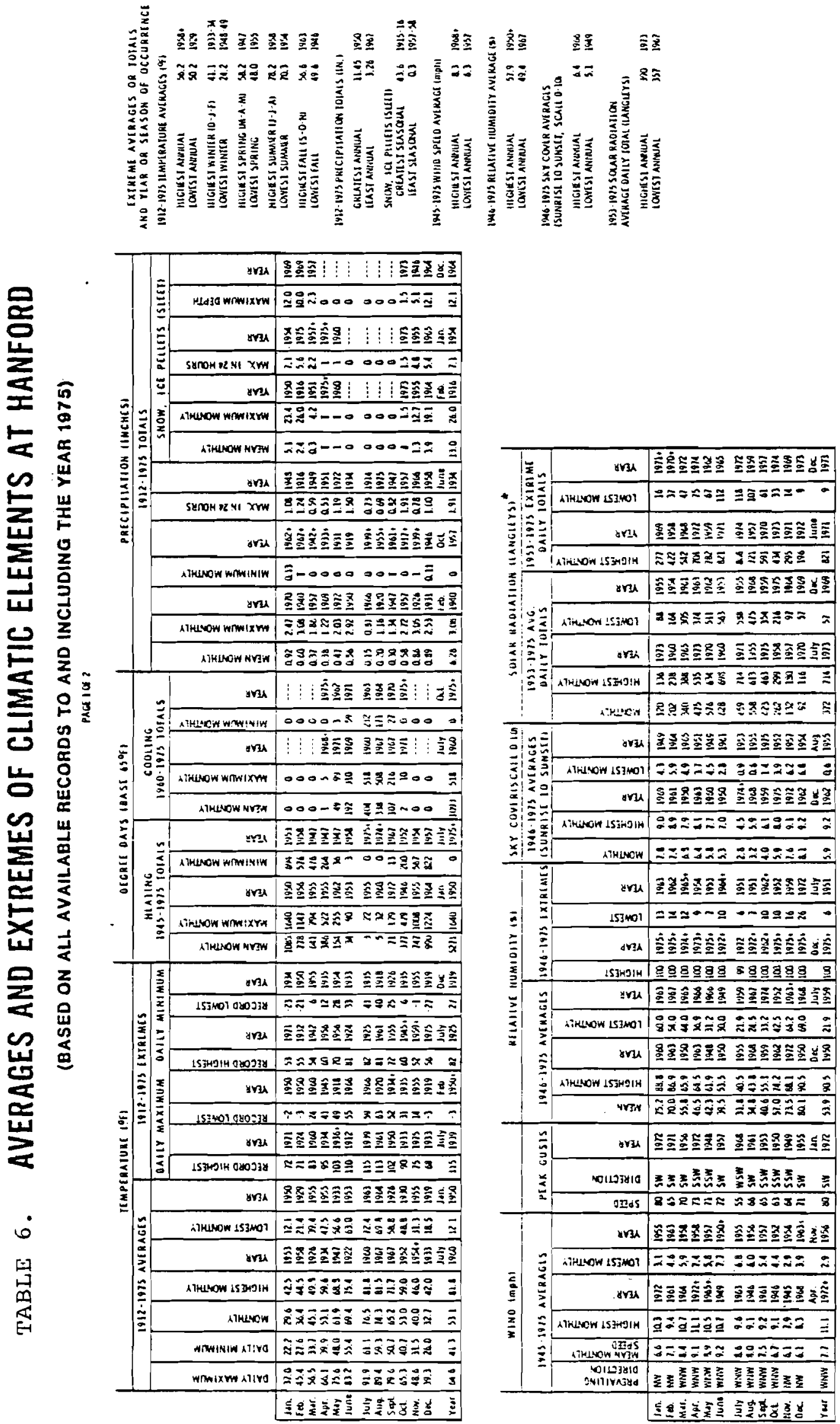

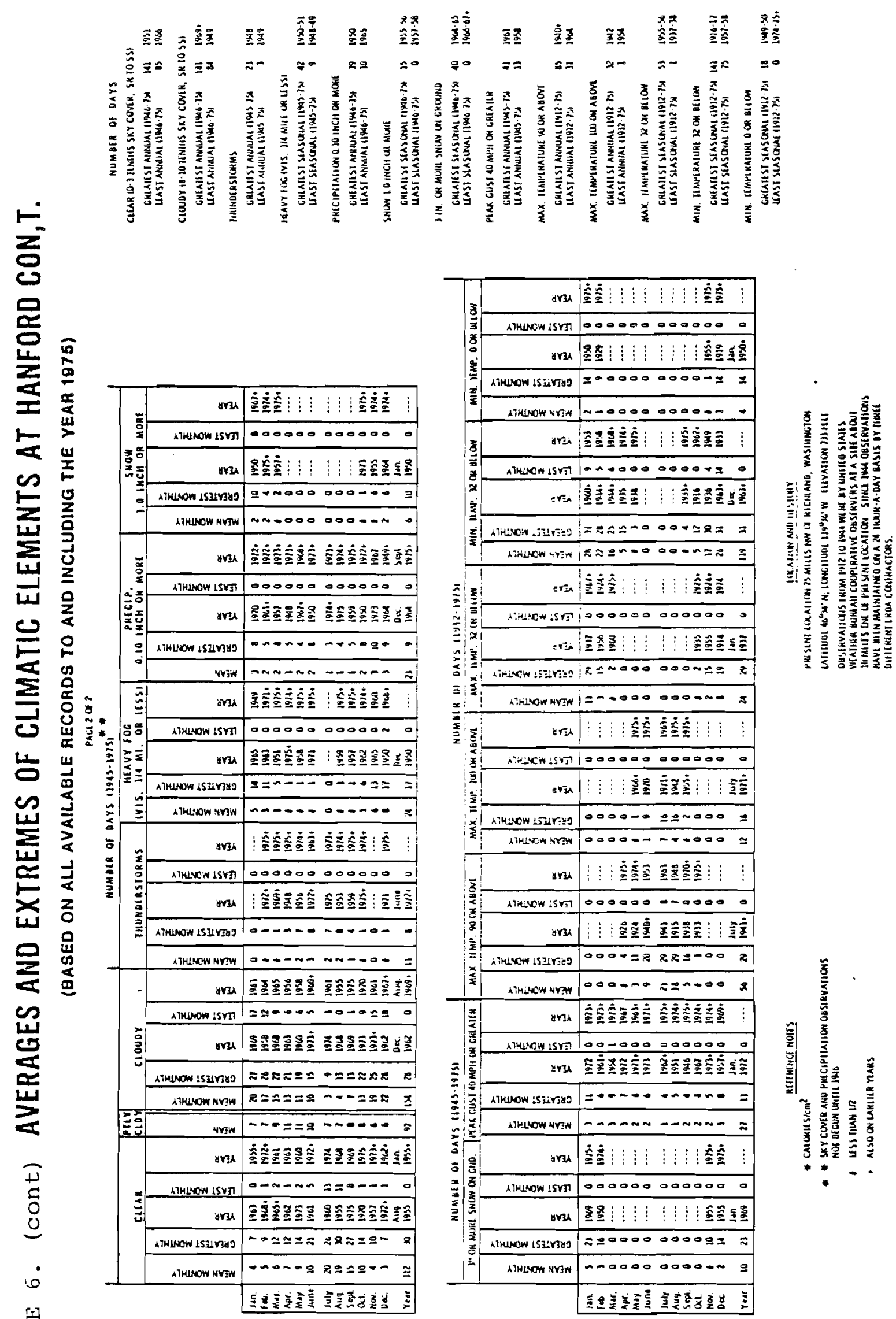


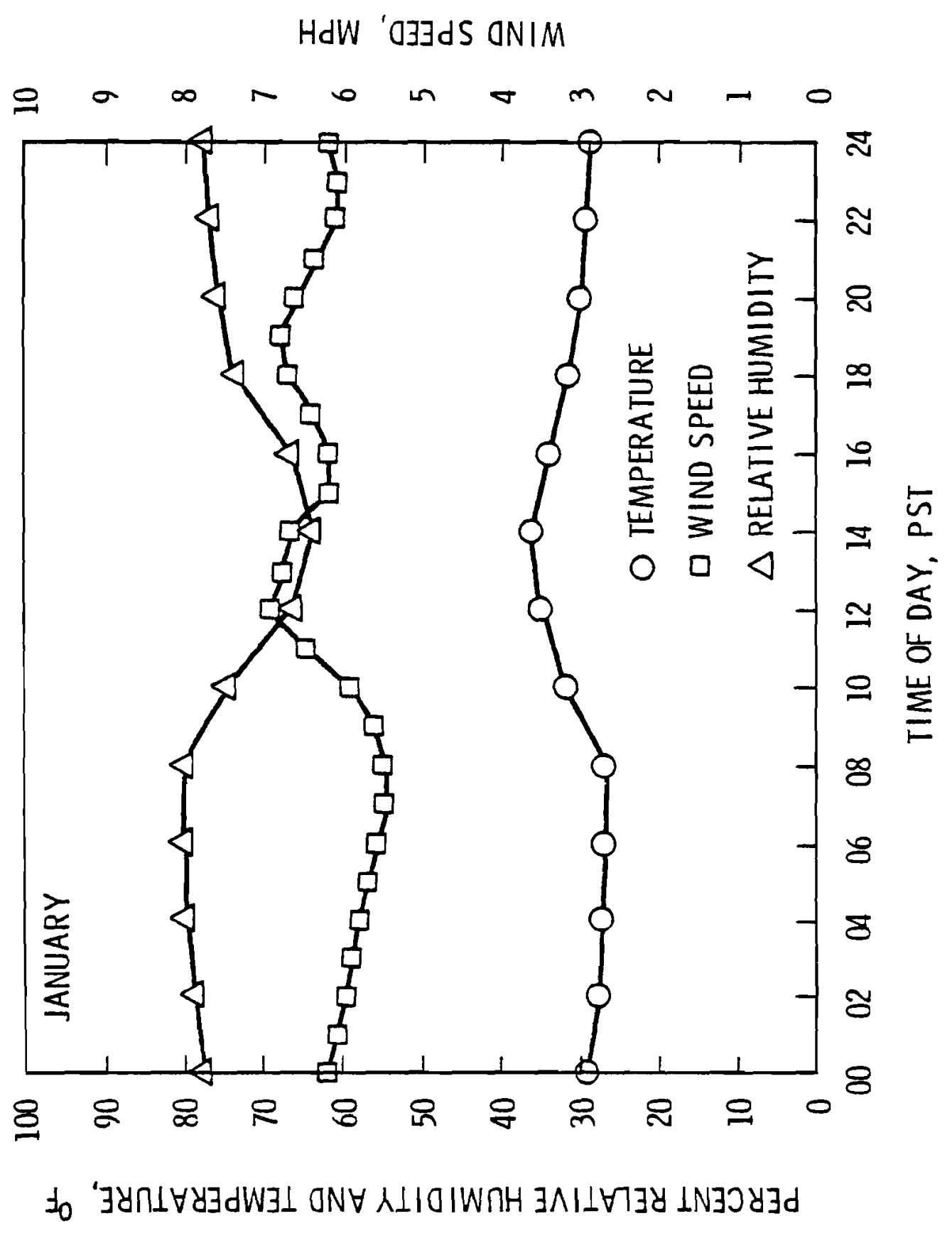

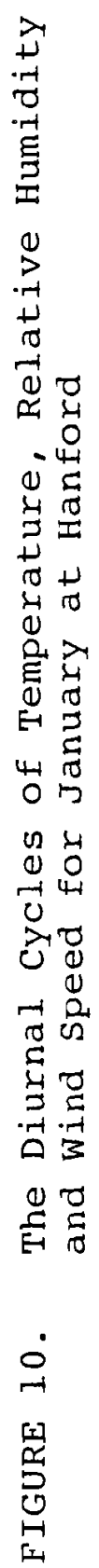




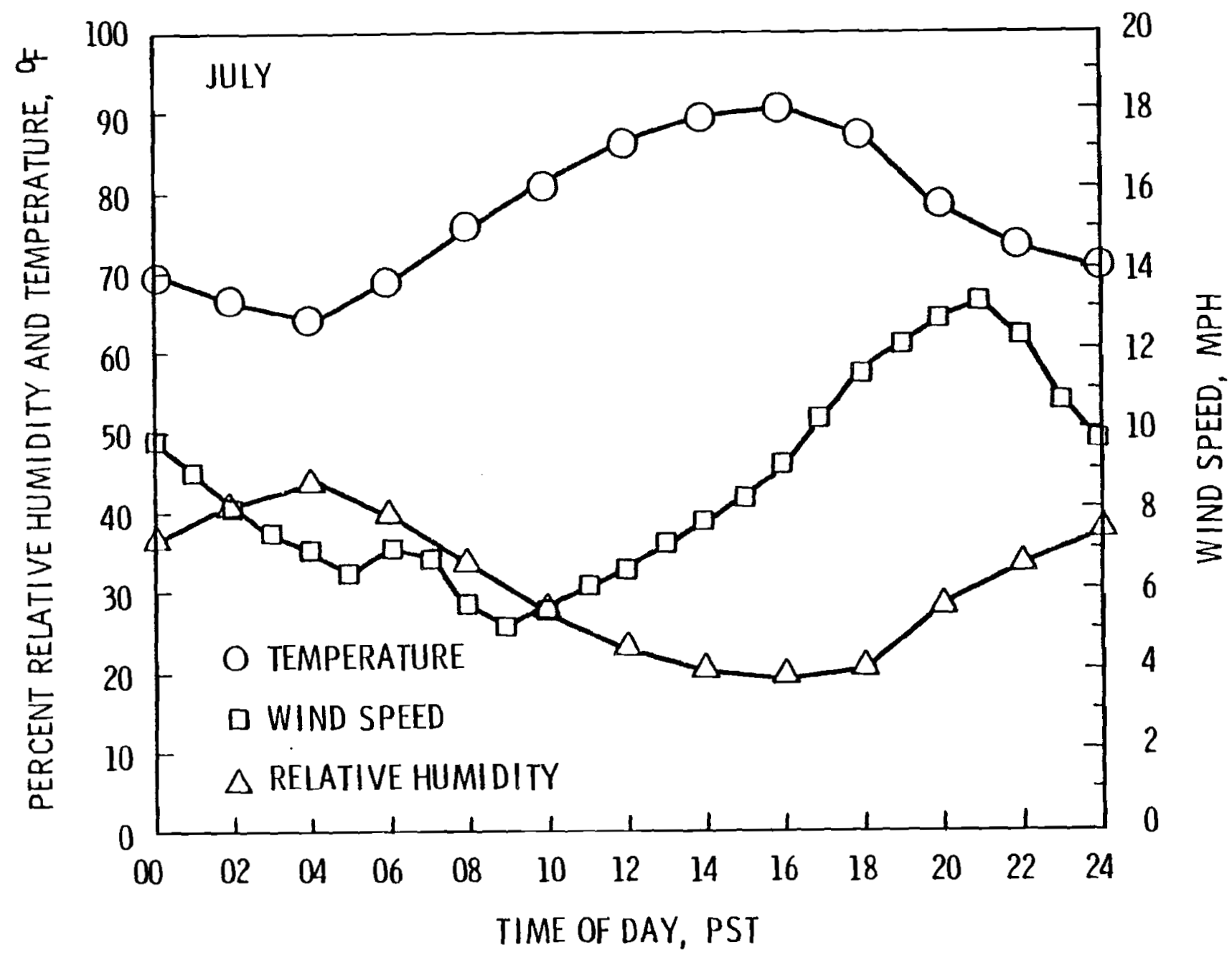

FIGURE 11. The Diurnal Cycles of Temperature, Relative Humidity and wind speed for July at Hanford 
The observations of temperature and humidity at Hanford during the period from 1960 through 1970 were used to establish the saturation deficit climatology. The seasonal and diurnal variations of both temperature and humidity shown in Table 6 and Figures 10 and 11 would indicate that the average saturation deficit should show pronounced seasonal and daily variation. This is very much the case as is shown in Figure 12. This Figure shows a minimum deficit at about the time of sunrise and a maximum in mid-afternoon. December and January nights have particularly low deficits and are therefore the most probable times for induced saturation from moisture releases. During the summer, the average deficits are relatively large at all times even though they show a very large daily oscillation.

The distribution of the hourly saturation deficit values was determined. The particular portion of the distribution that is of interest is that describing the probability of small deficits. Figure 13 shows the probability that the saturation deficit will be less than a given value (the cumulative distribution function). Distributions are shown for both total hours and hours without fog. It should be noted that these distributions functions approach a single value for large deficits, and that they differ noticeably for low saturation deficits.

The most frequent restriction to visibility in the Hanford area is fog that occurs on an average of 38 days per year. on 24 of these days the visibility is restricted to less than $1 / 2$ mile. Fog is highly seasonal, although it has occurred in every month. On a monthly basis, relative humidities range from a low of $30.5 \%$ in July to a high of $80.8 \%$ in December. High humidities ( $>90 \%$ ) occur less than $1 \%$ of the time in the summer, about $9 \%$ of the time in the fall, almost $31 \%$ of the time in the winter and slightly more than $3 \%$ of the time in 


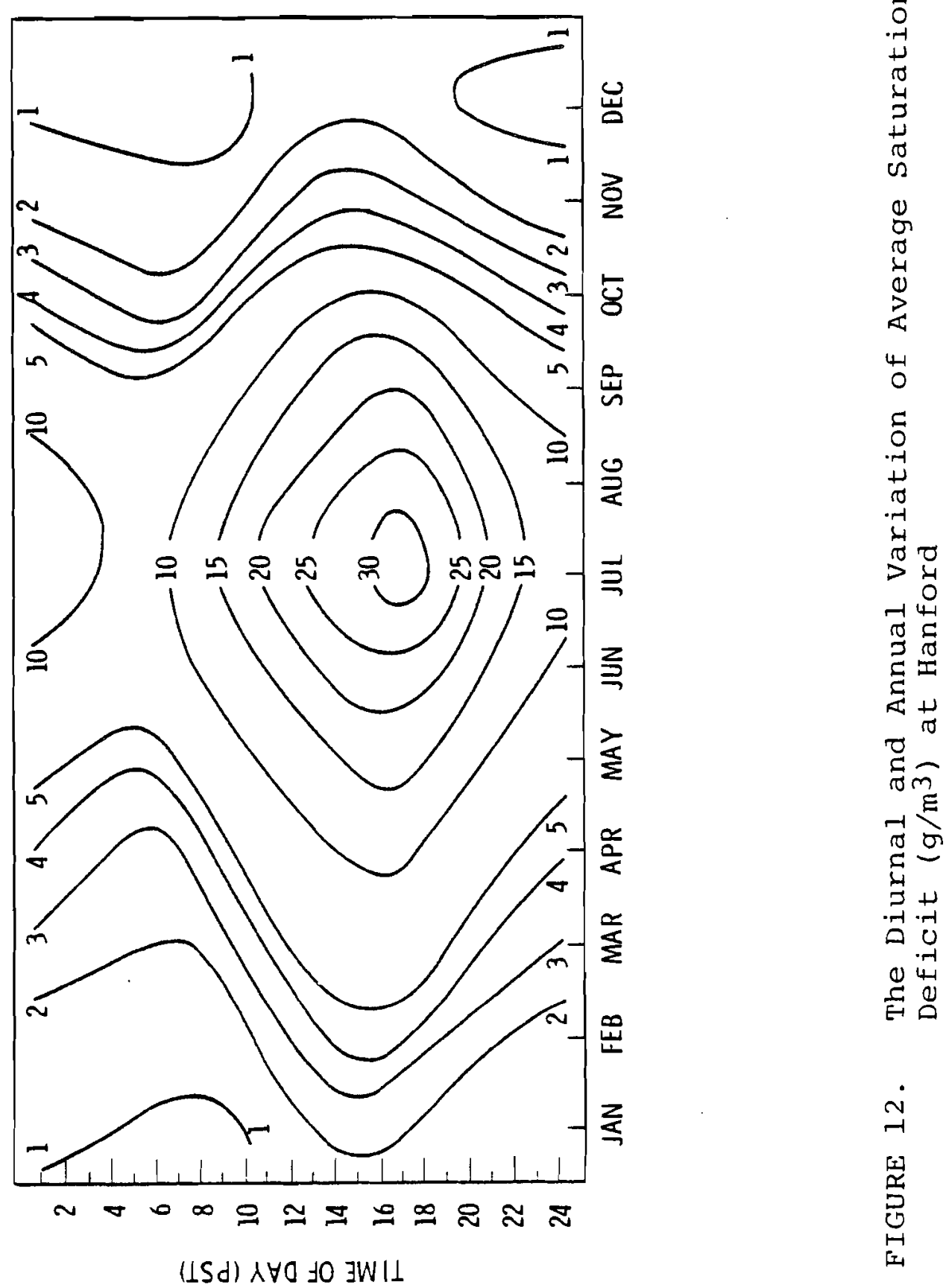




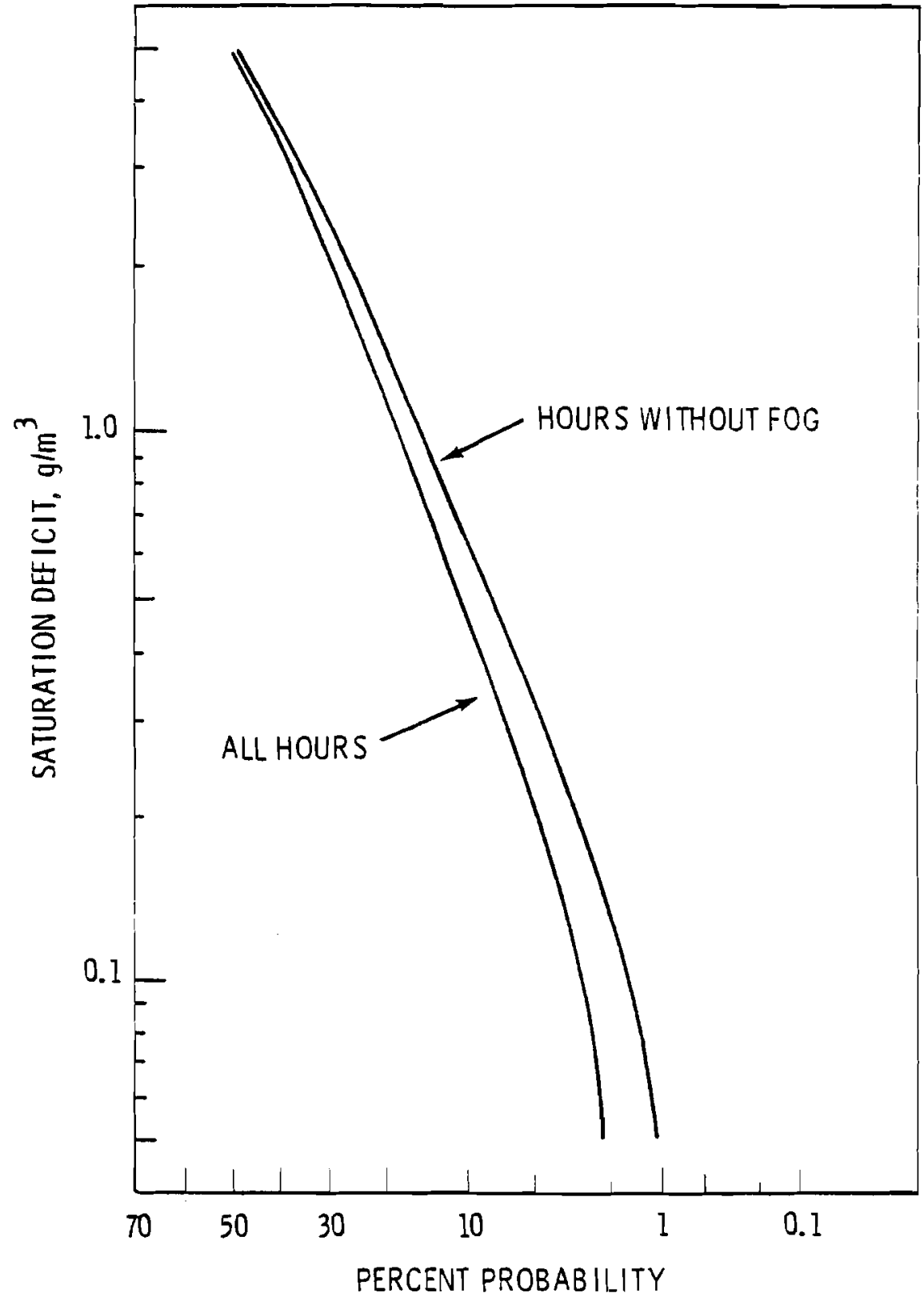

FIGURE 13. Cumulative Frequency Distributions for Saturation Deficits at Hanford 
the spring. These statistics are reflected in the occurrence of fog. Of the annual average of 278 hours of fog, $95 \%$ occurs from November through February. This percentage increases to 99.7\% when the months of October and March are included.

Hanford fogs are generally associated with low wind speed conditions. More than $70 \%$ of the hours of fog occur when the wind speed is less than $3.5 \mathrm{mph}$, and the average wind speed during fog is $2.5 \mathrm{mph}$. Table 7 gives detailed statistics on the duration and maximum persistence of both total and dense fog by months. January 1976 set a record for most hours of fog in a single month, 257. During that month fog was observed on a total of 20 days, including the last 16 days of the month.

Fog statistics indicate large natural variations in the occurrence of fog. The annual number of hours of fog at Hanford approximately follows a log-normal distribution as shown in Figure 14. Using observed values, a standard geometric deviation has been estimated for both hours of fog $(0.285)$ and hours of visibility less than 1/2 mi. (0.362). Examination of more recent records does not indicate a change following deactivation of the reactors at Hanford.

Hours of fog is a rather nebulus figure for use in evaluation of impacts of large moisture releases. A better measure is related to visibility during fog. Cumulative frequency distributions of visibility during fog at Hanford (19601970) are shown in Figure 15 as cumulative distribution functions (cdf). The curve on the right in the figure represents the cdf for all cases of fog. The curve on the left represents those cases when the atmosphere was at or near saturation, (i.e., the saturation deficit in terms of water vapor density $\left.\leq .05 \mathrm{~g} / \mathrm{m}^{3}\right)$. It is obvious, that an increase in atmospheric moisture increases the density fog (reduce visibility) as well as increase the frequency. 
Table 7. Total Duration and Maximum Persistence of Fog Tabulated in Hours for Hanford for the Period 1945-1970

\begin{tabular}{|c|c|c|c|c|c|c|c|c|}
\hline $\begin{array}{l}\text { ALL 106 } \\
\text { NI2 } 06 \text { MILS) }\end{array}$ & $\begin{array}{l}\text { AVG YOTAL } \\
\text { DURATION }\end{array}$ & $\begin{array}{l}\text { MuX IOTAL } \\
\text { DURAIION }\end{array}$ & YesR & $\begin{array}{l}\text { MIN IUTAL } \\
\text { DURAIIOW }\end{array}$ & YEAR & $\begin{array}{l}\text { AVG DURATION PER } \\
\text { OAY OF OCCURRENCE }\end{array}$ & MAX. PERSISIENCE & YGAR \\
\hline JNN & (4) 3 & 199.4 & 1965 & 0 & 1999 & 1.2 & 58.1 & 1955 \\
\hline 114 & 344 & 200.2 & $1 x_{3}$ & 0 & 1967 & 62 & 580 & 1903 \\
\hline$\underset{M N R}{M N R}$ & 1.4 & 20.6 & 1951 & 0 & $1968+$ & 3.1 & 122 & 1999 \\
\hline $\begin{array}{l}A P R \\
M Y\end{array}$ & a) & 28 & 1950 & 0 & $1910+$ & 1.4 & 28 & 1950 \\
\hline JuME & a3 & 21 & 1958 & 0 & $\begin{array}{l}19100 t \\
1970 t\end{array}$ & 12 & 2.17 & 1958 \\
\hline JUAY & $?$ & a) & 1966 & 0 & $1970+$ & at & a) & $\begin{array}{l}1998 \\
1966\end{array}$ \\
\hline Alli: & & 1.0 & & & 1970: & & & \\
\hline StPI & a3 & 5.5 & 1957 & 0 & $1970+$ & 20 & 26 & \\
\hline & & 636 & $1 \% 2$ & 0 & $1970+$ & 3.9 & 390 & 102 \\
\hline NCW & 55.4 & 148.0 & $14 ; 2$ & 1.0 & 1960 & 68 & 65.4 & 1963 \\
\hline wit: & 105.4 & 193.8 & iM7 & 45 & 1968 & 87 & 72.3 & $|x\rangle$ \\
\hline$r$ & 2784 & 462.5111 & $196 A-65$ & $147.7^{(2)}$ & $1948-49$ & 1.0 & 723 & $1997-48$ \\
\hline \multicolumn{9}{|l|}{ 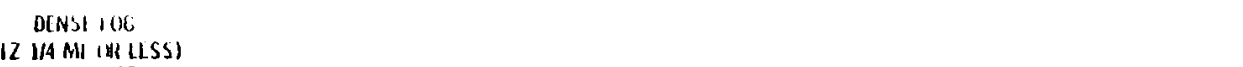 } \\
\hline JAN & 204 & & 1955 & & 1949 & 3.4 & 15.0 & \\
\hline ite & & 86.7 & 1963 & 0 & $1967+$ & 3.8 & & 1963 \\
\hline$M R$ & 1.8 & 7.8 & 1999 & a & $1968+$ & 22 & 5.0 & 1961 \\
\hline$A+B$ & al & 1.8 & 1955 & 0 & $1970+$ & 1.8 & 0 & \\
\hline MiY & 01 & 1.6 & 1988 & 0 & $1970+$ & 1.6 & 1.6 & 1958 \\
\hline 介til. & 0 & 0 & 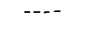 & 0 & $\cdots-$ & 0 & 0 & \\
\hline Aill & i & $\begin{array}{l}0 \\
1.0\end{array}$ & $1 \% 9$ & 0 & 1970 & $\begin{array}{l}0 \\
1.0\end{array}$ & $\begin{array}{l}0 \\
0.1\end{array}$ & $1 \%, 4$ \\
\hline silit & a. & 3.2 & 1457 & 0 & $19700^{\circ}$ & 3.2 & 1.4 & 1487 \\
\hline$x: 1$ & 3.1 & 35.2 & 1962 & 0 & $1970+$ & 3.1 & 15.8 & 19,2 \\
\hline (Win) & 21.1 & 17.4 & $142 ?$ & 0 & 1960 & 4.1 & 20.6 & {$\left[K_{1}\right]$} \\
\hline D:t. & 420 & 111.8 & 1317 & 1.3 & 1968 & 5.4 & 47.0 & {$[y]$} \\
\hline$\gamma$ & 101.4 & 201.5111 & $1962-63$ & $41,3^{(22)}$ & $1918-49$ & 4.2 & 47.0 & $1 \times 787-58$ \\
\hline
\end{tabular}

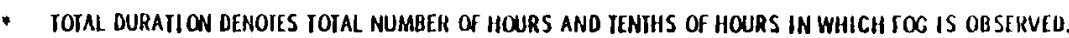

1. DeNOTES LESS THAN Q.0S HOUR

(II) DENOTES THE GReAIEST NUMOER Of HOURS IN A SEASON

(2) DeNOTES IIIE LEASI NUMBER OF HOURS IN A SEASON

(3) IMXIMUM PERSISILNCE OF OENSE FOC IS BASED ON THE PERIO0 1933-70 


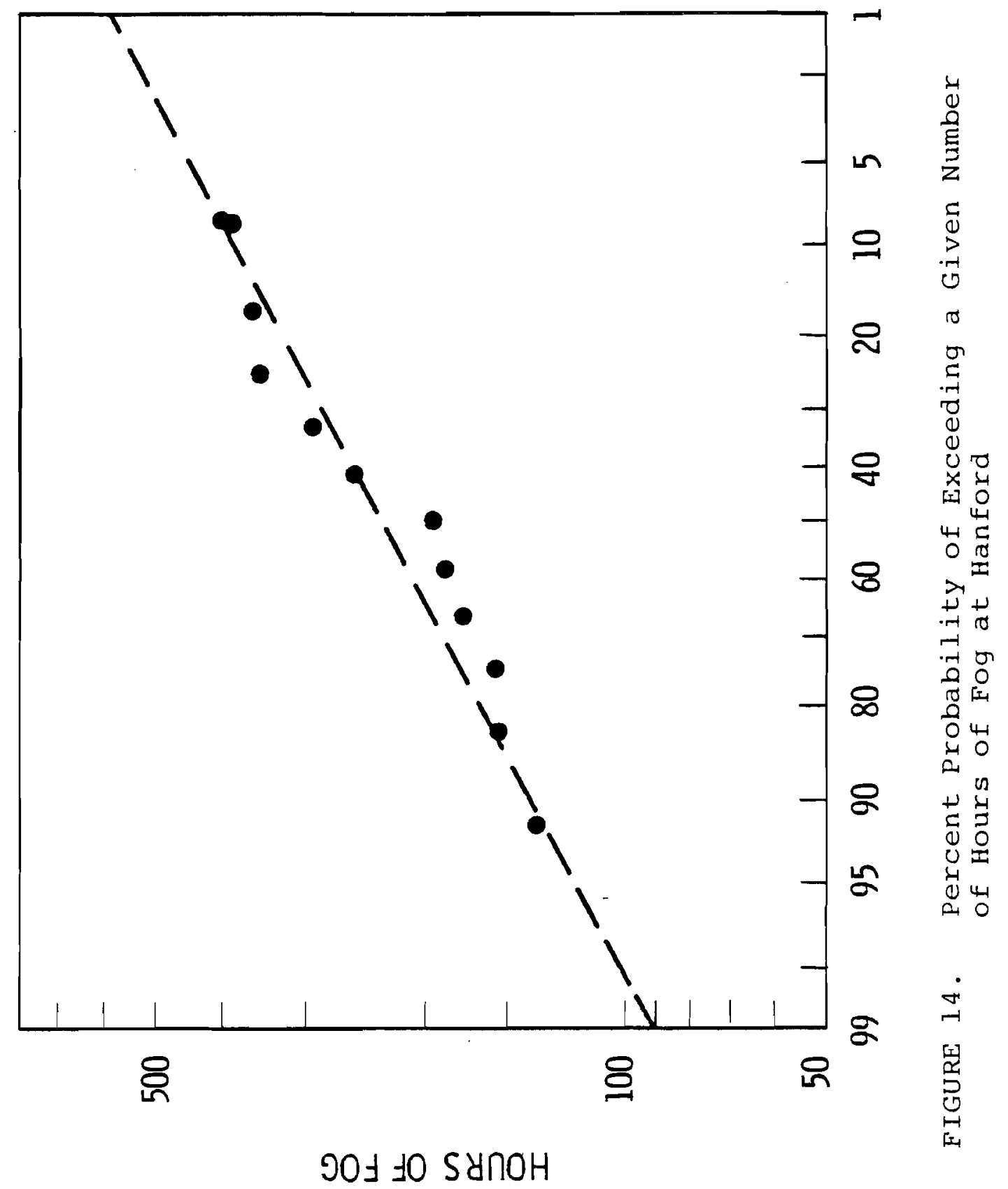




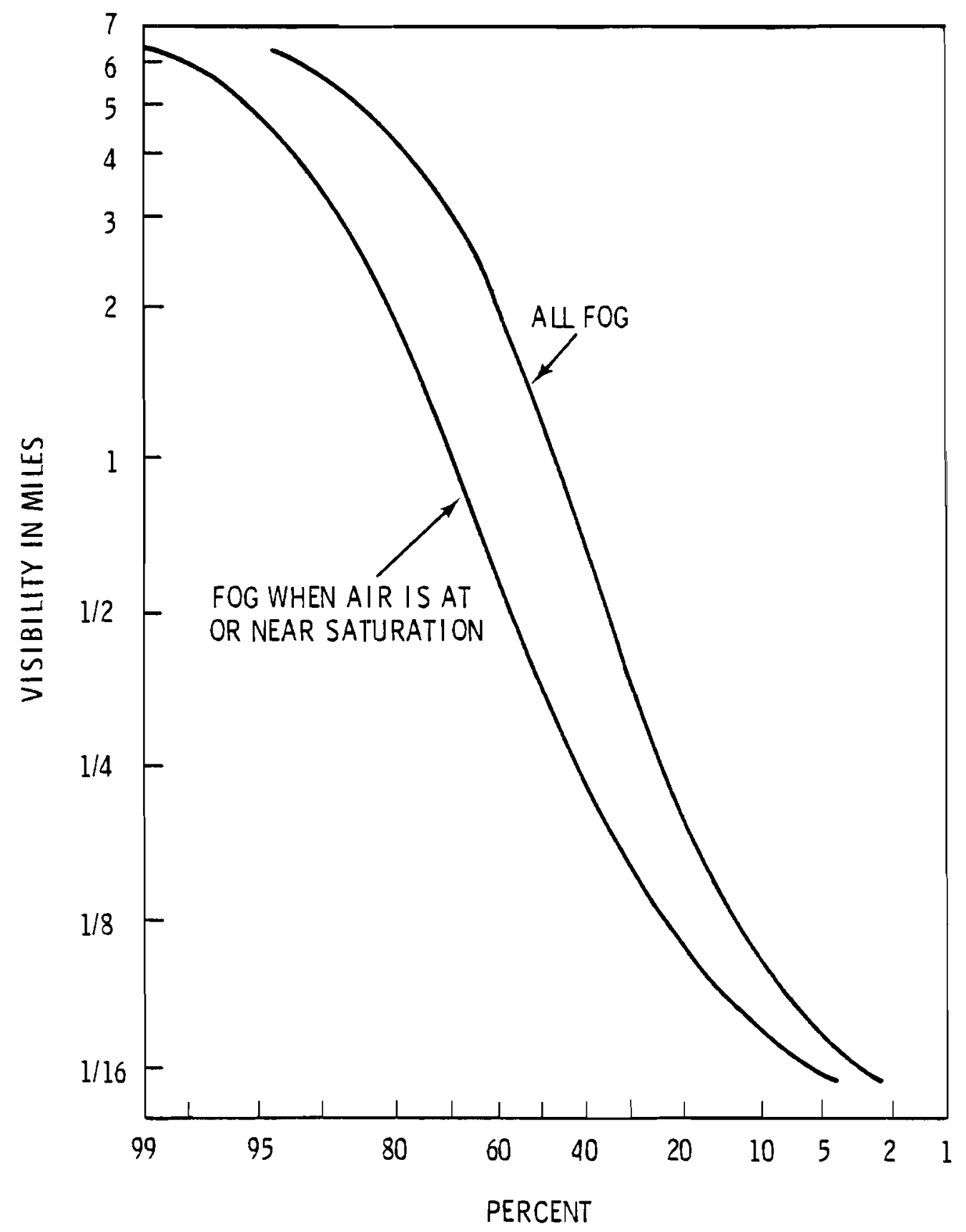

FIGURE 15. Cumulative Frequency Distributions for Visibility During Fog at Hanford 
The climatological data for the HMS are generally assumed to be representative of the entire region, although local variations in the climate are known to exist. Variations of importance are those associated with the Columbia River and the major topographic features which form the sides of the basin. There are differences between the northern and southern portions of the Hanford reservation. These are primarily small differences in temperature, humidity and wind.

\section{Diffusion Climatology}

The major impact of a Hanford Nuclear Energy Center on the atmosphere will result from the release of waste heat. The extent of the impact will be further related to the ability of the atmosphere to disperse the heat. The primary factors which govern dispersion or diffusion are atmospheric stability and the wind. The stronger the wind or less stable the atmosphere the more rapid the dispersion.

Results of numerous atmospheric diffusion experiments at Hanford indicate that 4 categories adequately describe atmospheric stability variations for the purposes of diffusion modeling. Figure 16 shows wind roses for Hanford for each of these stability categories and for all categories combined. The data are presented in tabular form in Table 8. The wind roses clearly show the prevailing wind direction at Hanford is from the west northwest and northwest.

If this area were void of significant topographic features, the major impact of an HNEC would be expected to occur to the east-southeast and southeast. However, the influence of the existing topographic features makes this a very tenuous assumption. Air flow measurements made over the reservation in the past few years indicate there are frequent local circulation patterns in which the HMS wind direction does not adequately 


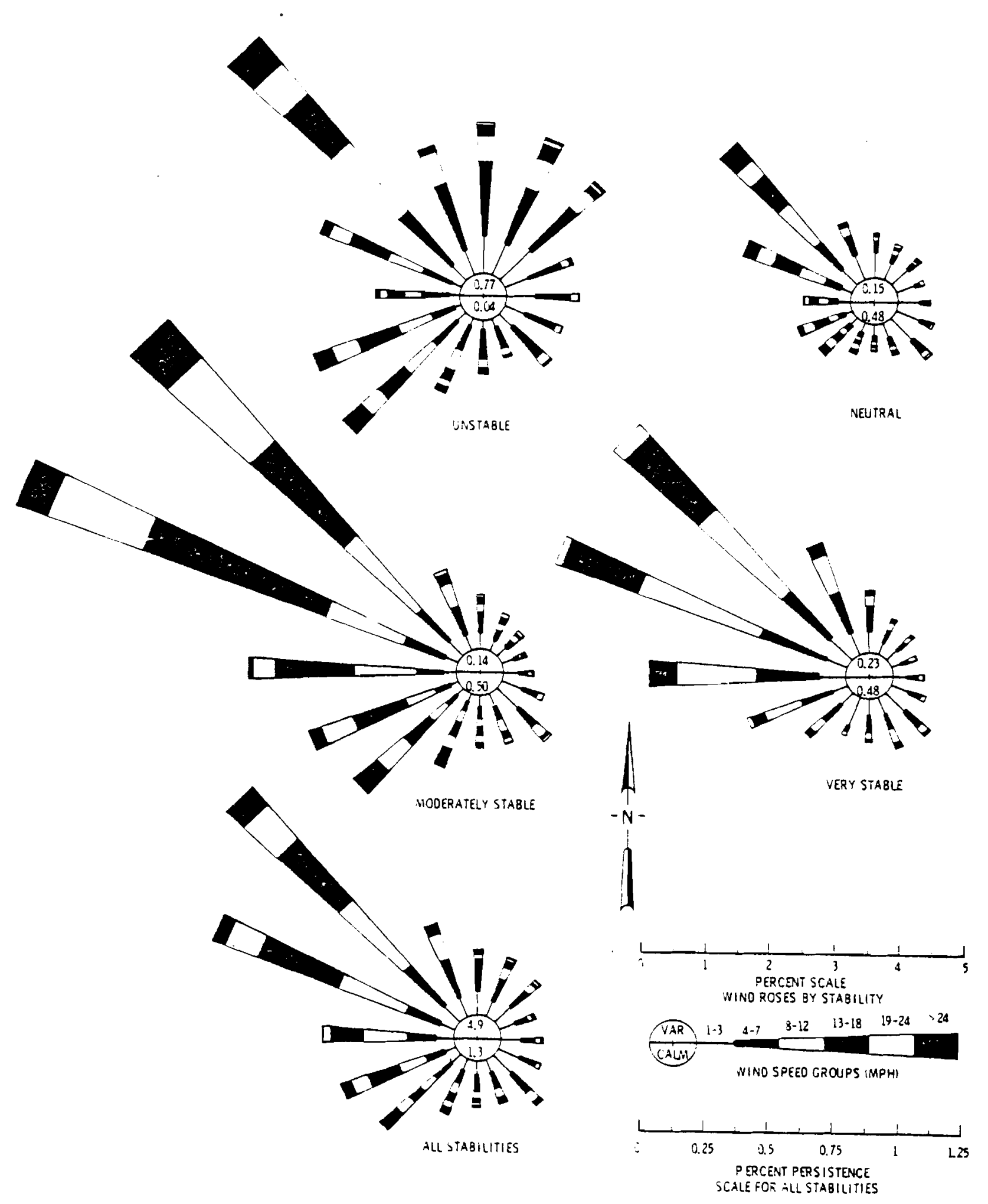

FIGURE 16. Wind Roses by Atmospheric Stability for Hanford 
Table 8. Joint Probability of wind Direction, wind speed and Atmospheric Stability at $200^{\prime}$ for Hanford

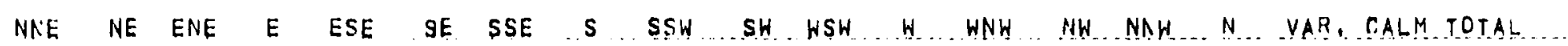

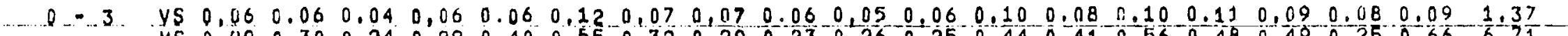
MS $0.290 .30 \quad 0.240 .290 .40 \quad 0.550 .320 .290 .23 \quad 0.260 .250 .440 .41 \quad 0.56 \quad 0.48 \quad 0.490 .250 .66 \quad 6.71$

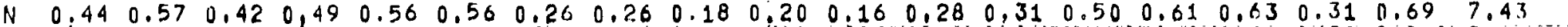
$\begin{array}{llllllllllllllllll} & 0.37 & 0.44 & 0.25 & 0,30 & 0.25 & 0.26 & 0.13 & 0.11 & 0.08 & 0,10 & 0.08 & 0.10 & 0.090 .190 .220 .38 & 0.30 & 0.06 & 3.71\end{array}$

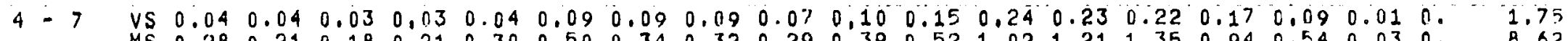

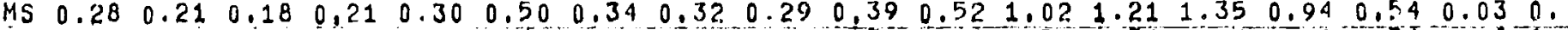

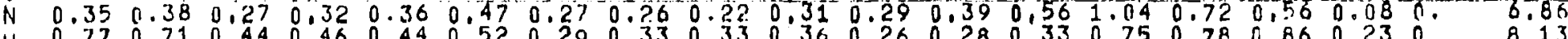
$\begin{array}{llllllllllllllllllllll}0.77 & 0.71 & 0.44 & 0.46 & 0.44 & 0.52 & 0.29 & 0.33 & 0.33 & 0.36 & 0.26 & 0.28 & 0.33 & 0.75 & 0.78 & 0.86 & 0.23 & 0.3 & 0.13\end{array}$

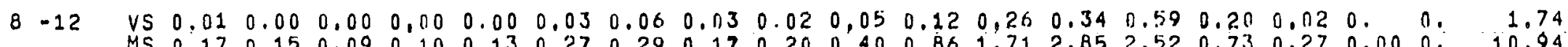

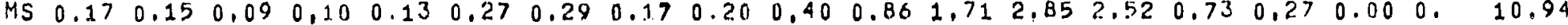

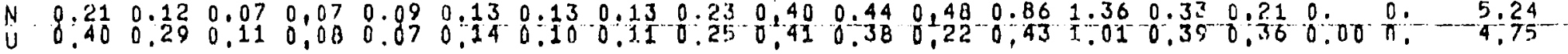

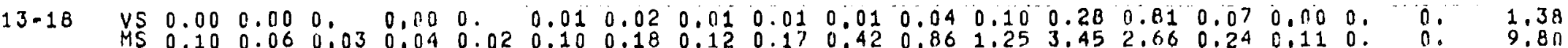

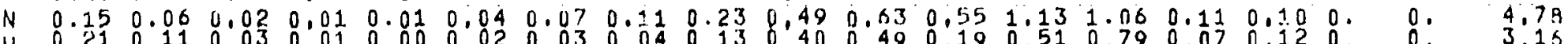

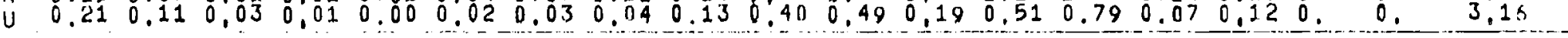

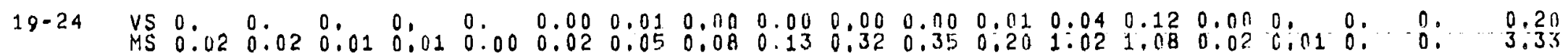

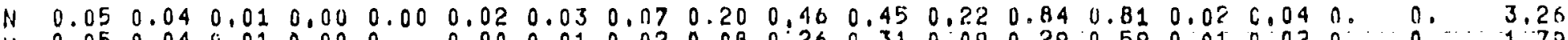
U $0.050 .040 .010,000.00 .000 .010 .020 .080,260.310,090.290 .590 .010 .020 . \cdots 0 . \cdots 1.79$

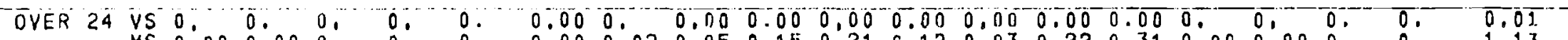

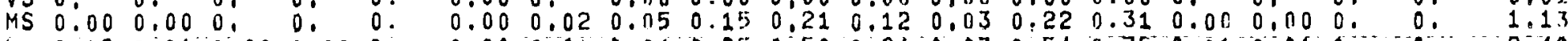

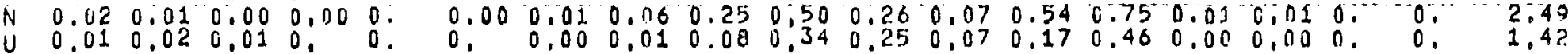

$\begin{array}{lllllllllllllllllllllll}\text { TOTALS VS } & 0.11 & 0.11 & 0.07 & 0.10 & 0.11 & 0.25 & 0.24 & 0.20 & 0.16 & 0.22 & 0.39 & 0.71 & 0.96 & 1.85 & 0.56 & 0.20 & 0.09 & 0.09 & 6.44\end{array}$ MS 0.070 .750 .550 .650 .651 .491 .201 .021 .17 .012 .964 .659 .168 .492 .451 .420 .280 .6640 .53

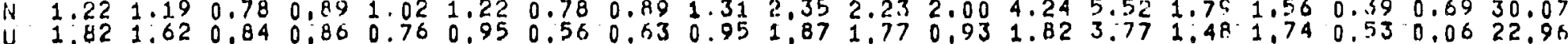


represent air flow over the entire reservation. Evidence of these local circulations is seen in Figure 17, which shows wind roses for several locations on and surrounding the Hanford keservation. In some cases these circulations will act to increase the rate at which the waste heat is dispersed, and in other cases they will have the opposite affect. Figure 18 further demonstrates differences in wind that can be observed at two places in relatively close proximity. The physical separation between the FFTF and the WNP-2 sites is about 2 miles, with FFTF to the west of WNP-2. The large frequency of winds from south-southwest through west at FFTF can be attributed to local circulations related to Rattlesnake Mountain that do not affect WNP-2.

A detailed evaluation of the transport and diffusion of thermal effluents from an HNEC would be a complex and relatively expensive process as a result of the local circulations. Therefore, a relatively simple dispersion model that uses HMS wind and stability data and assumes straight line transport has been used to examine the impact of various HNEC heat sink management alternatives on fog and humidity. The results of this evaluation are discussed in the next section.

\section{HNEC SIMULATION RESULTS}

More than 50 different numerical simulations using BATMAN have been made to examine the potential impacts of moisture releases from a Hanford Nuclear Energy Center on fog and ground level humidity. Presentation of a complete set of the numerical results is beyond the scope of the present work. Rather, a summary of the pertinent results is presented. In the following sections, the predicted impact on the total number of hours of fog, the effect of site location and cooling system choice on the fog impact, and the effect of the HNEC 


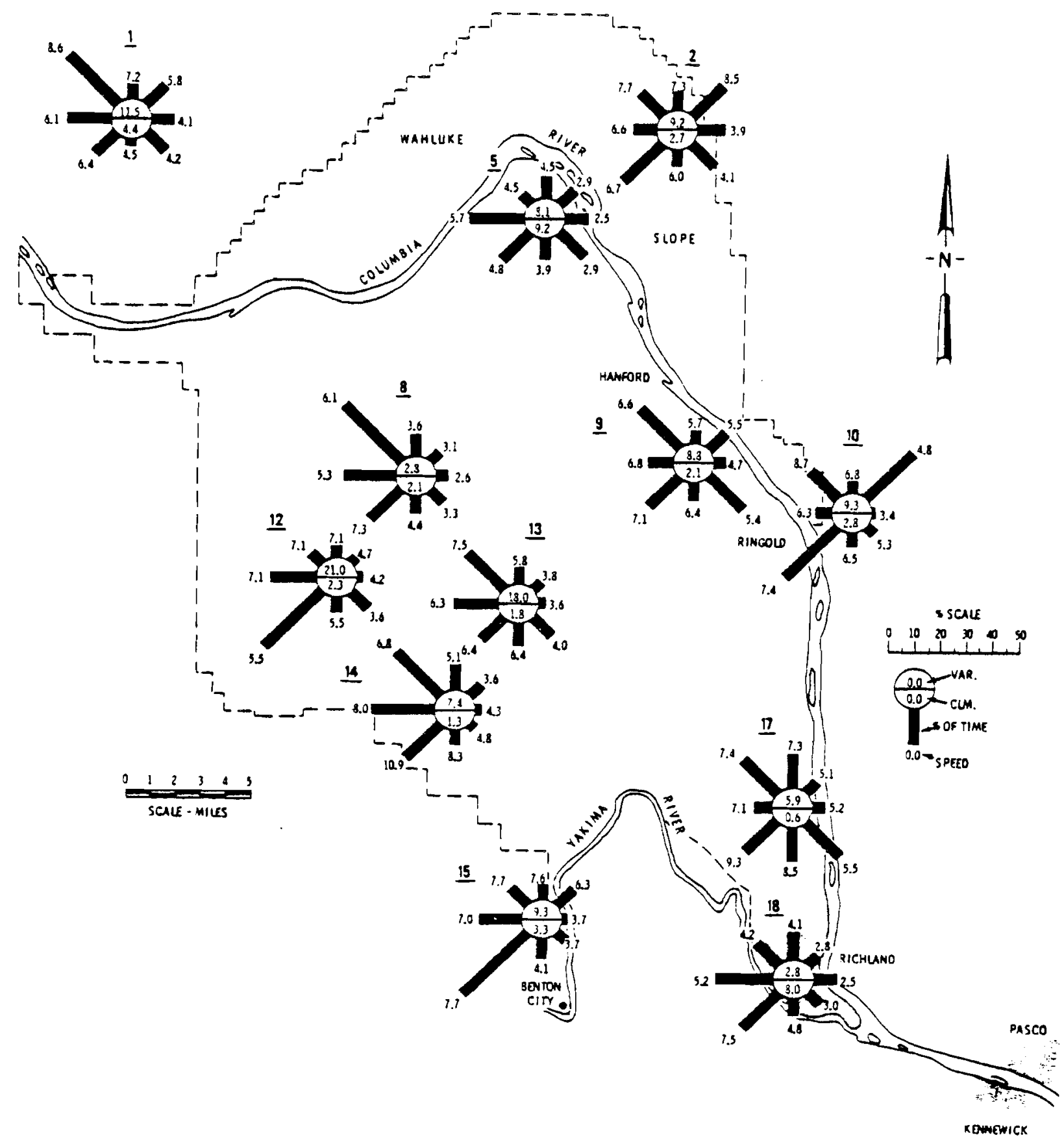

FIGURE 17. Surface Wind Roses for Various Locations on and surrounding the Hanford site. (The points of the rose represent the directions from which the winds come) 

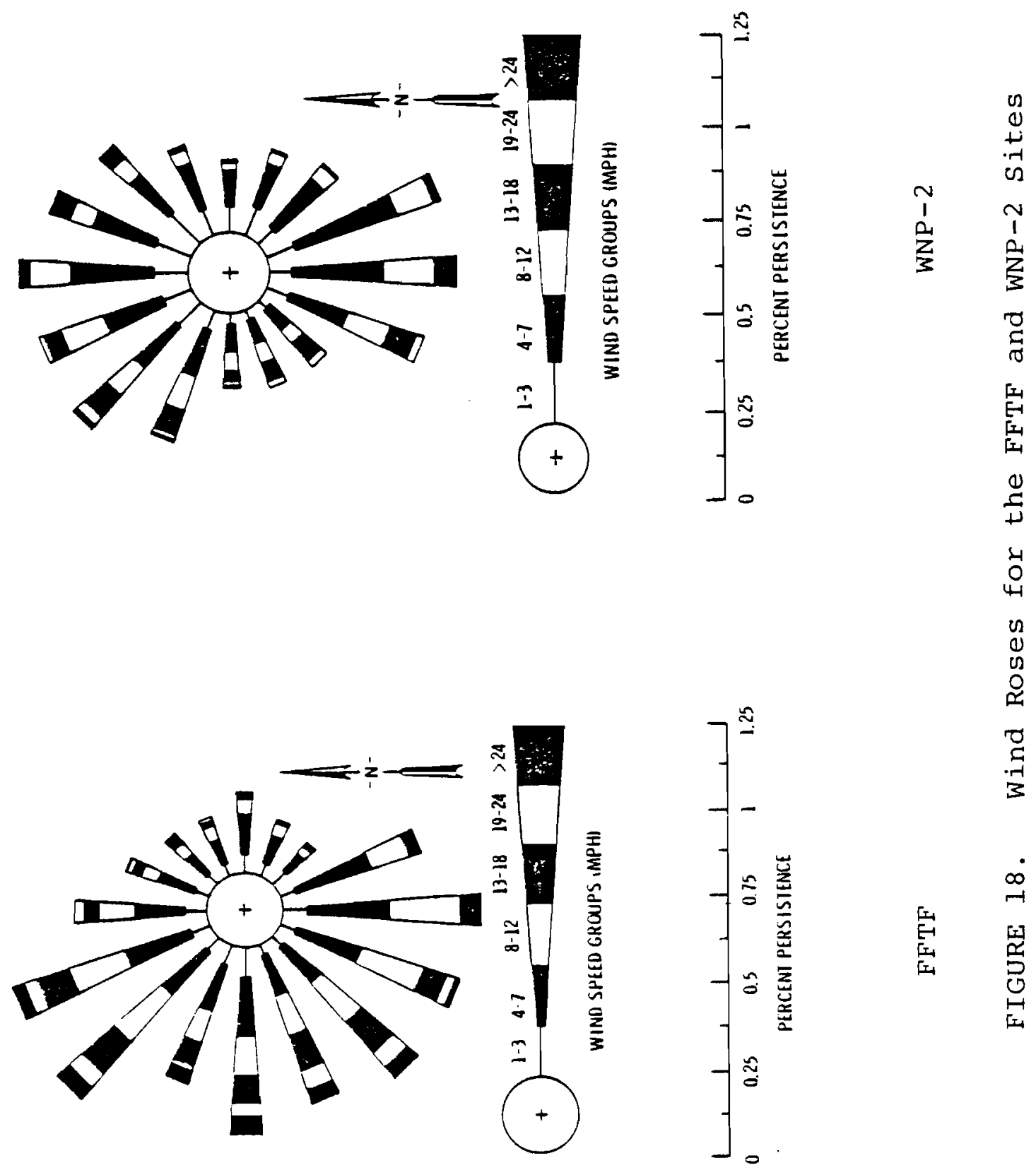

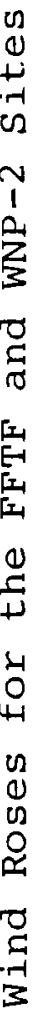


on visibility are discussed. In addition, the statistical significance of the predicted increases in fog is evaluated. Finally, the effects of an HNEC on summer humidity are examined.

The Predicted Increase in Hours of Fog

For each case BATMAN computed the predicted increase in fog at all grid points. Rather than summarize the predictions at specific locations, a number of general areas have been selected. These areas are: the Tri-Cities (Richland, Kennewick and Pasco), Eltopia, Othello, Beverly, the Hanford Meteorological Station, and Benton City. Table 9 gives the predicted increase in hours of fog at each of these locations for the 27 cases under consideration.

The numbers given in the Table are representative of the general region; they should not be taken as absolute. It is more realistic to compare the predictions for various cases at a site and to make evaluations on that basis than it is to assume each number is accurate.

The Tri-Cities is the most populous area near Hanford. Thus increases in fog in that area would have the maximum impact on individuals. Predicted increases in fog range from 15 hours for a single, 4 reactor cluster to 288 hours for a 40 reactor energy center. The larger predicted increases in fog could have a significant socio-economic effect.

Eltopia was selected to represent the agricultural region east of the Columbia River and north of Pasco. It also represents the conditions on Highway 395 north of Pasco. Increases in fog in this area might have some impact on agriculture, but the probable timing of fog would tend to mitigate this impact. A potentially more significant impact is the reduction of visibility along the highway. There are already frequent accidents above this section of road. In general the predicted 
Table 9, Predicted Increases in Hours of Fog in Selected Areas

\begin{tabular}{|c|c|c|c|c|c|c|}
\hline Case & $\begin{array}{c}\text { Tri-Cities } \\
\text { Average }\end{array}$ & Eltopia & Othello & Beverly & $\begin{array}{c}\text { Hanford } \\
\text { Met Station }\end{array}$ & $\begin{array}{l}\text { Benton } \\
\text { City }\end{array}$ \\
\hline 1 & 15 & 6 & 1 & 6 & 2 & 2 \\
\hline 2 & 98 & 97 & 19 & 30 & 30 & 39 \\
\hline 3 & 88 & 84 & 36 & 21 & 112 & 28 \\
\hline 4 & 106 & 57 & 30 & 33 & 116 & 33 \\
\hline 5 & 102 & 74 & 32 & 31 & 129 & 35 \\
\hline 6 & 100 & 81 & 16 & 29 & 29 & 21 \\
\hline 7 & 250 & 208 & 118 & 187 & 578 & 152 \\
\hline 8 & 207 & 154 & 94 & 161 & 480 & 135 \\
\hline 9 & 78 & 52 & 26 & 25 & 84 & 25 \\
\hline 10 & 55 & 41 & 11 & 26 & 14 & 14 \\
\hline 11 & 122 & 83 & 41 & 118 & 197 & 74 \\
\hline 12 & 210 & 197 & 75 & 53 & 168 & 88 \\
\hline 13 & 112 & 84 & 28 & 44 & 50 & 50 \\
\hline 14 & 288 & 211 & 118 & 191 & 524 & 175 \\
\hline 15 & 74 & 68 & 18 & 23 & 19 & 26 \\
\hline 16 & 57 & 37 & 11 & 18 & 15 & 21 \\
\hline 17 & 37 & 32 & 8 & 11 & 4 & 10 \\
\hline 18 & 164 & 147 & 51 & 46 & 110 & 69 \\
\hline 19 & 117 & 97 & 34 & 34 & 71 & 48 \\
\hline 20 & 63 & 37 & 13 & 22 & 24 & 24 \\
\hline 23 & 60 & 36 & 12 & 30 & 30 & 20 \\
\hline 24 & 144 & 127 & 50 & 47 & 103 & 49 \\
\hline 25 & 44 & 34 & 9 & 21 & 10 & 12 \\
\hline 26 & 34 & 29 & 6 & 18 & 8 & 7 \\
\hline 27 & 90 & 54 & 25 & 40 & 37 & 30 \\
\hline
\end{tabular}


increases in fog for Eltopia are smaller than for the Tri-Cities, but they are larger than for other areas off the Hanford Reservation.

The impact of an HNEC on the area north of the Hanford Reservation is represented by the predictions for othello and Beverly. The population in the area is small, however Highways 24 and 243 are reasonably well traveled. In general the predicted increases here are relatively small. This is a reflection of atmospheric conditions favorable to diffusion and a low frequency of occurrence of southerly winds.

Advantages of Hanford as a potential site for a nuclear energy center are the large area available and the distance to populated locations. These factors tend to diminish the effect of any impact that moisture releases might have on fog. The predictions for Hanford Meteorological station were selected to represent the conditions in the vicinity of and within the NEC. As such it is to be expected that the largest increases in fog should occur there. Under some conditions the impact there is twice that for the Tri-Cities. However, there are other cases where the reverse is true.

Finally Benton City was selected to represent the region to the west of Richland and south of Rattlesnake Mountain. Increases in fog in this area could significantly affect traffic along Highway 12. They could also affect agriculture by preventing or reducing the severity of late spring freezes that damage fruit crops in the area. In most cases the predicted fog increases for Benton City are relatively small.

The Influence of Site Location on Fog Increases

If the predicted increases in fog in Table 9 for cases 2 through 6 are examined, the influence of general siting strategies on the impact of fog increases can be evaluated. In cases 2 and 3 the clusters are located on lines approximately 
perpendicular and parallel, respectively, to the prevailing wind direction. In case 4 they are spread over the entire reservation, and in cases 5 and 6 they are clustered on the north and south sides of the reservation, respectively. In each case all clusters were assumed to use low-level, mechanical draft cooling towers.

The effect of varying cluster locations on the predicted increase of fog in the Tri-Cities is rather small. The single largest factor in the changes in the predictions is the use of sites 6 and 7 or site 11. In general the variations in the other areas of interest off the Hanford Reservation are also small, and can be tied to the use of particular sites rather than a particular siting strategy.

The Hanford Meteorology Station represents the area where the predicted fogging impact is most affected by the choice of cluster locations. Because of the prevailing Northwest winds, the HMS is very susceptible to increases in fog when clusters are located at sites 6 and 7 .

On the basis of foregoing evaluation, it was concluded that, except for local effects, the formation of fog was a secondary factor in determining the location of the clusters. As a corollary, it was concluded that the fogging impact of an HNEC would be only secondarily related to the ultimate location of reactor clusters.

The Influence of Cooling system Type on Fog Increases

The influence of cooling system type on the increase in fog was examined for a 20 reactor HNEC using the results of cases 2, 7 through 10, and 15 through 17. In these cases the clusters were positioned to take advantage of river water for helper cooling systems, natural basins for ponds, and proximity of the Tri-Cities for cooling towers. 
The results given in Table 9 indicate that for conventional cooling systems the greatest fogging impact is caused by ponds. Tall cooling towers (natural draft or mechanically-assisted, natural draft) have the least impact. The Columbia River is too small to accommodate a 20 reactor HNEC on once through cooling, however substitution of the river for a portion of load should reduce the total impact off the Reservation. This is confirmed by the results of cases 25 and 26 .

The impacts predicted for the use of either cooling ponds or helper cooling ponds were enough larger than those for cooling towers and helper towers to eliminate consideration of these two systems as the primary systems in a 40 reactor center. Case 14 did consider the combination of tall cooling towers and helper ponds, and it will be noted that this combination has the greatest impact on the Tri-Cities. It is improbable that adequate sites exist for cooling more than 2 or 3 clusters with ponds at Hanford.

The use of hybrid wet/dry cooling towers can significantly reduce the predicted increases in hours of fog. The results of cases 1, 2, 15, 16 and 17 have been combined to indicate the potential reduction as shown in Figure 19. By the use of a sufficiently large dry cooling fraction, hybrid wet/dry systems can reduce the fogging impact to essentially zero. The 15 hours of fog shown for 0 \% wet cooling result from 4 low-level, wet towers assumed for site 1 in all simulations.

Examination of the results of the mixed cooling system simulations shows that the use of once-through cooling for 1 or 2 clusters has essentially the same effect as using a relatively large fraction ( $20 \%$ ) of dry cooling.

On this basis, it is concluded that the use of tall cooling towers supplemented with once-through cooling is the optimum combination of conventional cooling systems. Almost 


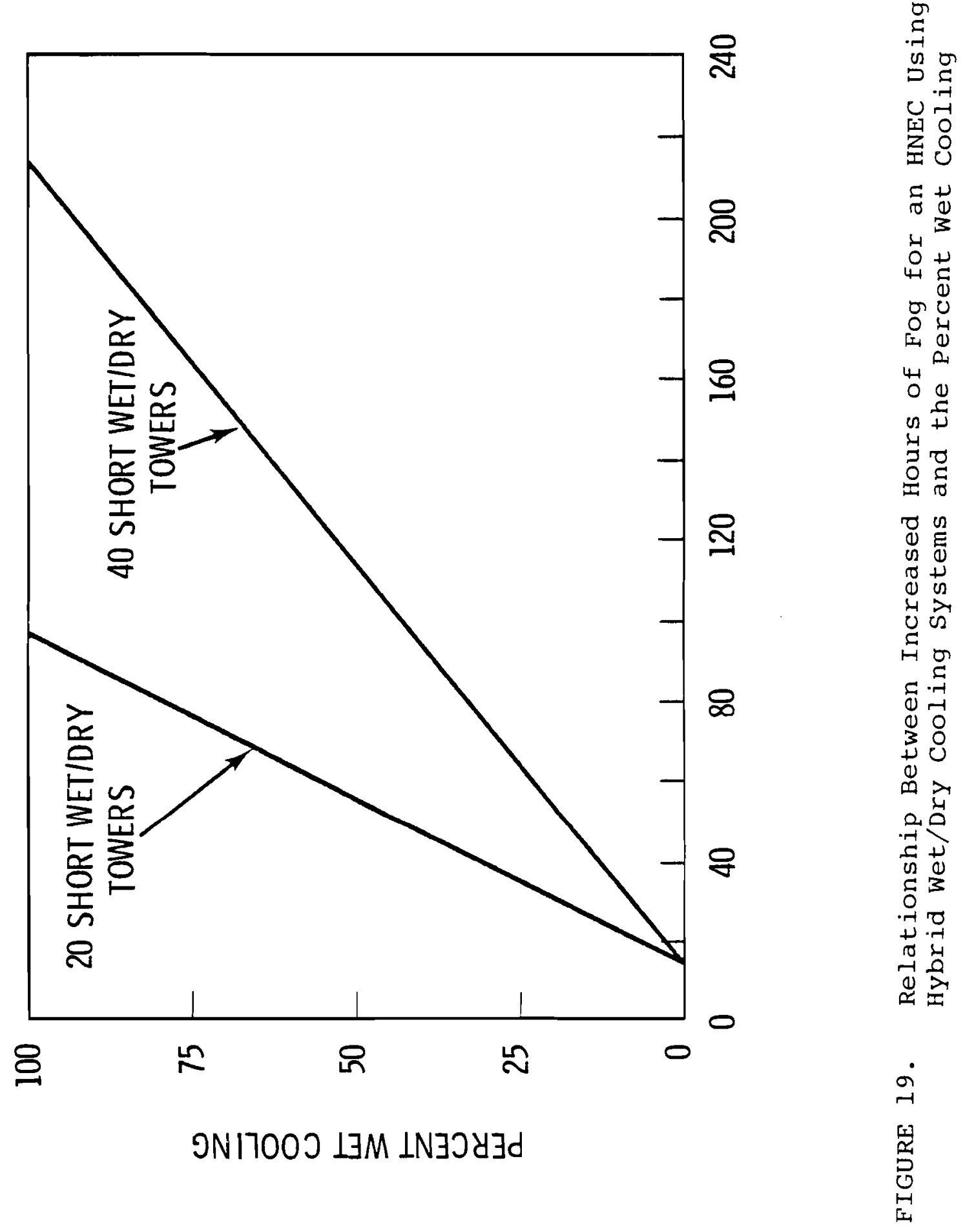


as acceptable is the sole use of tall towers. If a lesser impact on fog is required the only alternative, short of not constructing an HNEC, is the use of hybrid wet/dry towers with a very high percentage of dry cooling. It is also concluded that ponds are not acceptable for HNEC cooling for other than as emergency systems.

The Reduction of Visibility in the Tri-Cities

As indicated earlier, hours of fog is a somewhat nebulus impact. Fog may be relatively light and have little impact, or it may be dense and have a very significant economic impact. Thus, to establish the socio-economic impact of an HNEC through increased fog, it is necessary to describe the increase in frequency of fog in terms of visibility. This is also important as an aid in reducing the subjectiveness of the definition of fog when dealing with the public.

In order to convert hours of fog to visibility, it was necessary to develop a relationship between the two. The moisture releases from an NEC can contribute to fog by causing fog to form or by making naturally occurring fog more dense. Both contributions must be considered when making the conversion from hours of fog to visibility.

The relationship between increases in fog and increases in the occurrence reduced visibility assumed in this study is:

$$
\Delta H v_{k}=\left[\Delta H f_{k}+(H f-H v) P_{k}(\theta)\right] P\left(V<V_{r} \mid d \leq .05 \mathrm{~g} / \mathrm{m}^{3}\right)
$$

where $\Delta \mathrm{Hv}_{\mathrm{k}}$ is the increase in hours of $\mathrm{V}<\mathrm{V}_{\mathrm{r}}$ at receptor $\mathrm{k}$; $\Delta \mathrm{HF}_{\mathrm{k}}$ is the increase in the total hours of fog (Table 9); Hf is the average number of hours of natural fog; $\mathrm{Hv}$ is the average number of hours with $V^{<} V_{r}$ under current conditions; $P_{k}(\theta)$ is the probability the wind direction will carry moisture from the 
HNEC to the receptor, $\mathrm{P}\left(\mathrm{V}<\mathrm{V}_{\mathrm{r}} \mid \mathrm{d} \leq .05 \mathrm{~g} / \mathrm{m}^{3}\right)$ is the probability that the visibility will be less than $v_{r}$ given the occurrence of fog and a saturation deficit of $.05 \mathrm{~g} / \mathrm{m}^{3}$ or less (Figure 15); and $V$ and $V_{r}$ are the visibility and reference visibility respectively. For an HNEC and a receptor in the Tri-Cities, $\mathrm{P}_{\mathrm{k}}(\theta)$ is .2205 . Further, assuming that HMS fog statistics are representative for the Tri-Cities, Hf is 278 hours. For visibilities of $3,1,1 / 2,1 / 8$ and $1 / 16$ miles the values of $\mathrm{HV}$ are $195,132,97,39$ and 8 hours, respectively.

The increased visibility reductions that are predicted for the Tri-cities are given in Table 10. It will be noted that for the single cluster case, and for other cases where the predicted increase in total hours of fog is small, the increase in the number of hours with visibility restriction to less than 3 miles exceeds the increased hours of fog. It will also be noted that the maximum increase in hours of visibility less than $1 / 16$ mile is less than a factor of 5 larger than the increase predicted for a single 4 reactor cluster.

The increases given in Table 10 are combined with climatological information on visibility in Table 11 to show the predicted conditions in the Tri-Cities for various HNEC configurations. The various visibility categories were chosen with transportation in mind. When visibility drops below $3 \mathrm{mi}$, flight rules change from visual to instrument and many private pilots are effectively grounded. At 1 mile all flight operations at the Richland Airport stop, and at $1 / 2$ mile the Pasco Airport closes. When the visibility falls to $1 / 8$ mile or less, ground transportation is affected.

The Statistical Significance of the Predicted Increases

The mention of the impact of visibility reduction on transportation indicates a potential measure of significance 
Table 10. Predicted Increases in Hours of Reduced Visibility in the Tri-Cities

4 Reactor Cluster

1

20 Reactor Center

2
7
8
9
10
11
15
16
17
23
25
26

40 Reactor Center

12
13
14
18
19
20
24
27

Al1

$\underline{F \circ g}$

15

98

250

207

78

55

122

74

57

37

60

44

34

4

7

7

6

4

\begin{tabular}{l} 
Hours of Visibility \\
\hline$\leq 3 \quad \leq 1 \quad \leq 1 / 2 \quad \leq 1 / 8 \quad \leq 1 / 16$
\end{tabular}

29

33

31

16

4

$\begin{array}{lllll}103 & 91 & 79 & 36 & 9\end{array}$

$\begin{array}{lllll}237 & 198 & 165 & 73 & 17\end{array}$

$\begin{array}{lllll}199 & 167 & 141 & 62 & 15\end{array}$

$\begin{array}{llllll}85 & 77 & 67 & 31 & 8\end{array}$

$\begin{array}{lllll}65 & 61 & 54 & 26 & 6\end{array}$

$\begin{array}{lllll}124 & 108 & 92 & 42 & 10\end{array}$

$\begin{array}{lllll}82 & 74 & 65 & 30 & 7\end{array}$

$\begin{array}{lllll}65 & 62 & 55 & 26 & 6\end{array}$

$\begin{array}{lllll}49 & 48 & 44 & 22 & 5\end{array}$

$\begin{array}{lllll}69 & 65 & 57 & 27 & 7\end{array}$

$\begin{array}{lllll}55 & 53 & 48 & 23 & 6\end{array}$

$\begin{array}{lllll}46 & 46 & 42 & 21 & 5\end{array}$

210

202

170

142

63

15

112

115101

87

40

9

288

27

22

187

82

19

164

161

137

11

120

10

72

67

14

144

90

9

12

12

$\begin{array}{rrr}86 & 74 & 47\end{array}$

12

117

9

89

52

10

7

11

8

86


Table 11. Predicted Fog Conditions in the Tri-Cities with an HNEC (current conditions and predicted increases)

Current Conditions

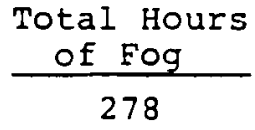

4 Reactor Cluster 1

20 Reactor Center

2
7
8
9
10
11
15
16
17
23
25
26

40 Reactor Center

12

13

14

18

19

20

24

27
293

376

528

485

356

333

400

352

335

315

338

322

312

488

390

566

442

395

341

422

368 $\begin{array}{lllll}298 & 223 & 176 & 75 & 17\end{array}$

$\begin{array}{lllll}432 & 330 & 262 & 112 & 25\end{array}$

$\begin{array}{lllll}394 & 299 & 238 & 101 & 23\end{array}$

$\begin{array}{lllll}280 & 209 & 164 & 70 & 16\end{array}$

$\begin{array}{lllll}260 & 193 & 151 & 65 & 14\end{array}$

$\begin{array}{lllll}319 & 240 & 189 & 81 & 18\end{array}$

$\begin{array}{lllll}277 & 206 & 162 & 69 & 15\end{array}$

$\begin{array}{lllll}260 & 194 & 152 & 65 & 14\end{array}$

$\begin{array}{lllll}244 & 180 & 141 & 61 & 13\end{array}$

$\begin{array}{lllll}264 & 197 & 154 & 66 & 15\end{array}$

$\begin{array}{lllll}250 & 185 & 145 & 62 & 14\end{array}$

$\begin{array}{lllll}241 & 178 & 139 & 60 & 13\end{array}$

$\begin{array}{rrrrr}397 & 302 & 239 & 102 & 23 \\ 310 & 233 & 184 & 79 & 17 \\ 466 & 356 & 284 & 121 & 27 \\ 356 & 269 & 213 & 91 & 20 \\ 315 & 236 & 186 & 80 & 18 \\ 267 & 199 & 156 & 67 & 15 \\ 339 & 255 & 202 & 86 & 19 \\ 291 & 218 & 171 & 73 & 16\end{array}$


of the predicted increases. Other socio-economic tests of significance can be envisioned; they are difficult to evaluate. It is possible, however, to evaluate the statistical significance of the predicted increases by using the Hanford fog data and making several assumptions.

If natural climatic change is neglected, pre and post operational climatological data are assumed to exist, and the HNEC is completed at a single time, the hypothesis that an increase in fog has occurred can be tested. The t-statistic for examining the change of geometric mean in a log-normal distribution is

$$
t_{\alpha, f}=\frac{\ln \left(\frac{\mathrm{H}_{f}+\Delta \mathrm{H}}{\mathrm{H}_{f}}\right)}{\sigma_{\ln _{\mathrm{f}}}\left[\frac{1}{\mathrm{n}_{0}}+\frac{1}{\mathrm{n}_{1}}\right]^{\frac{1}{2}}}
$$

where $\alpha$ is the level of significance, $f$ is the number of degrees of freedom $\left(n_{0}+n_{1}-2\right), H_{f}$ is geometric mean number of hours of fog, and $\Delta H$ is the increase, $\sigma_{\ell n H}$ is the standard geometric deviation of the distribution of $\mathrm{H}_{1}$ and $\mathrm{n}_{0}$ and $\mathrm{n}_{1}$ are the number of years of fog of climatology before and after the HNEC started operation. For 26 years of Hanford data $\mathrm{H}_{\mathrm{f}}$ is 278 hours and $\sigma_{\ell \mathrm{nH}}$ is .285 .

Rather than compute a t-statistic, it is more informative to use tabled values of $t$ and use (9) to compute the minimum statistically significant increases at a 5\% level assuming values for $\mathrm{n}_{1}$. This has been done and the results are given in Table 12 for both total increase in hours of fog and increase in hours of fog with visibility less than $1 / 2 \mathrm{mile}\left(\mathrm{H}_{r}=101\right.$ and $\sigma_{\ell n \mathrm{H}}=.362$ ). 
Table 12. Minimum Statistically Significant Increases in Fog in the Tri-Cities

\begin{tabular}{ccc}
$\begin{array}{c}\text { Years of } \\
\text { HNEC } \\
\text { Operation }\end{array}$ & $\begin{array}{c}\text { Increased } \\
\text { Hours of Fog }\end{array}$ & \multicolumn{2}{c}{$\begin{array}{c}\text { Increased Hours with } \\
\text { Visibility }<1 / 2 \text { mi }\end{array}$} \\
\cline { 2 - 3 } 2 & 102 & 58 \\
4 & 83 & 40 \\
6 & 68 & 33 \\
16 & 46 & 22 \\
36 & 36 & 17 \\
$\infty$ & 27 & 13
\end{tabular}

The minimum statistically significant increases in Table 12 should be compared with the appropriate predictions in Tables 9 and 10. It is immediately obvious that many of the predicted increases are statistically significant. It is also evident that the predicted increases in dense fog (visibility less than $1 / 2$ mile) may be significant when the increase in total hours of fog is not.

The Impact on Summer Humidity

Summer simulations were run to determine the impact of an HNEC on humidity to provide information for use in estimating the potential moisture release on human comfort. Figures 20, 21 and 22 show the number of hours that water vapor increases resulting from low-level, mechanical draft cooling towers would exceed $1 \mathrm{~g} / \mathrm{m}^{3}$ for a single cluster, a 20 reactor center and a 40 reactor center at Hanford, respectively. An increase of 1 $\mathrm{g} / \mathrm{m}^{3}$ in water vapor is equivalent to an increase in relative humidity of about $2 \%$ at $95^{\circ} \mathrm{F}$ (see Figure 8). At a lower temperature more typical of morning and evening hours the increase in relative humidity would be between 5 and $10 \%$. 


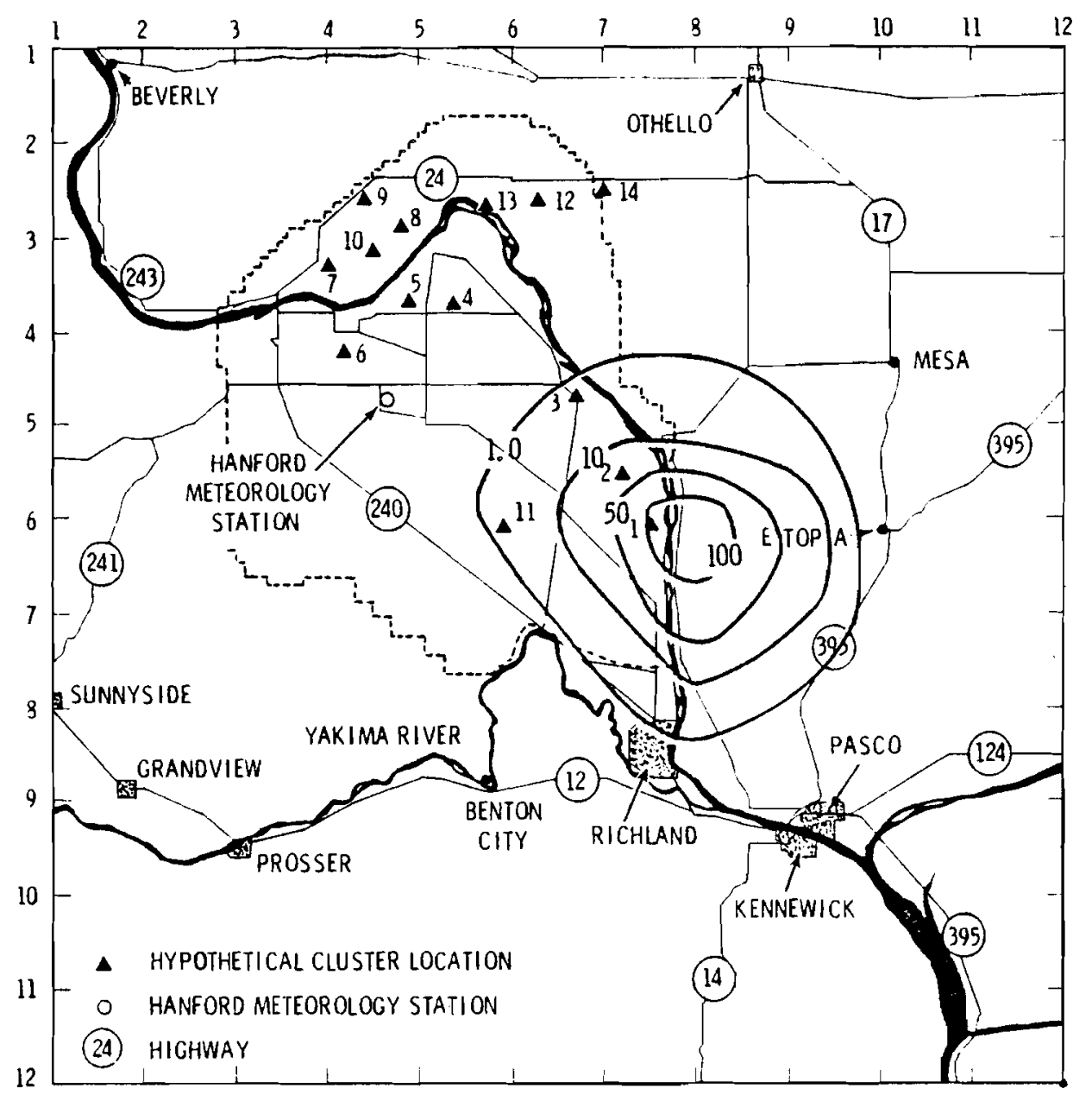

FIGURE 20. Hours of Water Vapor Density Increase Exceeding $1 \mathrm{~g} / \mathrm{m}^{3}$ During Summer Months for a single cluster at Hanford 


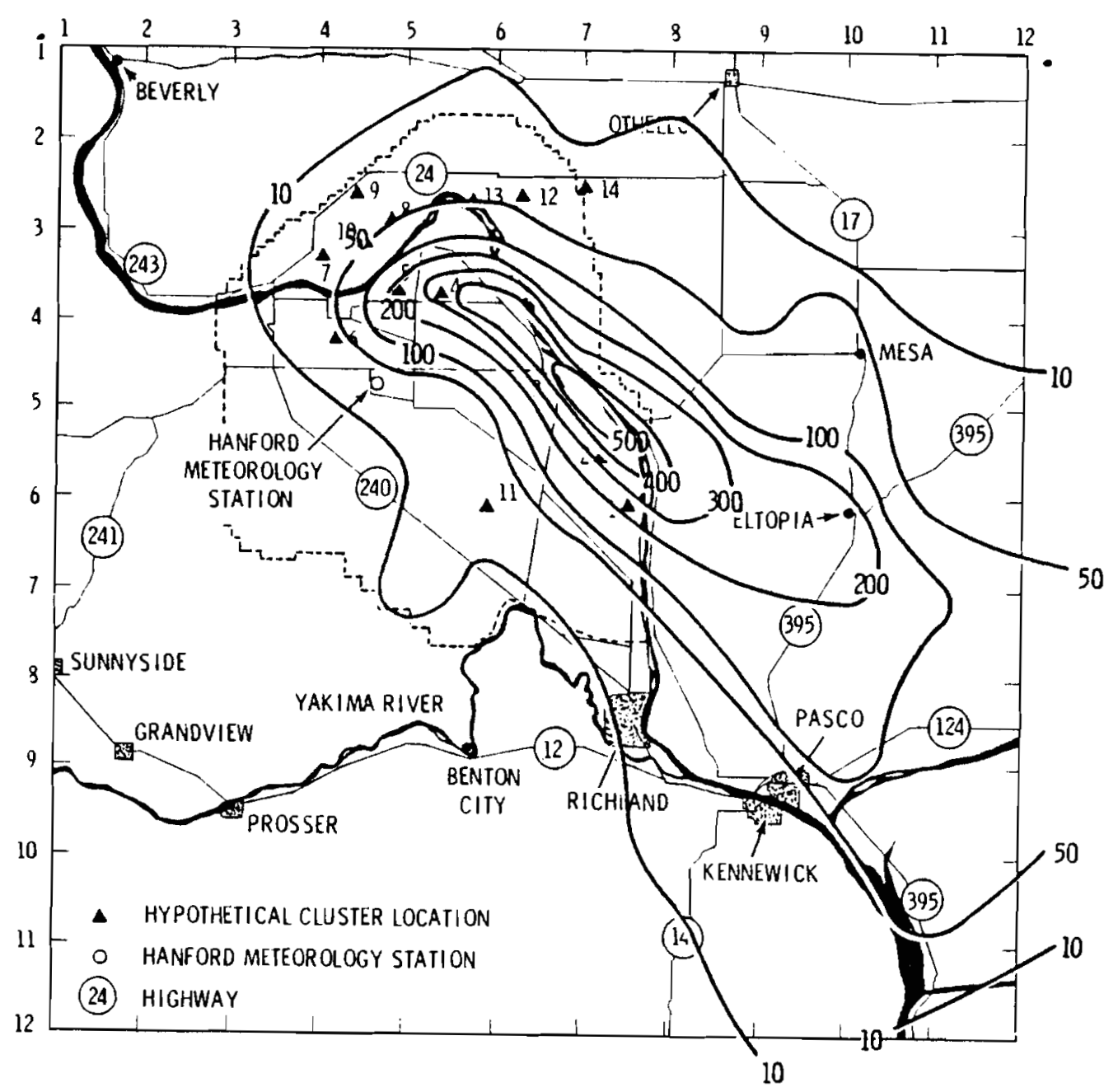

FIGURE 21. Hours of Water Vapor Density Increase Exceeding $1 \mathrm{~g} / \mathrm{m}^{3}$ During Summer Months for a 20 Reactor Energy Center at Hanford 


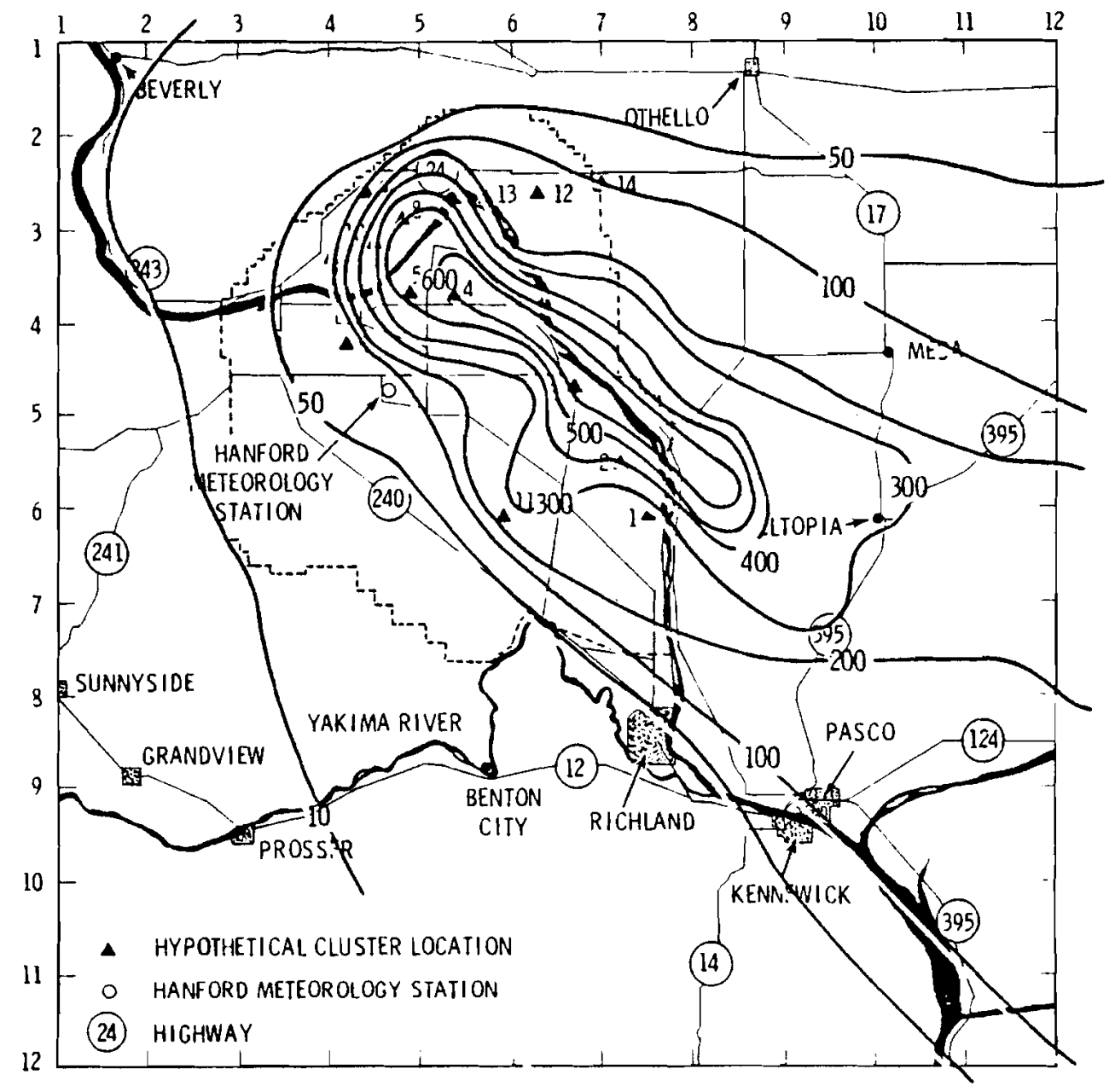

FIGURE 22. Hours of Water Vapor Density Increase Exceeding $1 \mathrm{~g} / \mathrm{m}^{3}$ During Summer Months for a 40 Reactor Energy Center at Hanford 
In examining these figures it is interesting to note the increase in both the frequency and areal extent of the HNEC impact as the number of reactors grows. Figure 20 shows the impact of a single cluster to be negligible and almost totally confined to the Hanford Reservation. As the number of clusters increases to 5 , the effect becomes more prevalent to the east of the Reservation, but still affects relative humidity in the Tri-Cities less than 100 hours. The full 40 reactor HNEC increases the atmospheric humidity by $1 \mathrm{~g} / \mathrm{m}^{3}$ in the $\operatorname{Tr} i-c i t i e s$ about 150 hours each summer.

While the predicted humidity increases are small at the normal summer time temperatures they may cause some discomfort. No attempt has been made to evaluate changes in a temperature humidity or comfort index due to the increased humidity.

\section{CONCLUSIONS}

The major conclusions of this study are:

1) The cooling systems used in an HNEC will be a primary factor in determining the fogging impact. For a given HNEC size the impact can be minimized by using a combination of tall (natural or mechanically assisted natural draft) cooling towers and once-through cooling. Hybrid wet/dry cooling towers can achieve a relatively low impact if a large fraction of the cooling $(\geq 50 \%)$ is accomplished by dry heat exchange. The maximum fogging impact would be associated with cooling ponds.

2) The positions of the 4 reactor clusters of the HNEC within the Reservation would only have a secondary effect on the fogging impact. Increase in fog should not be an important factor in selection of cluster locations. 
3) The number of hours of fog in the Tri-Cities could be increased by almost 300 for a 40 reactor HNEC and 250 for a 20 reactor center if conventional, low-level evaporative cooling systems are used. Other areas surrounding the Hanford Reservation would be affected less frequently. On the Reservation the number of hours of fog at the Hanford Meteorology Station could increase by almost 600 .

4) The moisture releases from an HNEC would increase the density of naturally occurring fog. The changes in number of hours with low visibility are percentagewise greater than those in the total number of hours of fog.

5) Both the predicted increases in number of hours of fog and numbers of hours of low visibility are greater than the minimum statistically significant increases. Thus, they would be apparent in climatological data.

6) The statistical significance of the predicted increases does not indicate the extent of their socio-economic impact. It is necessary to evaluate these increases in socioeconomic terms to identify the extent of the problems which might occur from increased fogging.

7) BATMAN is a relatively simple model which glosses over many physically important considerations in estimating the increased frequency of fog. If the predicted increases in fog are determined to present a serious problem, a detailed study should be made using more realistic models. 


\section{REFERENCES}

1. J. K. Soldat, Radiological Impact of a Nuclear Energy Center on the Environment, BNWL-B-333, Battelle, Pacific Northwest Laboratories, Richland, WA, January 1974.

2. Electric Power Transmission for a Hanford Nuclear Energy Center, BNWL-B-426, Battelle, Pacific Northwest Laboratories, Richland, WA, September 1975.

3. E. T. Merrill and R. M. Fleishman, Status Report - Conceptual Fuel Cycle studies for the Hanford Nuclear Energy Center, BNWL-B-437, Battelle, Pacific Northwest Laboratories, Richland, WA, November 1975 .

4. W. W. Laity, Heat Sink Management for a Hanford Nuclear Energy Center, BNWL-B-448, Battelle, Pacific Northwest Laboratories, Richland, WA, November 1975.

5. The Hanford Nuclear Energy Center, An Interim Conceptual Study, BNWL-B-458, Battelle, Pacific Northwest Laboratories, Richland, WA, October 1975.

6. J. R. Young, L. D. Kannberg, J. V. Ramsdell, W. H. Rickard and D. G. Watson, Selection of Heat Disposal Methods for a Hanford Nuclear Energy Center, BNWL-2003, Battelle, Pacific Northwest Laboratories, Richland, WA, June 1976.

7. Nuclear Energy Center Site Survey-1975, Part III. Technical Considerations, NUREG-0001, U. S. Nuclear Regulatory Commission, January 1976.

8. "Hail Suppression Up in the Air," Science, 191:932, 1976.

9. F. A.- Gifford, Jr., "An Outline of Theories of Diffusion in the Lower Layers of the Atmosphere," in Meteorology and Atomic Energy-1968, D. Slade, ed., TID-24190, U.S. Atomic Energy Commission, July 1968.

10. G. A. Briggs, Plume Rise, TID-25075, U. S. Atomic Energy Commission, November 1969.

11. G. A. Briggs, "Diffusion Estimation for Small Emissions," Atmospheric Turbulence and Diffusion Laboratory 1973 Annual Report, ATDL-106, pp. 83-145, December 1974 .

12. G. T. Csanady, Turbulent Diffusion in the Environment,

D. Reidel, Boston, MA, 248 pp., 1973. 
13. The Colheat River Simulation Model, HEDL-TME-72-103, Hanford Engineering Development Laboratory, Richland, WA, August 1972 .

14. W. A. Stone, D. E. Jenne and J. M. Thorp, Climatography of the Hanford Area, BNWL-1605, Battelle, Pacific Northwest Laboratories, Richland, WA, 1972 .

15. S. Petterson, Introduction to Meteorology, McGraw-Hill, New York, 327 pp., 1958. 
APPENDIX A

BATMAN USER'S GUIDE AND COMPUTER CODE 


\section{BATMAN USER'S GUIDE AND COMPUTER CODE}

Although no attempt has been made to optimize the programming in BATMAN, it is a relatively compact code. The maximum core required in compilation on a CDC 6600 is less than 20,000 words, and the maximum in program execution is less than 12,000 words. Program run time is about $20 \mathrm{sec}$ for a 5 complex NEC with 320 possible combinations of wind direction, wind speed and atmospheric stability. Computations for a 10 complex reactor require about $35 \mathrm{sec}$. This appendix describes the input deck required to run BATMAN, gives 2 examples of input decks, and gives a listing of the program.

The input deck for BATMAN consists of 16 different types of cards. The read and associated format statements for these cards are shown in Figure Al. Not all of these cards are required for a given simulation.

The first card, NCASES, indicates the number of different simulations to be run in a single submission. It is followed by a cards, IOPT, which controls input and output options. If IOPT $(1)=0$ the code computes the increases in water vapor density for a single set of atmospheric conditions and prints them (see Figures 4 and 5). If IOPT $(1)=1$, increases in vapor density are computed for several sets of atmospheric conditions and the results are converted to hours of increase within selected ranges (see Figure 6 ). IOPT(2) controls the number of climatic data cards. If IOPT $(2)=1$, the program reads in the number of climate cards, otherwise it computes the number of cards from the number of wind direction and speed categories. Setting $\operatorname{IOPT}(3)=1$ causes BATMAN to convert the hours of increased water vapor density into increased hours of saturation (fog) (see Figure 7). 

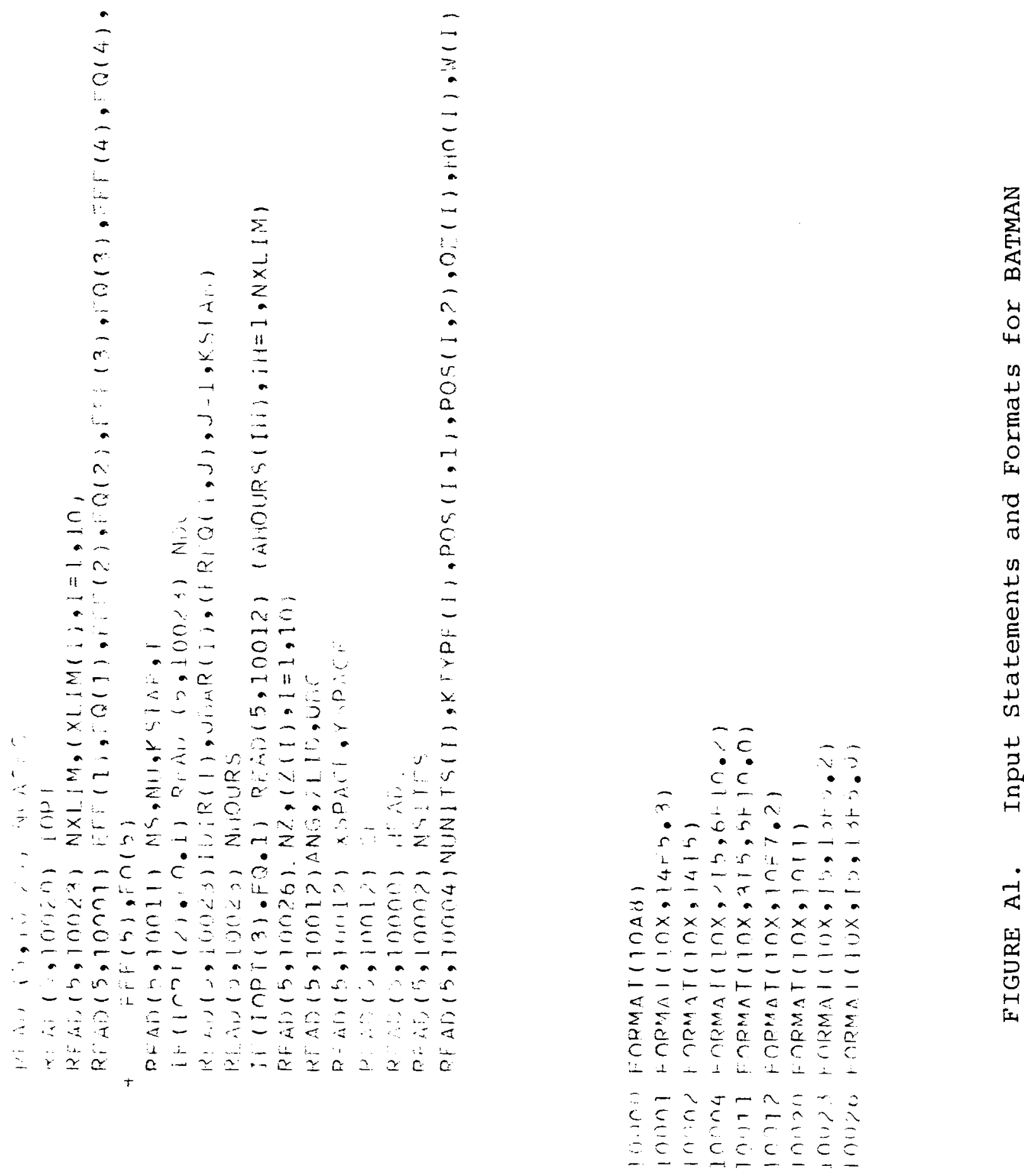

$\stackrel{+}{\Xi}$

告 
The third card in the deck defines ranges for summarization of the frequency of vapor density increases. It is an optional card required only if $\operatorname{IOPT}(1)=1$. The first entry on the card is the number of categories; it is followed by the lower limit for each category $\left(\mathrm{g} / \mathrm{m}^{3}\right)$, in increasing order. The upper limit of all categories is assumed to be infinite. The fourth control card contains information on the overall efficiencies and latent heat release fractions associated with the various cooling system types.

The climatological data input starts with the fifth card. NS, NU, and KSTAB are the number of wind direction sectors, wind speed and atmospheric stability categories, respectively. The final entry on this card is an average temperature $\left({ }^{\circ} \mathrm{K}\right)$ for use in plume rise computations. This parameter is not necessary unless cooling towers are simulated.

If a limited set of atmospheric conditions is being examined and IOPT $(2)=1$, a card is required which specifies the number of climatological data cards to follow. If IOPT $(2)=0$, BATMAN computes $\mathrm{NDC}=\mathrm{NS} \times \mathrm{NU}$.

Next, the climatological data cards are read in. Each card consists of a wind direction sector, wind speed $(\mathrm{m} / \mathrm{s})$, and the frequency of occurrence $(\%)$ for each stability category with the given direction and speed. These cards are followed by a card containing the number of hours in the period being considered (8766 if annual averages are desired).

The final climatological card contains information on the climatology of saturation deficits and is needed only if IOPT $(3)=1$. The data on this card are the hours available for the formation of fog in each of the saturation deficit classes defined by the limits on card 3. The lower limit of the first class is assumed to be zero and the divisions between successive 
classes are defined by the values of XLIM(I). If this card is used, there must be available hours for a total of NXIIM classes.

The four cards that follow define the computational grid and the individual cluster plume characteristics. The first card of the group determines the number of computational levels in the vertical (NZ) and establishes the height of each level $Z(I)$. It is not necessary to define more than 1 level for computations. The second card sets the angular width of the plume (in degrees), establishes the height of the limit on vertical dispersion, ZLID(m), and sets a critical wind speed $\mathrm{UBC},(\mathrm{m} / \mathrm{s})$ which limits the rise of cooling tower plumes. If ZIID is zero, the plume is permitted to rise to the full height estimated in Subroutine PRISE and vertical dispersion is unlimited. If the wind speed exceeds UBC in any case, the plume rise for that case is set to zero and downwash and wake corrections are made. The following card establishes the grid spacing. XSPACE is the north-south spacing and YSPACE is the east-west spacing. It is not necessary that XSPACE and YSPACE be the same, however the computer output has approximately equal spacing in the two directions. The values of XSPACE and YSPACE should be large compared to the characteristic horizontal dimensions of the cooling systems simulated. The final card in this group is a plume rise correction factor to account for additional plume rise resulting from the release of latent heat. A value of 3 has been used for this factor.

The last group of 3 card types defines the case being simulated. This group must be repeated NCASES times. The first card in the group is a heading card which describes the case being simulated, and the second card gives the number of sources (clusters) in the case. The final card type is the source description. The information on this card includes the number of reactors in the cluster, the type cooling system and 
its position in grid coordinates, the rated output of the reactor in $\mathrm{MW}_{e}$, the moisture release height $(\mathrm{m})$, and a characteristic horizontal dimension for the cluster. One card of this type is required for each cluster in the case. If a cluster uses two cooling system types, each must be described on a separate card. In this case the positions may be superimposed on one another.

Figures A2 and A3 give sample data decks for use with BATMAN. These Figures are followed by a complete listing of the BATMAN Code. 

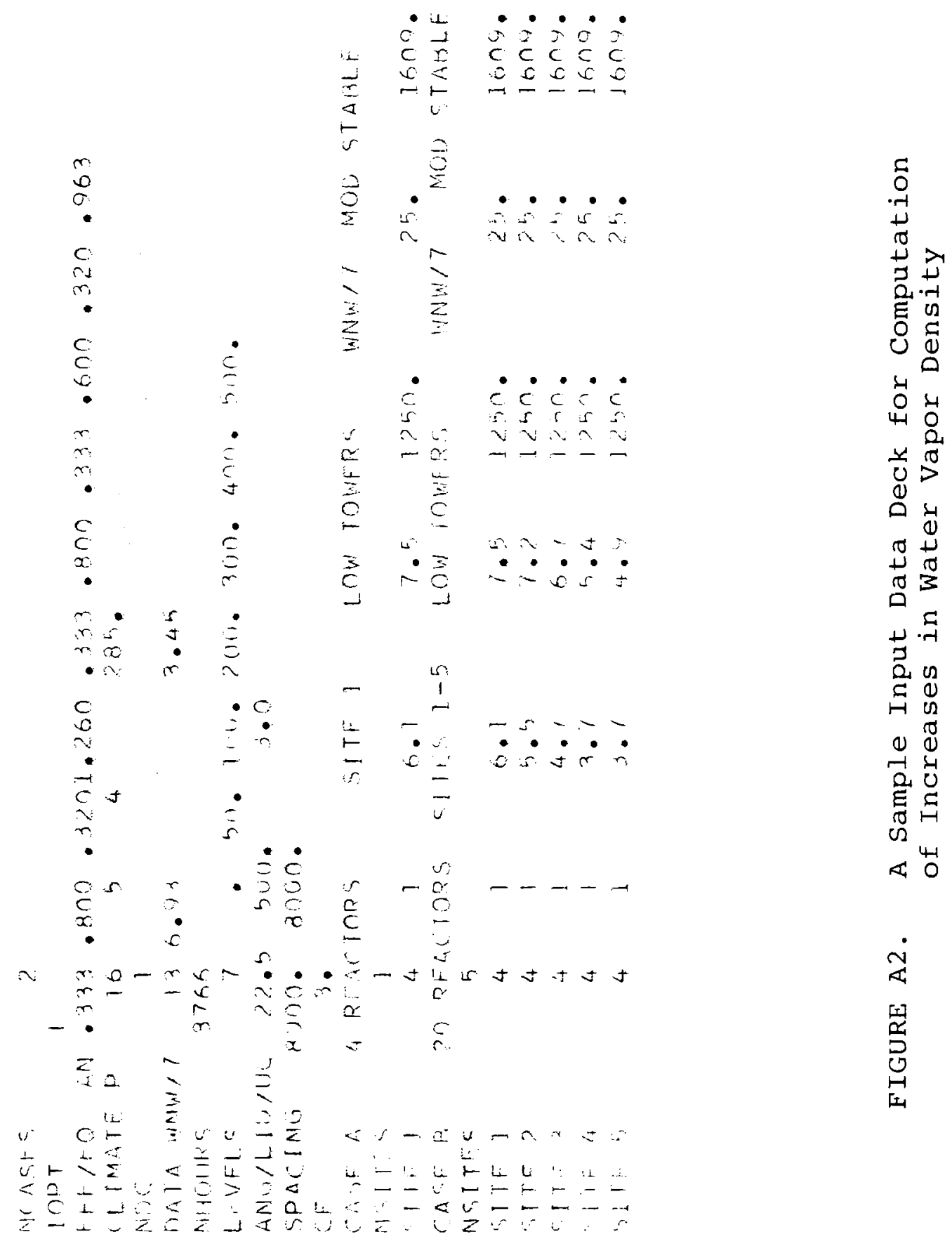

崫 


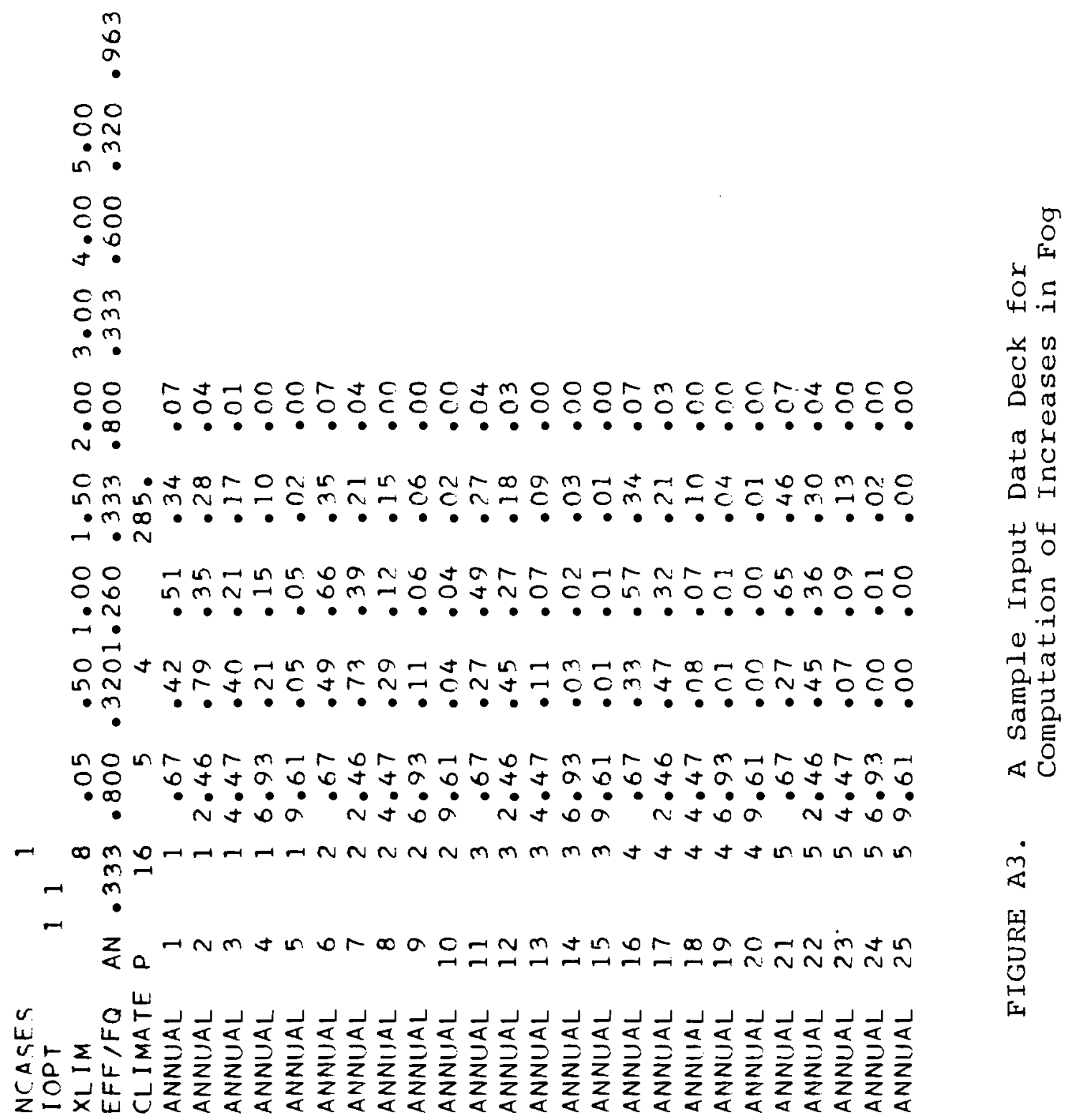


mom

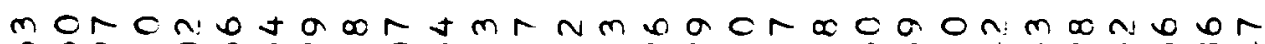
on?

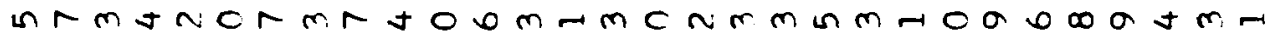

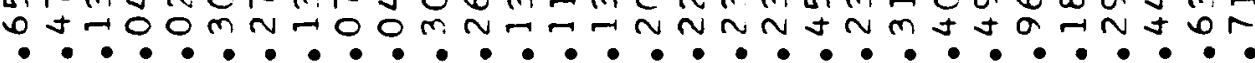

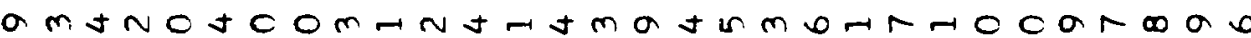

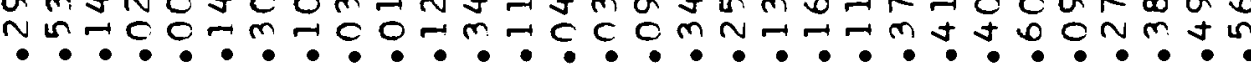

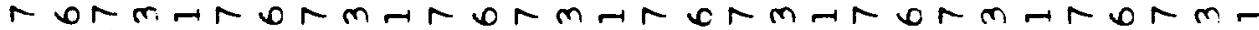

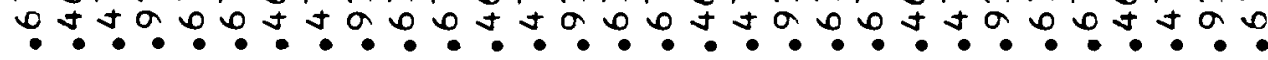

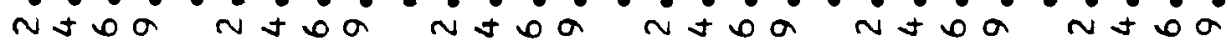
0 000R+NR

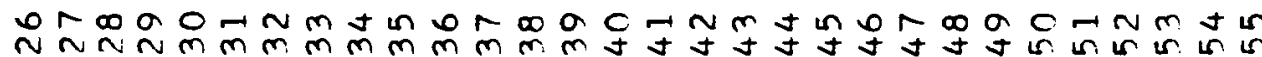
m

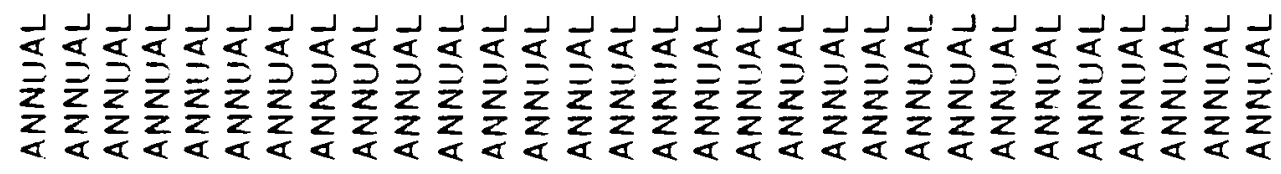


Figure A3 (continued)

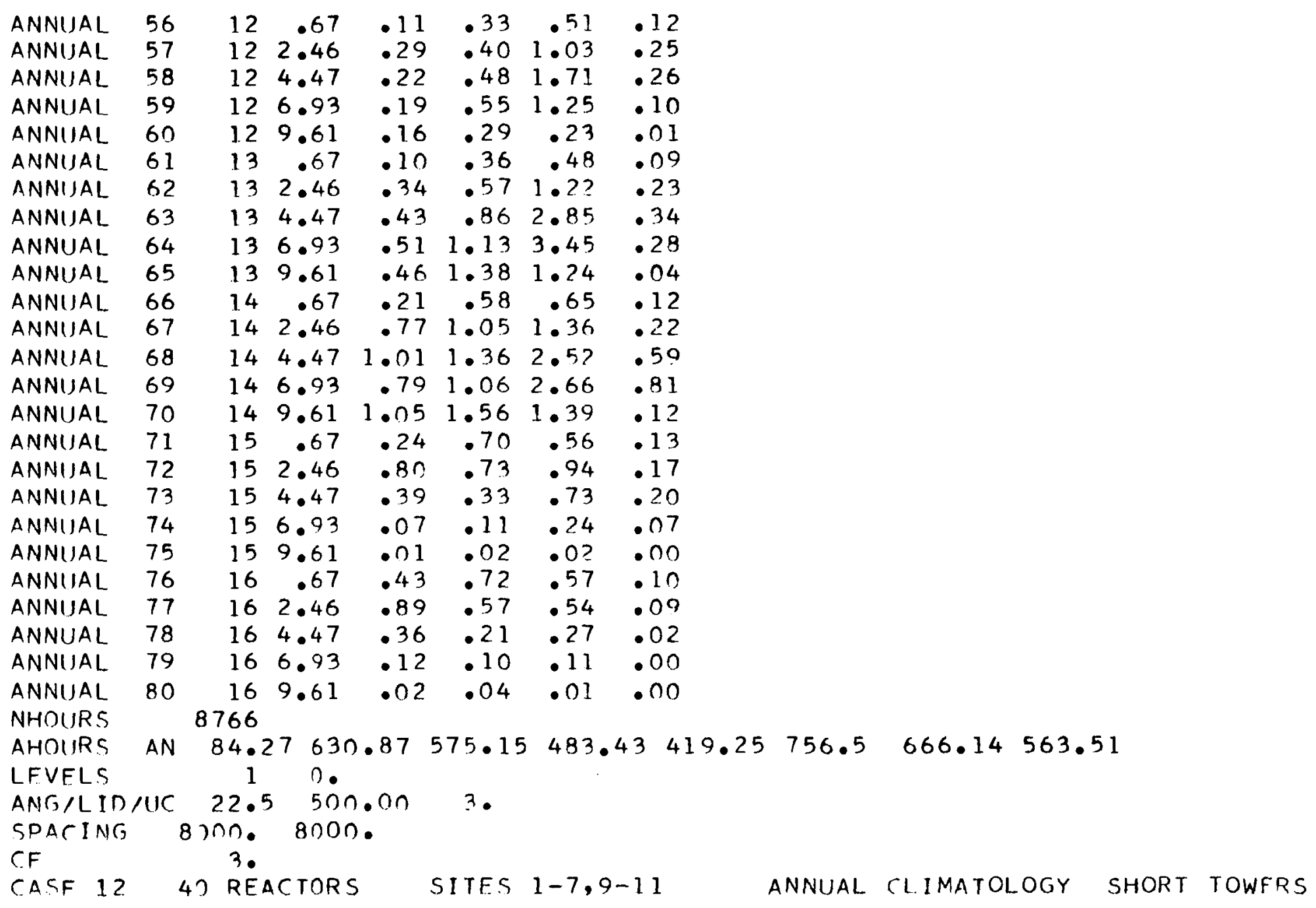


Figure A3 (continued)

$\begin{array}{lrllllll}\text { NSITES } & 10 & & & & & \\ \text { SITE } 1 & 4 & 1 & 6.1 & 7.5 & 1250 . & 25 . & 1609 . \\ \text { SITF } 2 & 1 & 1 & 5.5 & 7.2 & 1250 . & 25 . & 1609 . \\ \text { SITF } 3 & 1 & 1 & 4.7 & 6.7 & 1250 . & 25 . & 1609 . \\ \text { SITF } 4 & 1 & 1 & 3.7 & 5.4 & 1250 . & 25 . & 1609 . \\ \text { SITF } 5 & 1 & 1 & 3.7 & 4.9 & 1250 . & 25 . & 1609 . \\ \text { SITF } 6 & 1 & 1 & 4.2 & 4.2 & 1250 . & 25 . & 1609 . \\ \text { SITF } 7 & 1 & 1 & 3.3 & 4.0 & 1250 . & 25 . & 1609 . \\ \text { SITF } 9 & 1 & 1 & 2.6 & 4.4 & 1250 . & 25 . & 1609 . \\ \text { SITF } 10 & 1 & 1 & 3.1 & 4.5 & 1250 . & 25 . & 1609 . \\ \text { SITF } 11 & 1 & 1 & 6.1 & 5.9 & 1250 . & 25 . & 1609 .\end{array}$



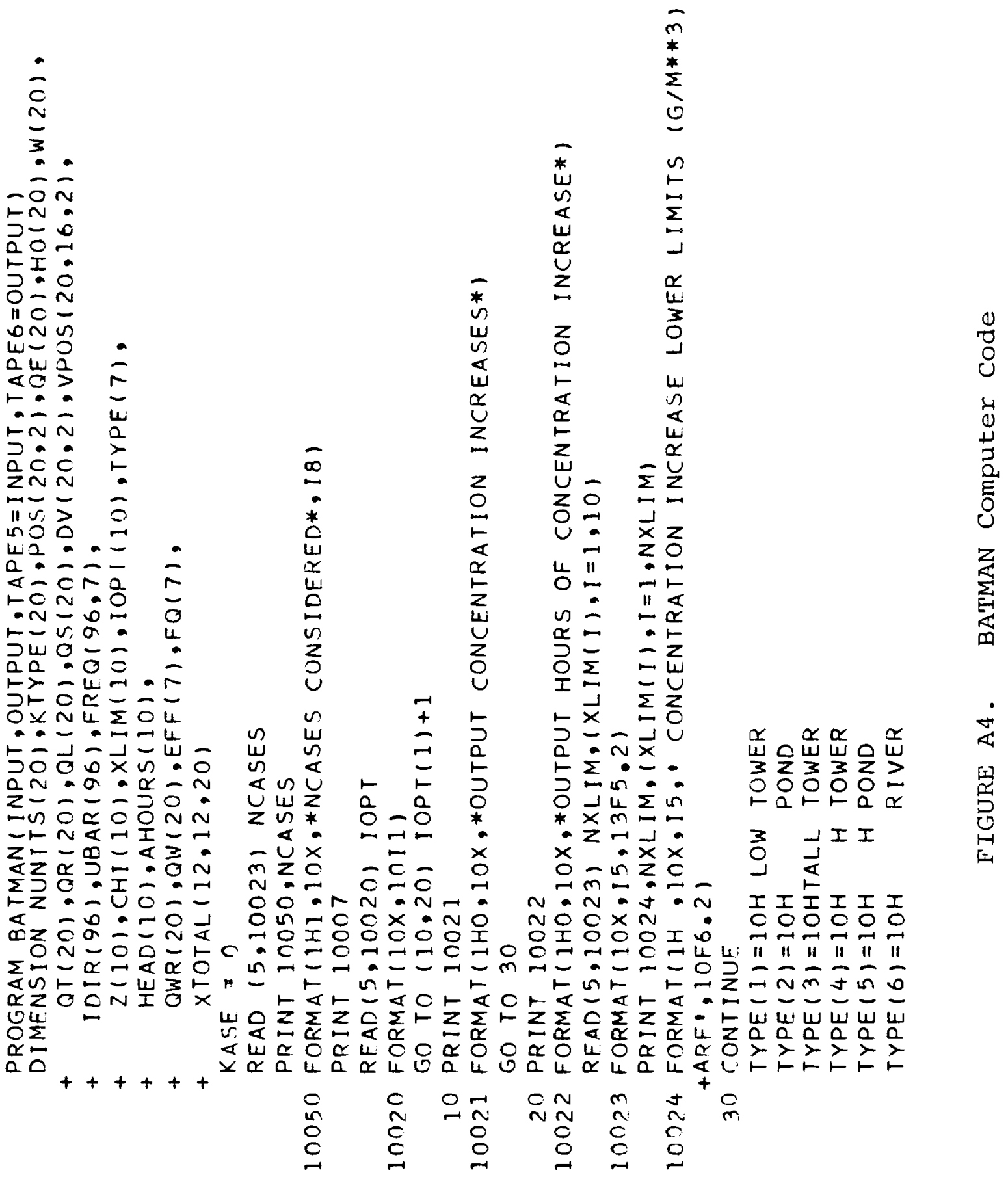
Figure A4 (continued)

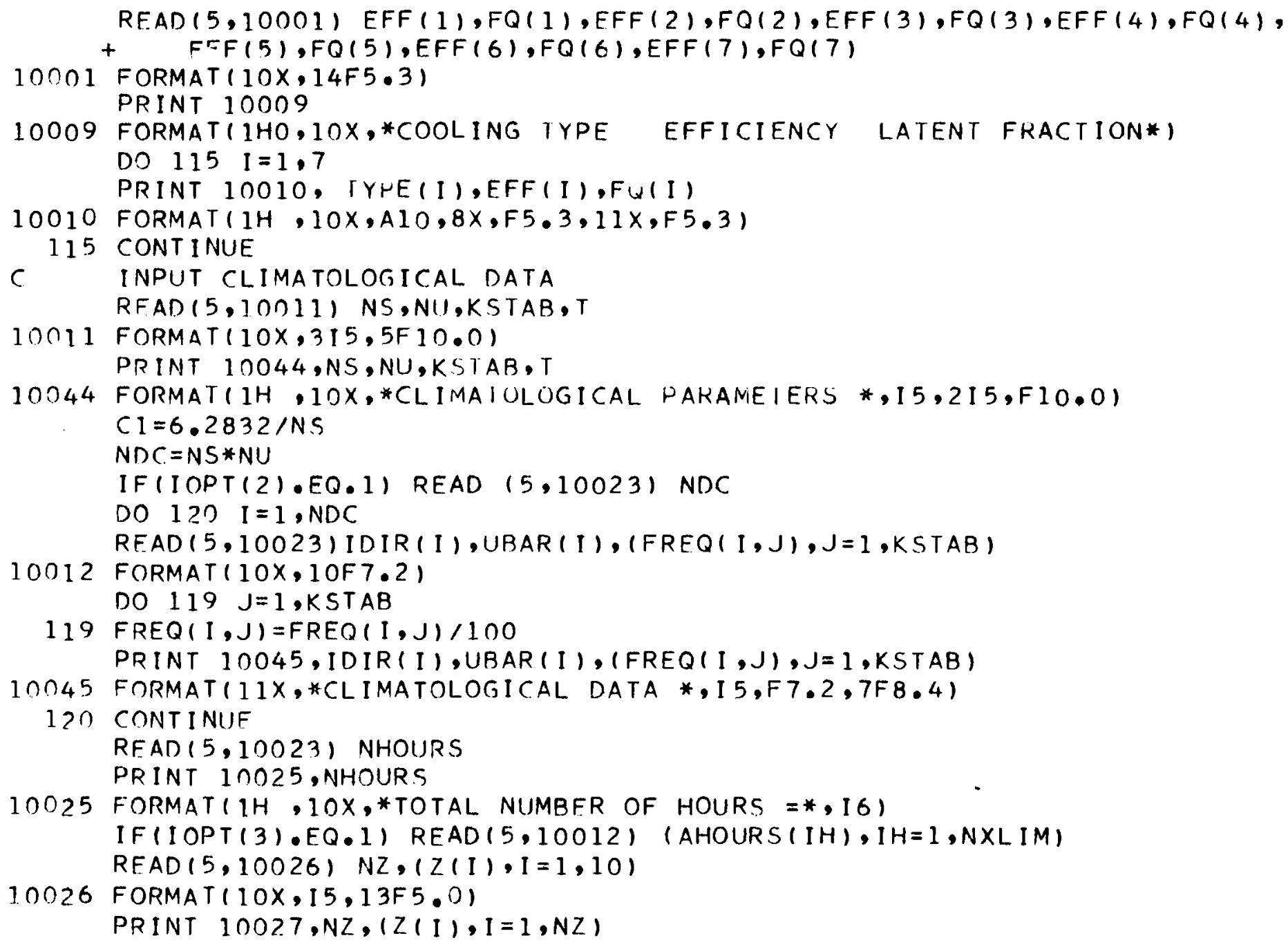


Figure A4 (continued)

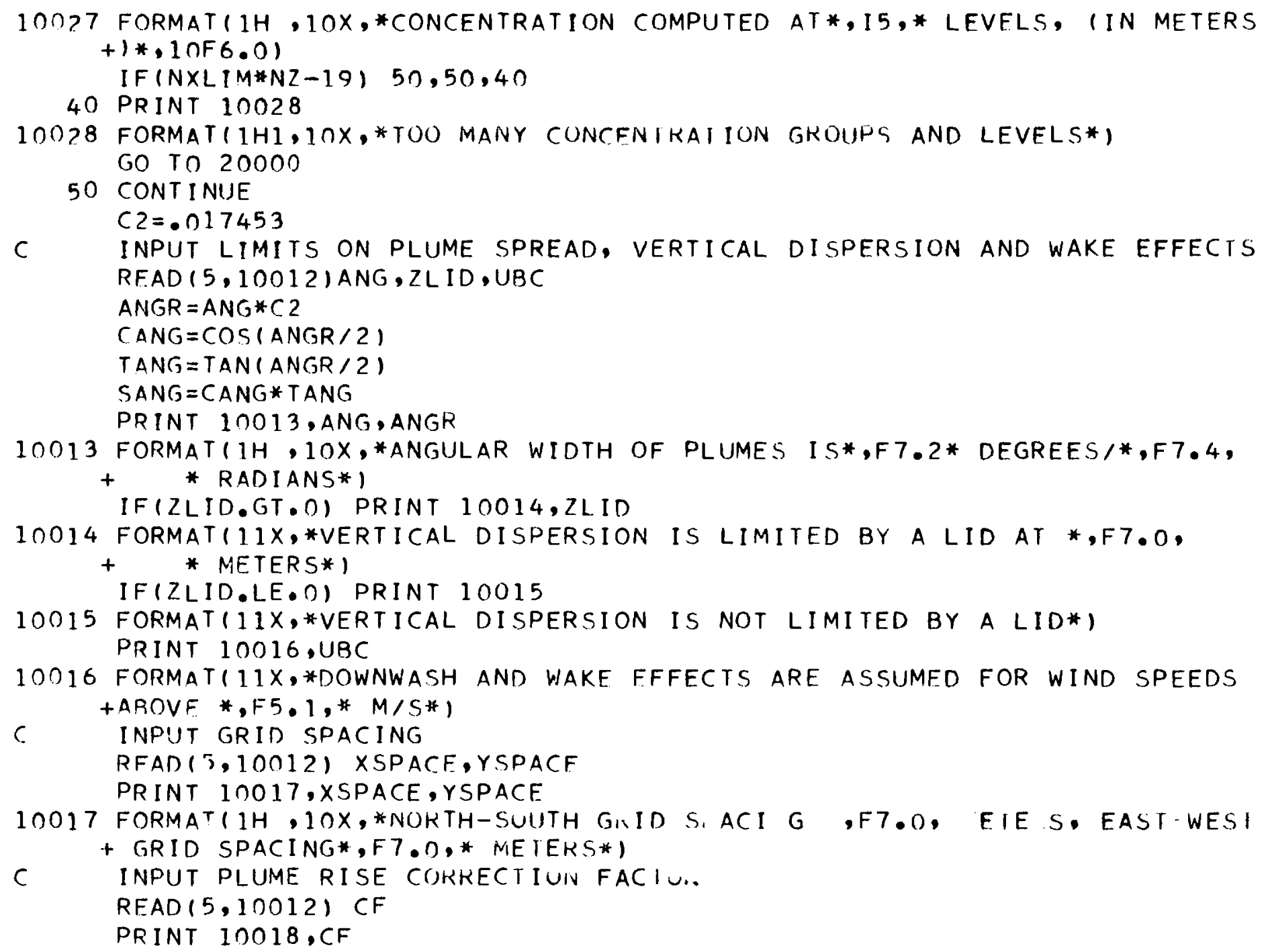


Figure A4 (continued)

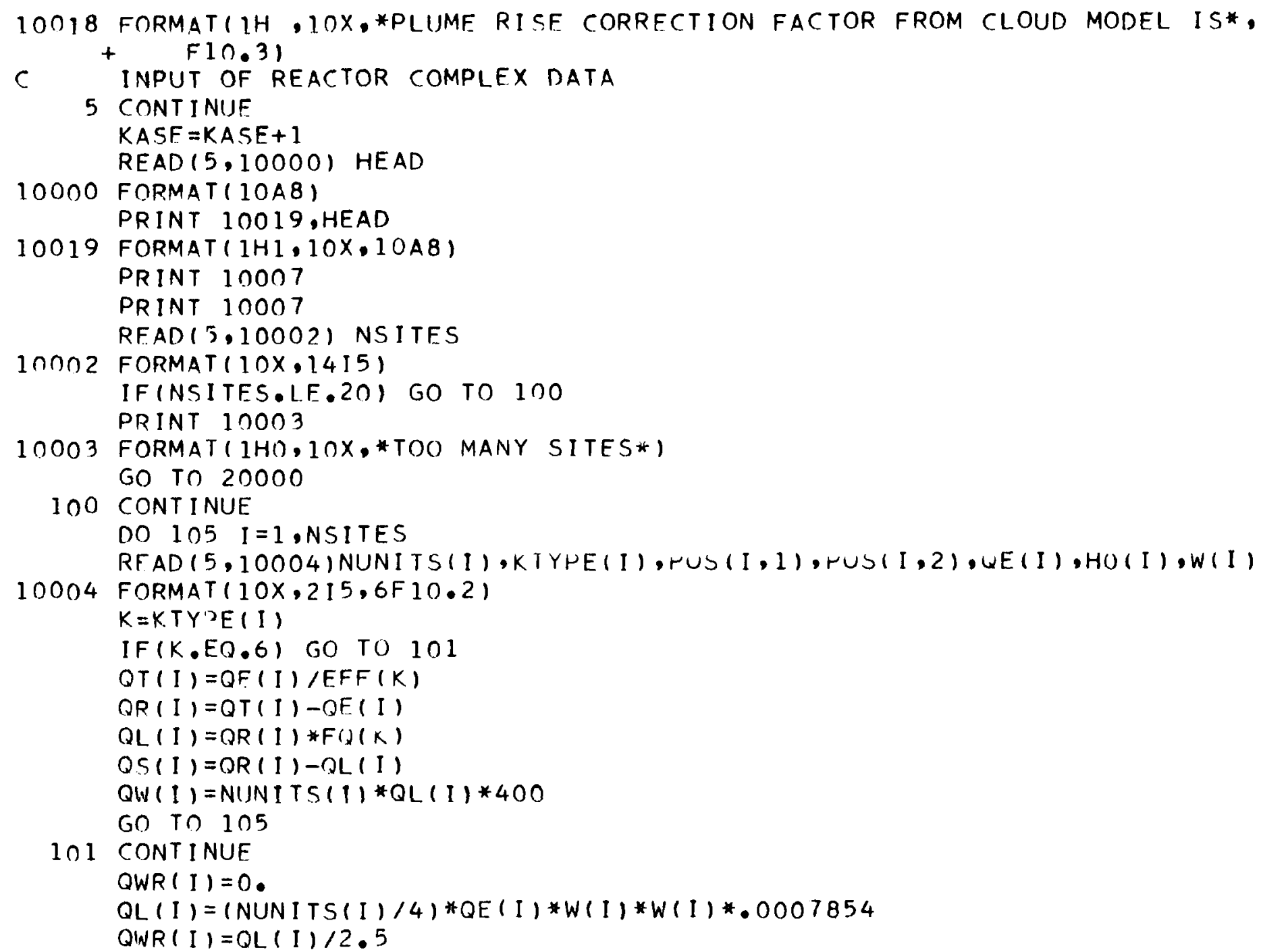




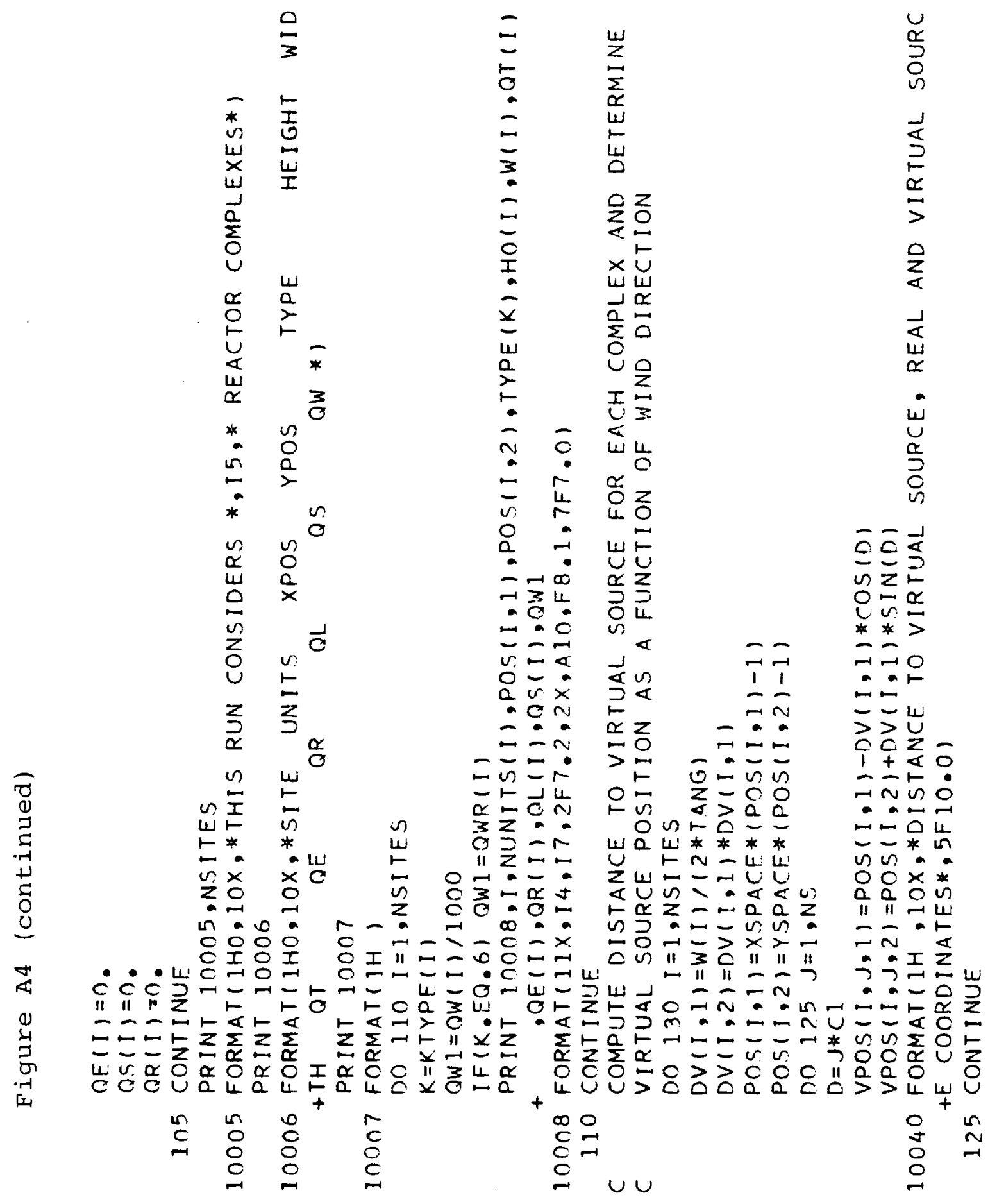


Figure A4 (continued)

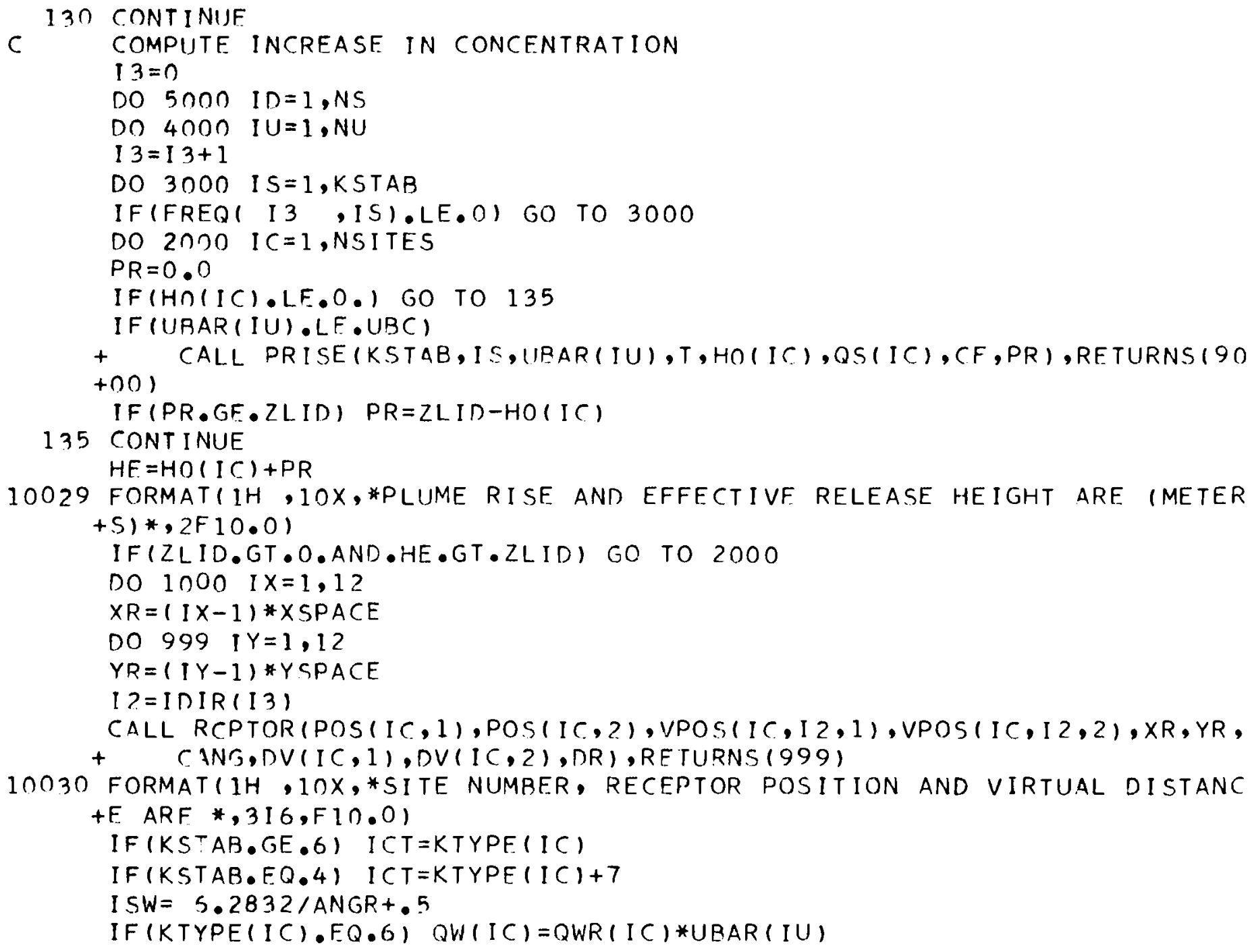




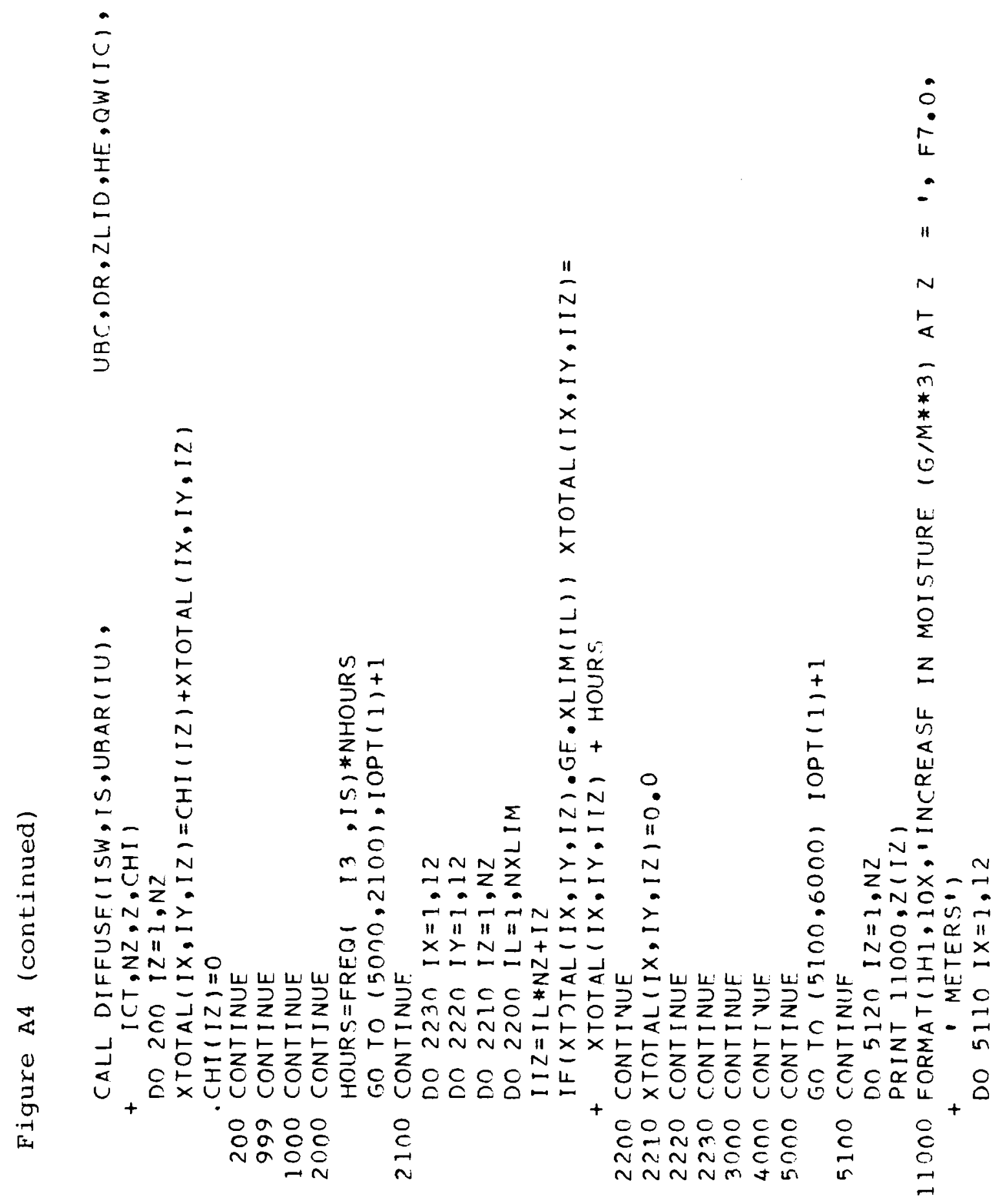


Figure A4 (continued)

PRINT $11001,(X T O T A L(I X, I Y, I Z), I Y=1,12)$

11001 FORMAT(1HO,10X,12F10.2)

DO 5125 I $Y=1,12$

$5105 \times$ TOTAL $(I X, I Y, I Z)=0$.

PRINT 11003

11003 FORMAT $(1 \mathrm{HO})$

5110 CONTINUE

PRINT 11002, HOURS

11002 FORMATIIHO, 10X, THIS CONDITION OCCURS AN AVERAGE OF *,F7.0,* HOUR +S PER YEAR*)

5120 CONTINUF

GO TO 20000

6000 CONTI VUE

DO $6 \cap 3 \cap$ I $Z=1, N Z$

DO $6 \cap 2 \cap \quad I L=1, N \times L I M$

11010 FORMAT $(1 \mathrm{H} 1,10 \mathrm{X}, 1$ NUMBER OF HOURS THAT THF INCREASE IN MOISTURE AT $Z$

$+=1, F 7.0,1$ METERS EQUALED OR EXCEEDED $1, F 7.2,1 G / M * * 311$

PRINT $11010,2(I Z), X L I M(I L)$

II $Z=I L * N Z+I Z$

DO $60101 \mathrm{X}=1,12$

PRINT $11004,(X$ TOTAL (IX,IY,IIZ),IY=1,12)

11004 FORMAT (1HO,10X,12F7.1)

PRINT 11003

IF (IODT (3) . FQ.1) GO TO 6010

DO $6 \cap 25$ I $Y=1,12$

$6025 \times$ TOTALIIX,IY,IIZ)=0.

6010 CONTINUF

IF(IOPT(3).NE.1) GO TO 6020

DO 6012 I $X=1,12$

DO 6011 I $Y=1,12$

$X$ TOTAL $(I X, I Y, I Z)=X T O T A L(I X, I Y, I Z)+A H O U R S(I L) * X T O T A L(I X, I Y, I I Z$ )

$+\quad$ /NHOURS

$X$ TOTAL $(I X, I Y, I I Z)=0$. 


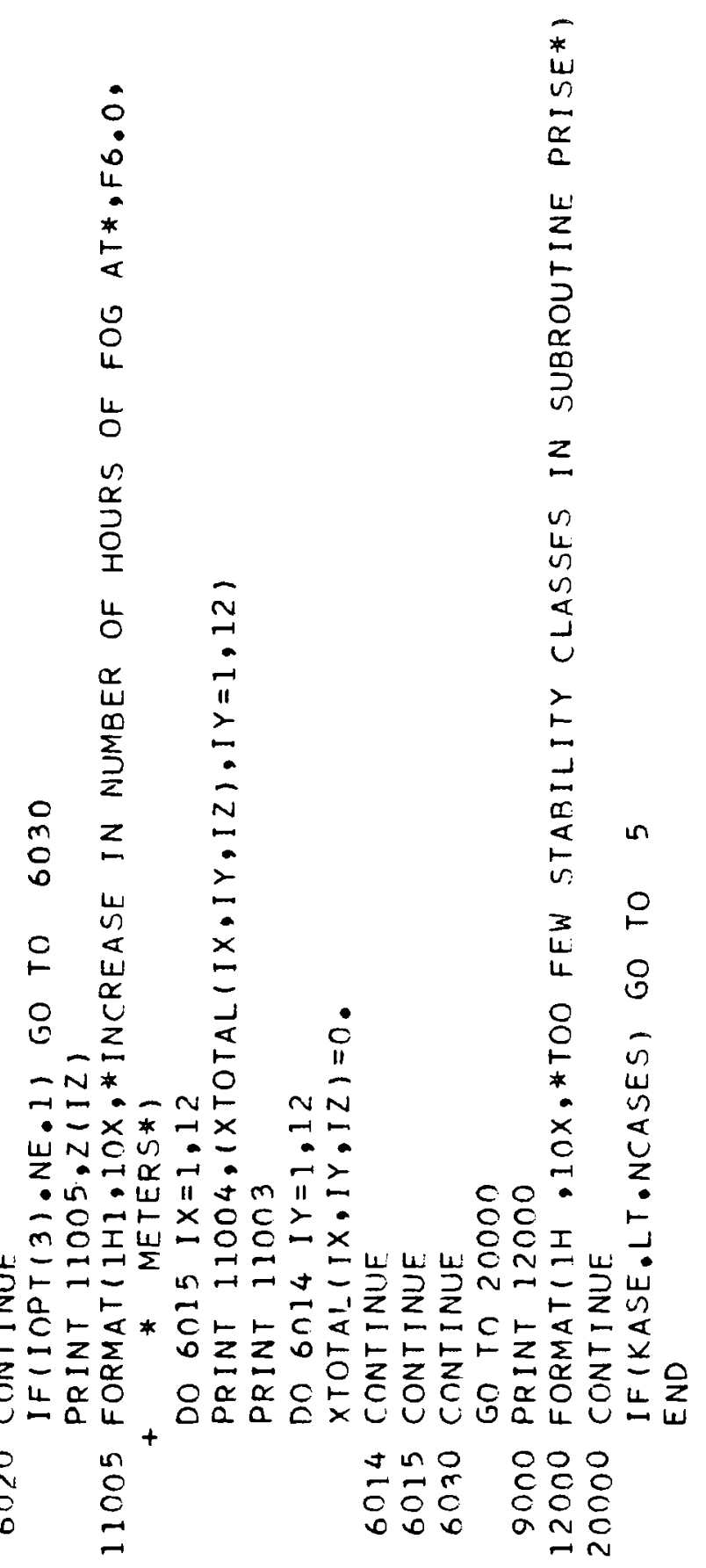


Figure A4 (continued)

SURROUT INE PRTSF (KSTAR,KSTR, IJRAR, T, HO,QS, CF, PR), RETURNS (AI)

SURROUTINE. PRISF COMPUTFS FINAL PLUMF RISE USING BRIGGS 1969

FORMULAE. IF UBAR IS LFSS THAN I M/S THE CALM EQN IS USED FOR

STABLE CONDITIONS OR UBAR IS SET EQUAL TO .5 M/S IN UNSTABLE AND

NEUTRAL CONDITIONS. INPUT IN METRIC UNITS, QS IN MW. PLUME RISE IS

CORRECTED FOR LATENT HEAT IJSING RESULTS OF COMPARISON WITH A I-D

CUMULUS CLOUD MODEL.

$\mathrm{FB}=8 \cdot 9 * \mathrm{QS}$

GO TO $(100,100,100,10,100,11,12)$, KSTAB

$10 G 0$ TO $(21,21,31,32), K S T R$

11 GO TO $(21,21,21,21,31,32)$, KSTA

12 GO TO $(21,21,21,21,31,32,33), K S T S$

21 IF (URAR-.5) 22,23,23

$22 U=.5$

GO TO 24

$23 U=U B A R$

$74 \mathrm{PR}=(1.6 / U) *(100 * \mathrm{HO} * \mathrm{HO} * \mathrm{FR}) *(1 . / 3). * \mathrm{CF}$

GO TO 200

$31 S=.049 / T$

GO TO 40

$32 S=.27 \prime T$

GO TO 40

$33 S=.49 ! T$

40 CONTINIJF

IF(URAR-1) $50,60,50$

$50 P R=5.0 *(F R * F B /(S * S * S)) *(1 . / 8) * C$.

GO TO 200

$60 P R=2.7 *(F B /(U B A R * 5)) * *(1 . / 3 \cdot) * C F$

GO TO 200

100 RETURN Al

200 RE TURN

END 
Figure A4 (continued)

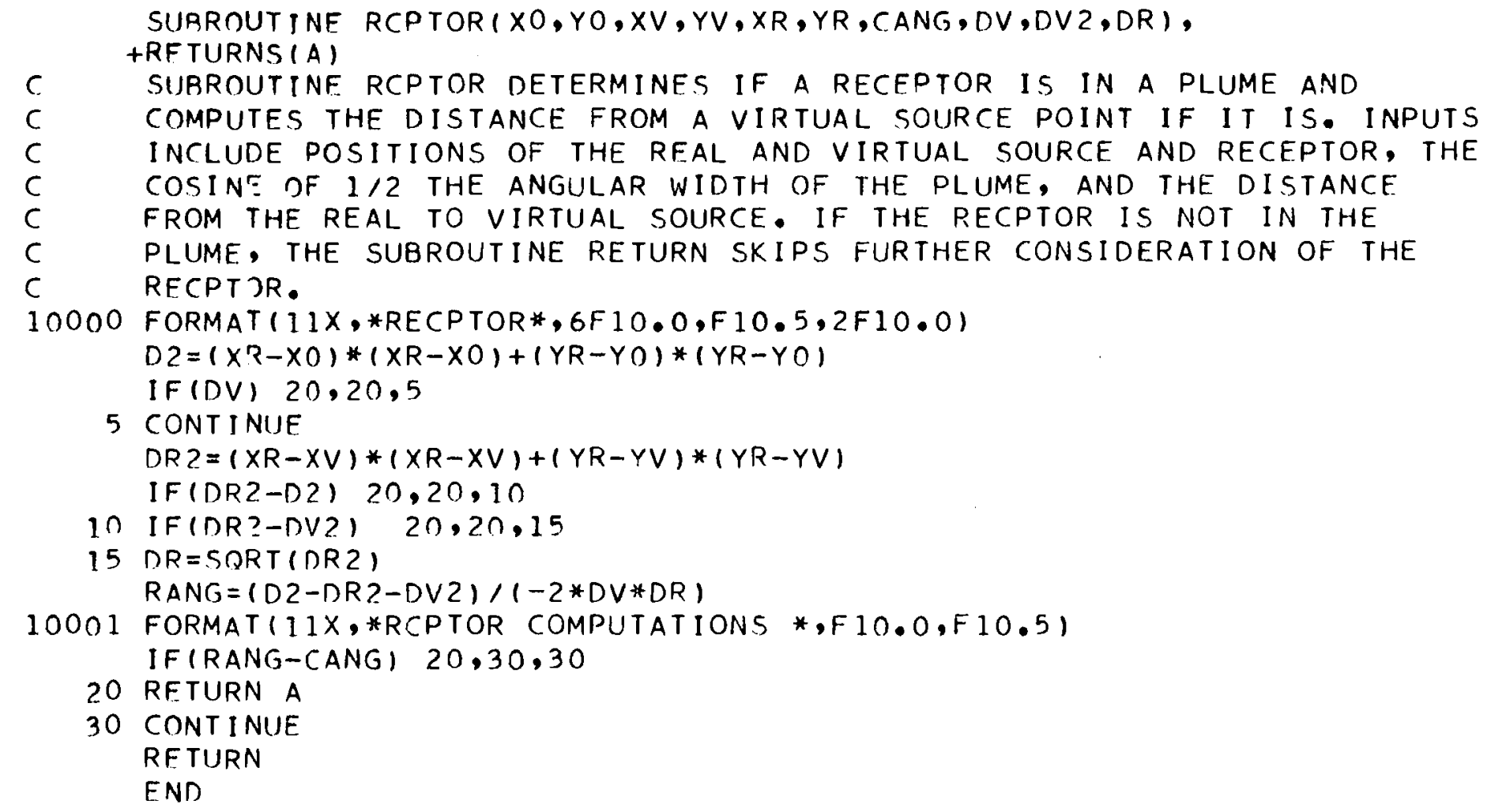


Figure A4 (continued)

SURROUTINF DIFFUSE (NS,KSTB,UAAR, UBC, DR, ZLID,H, Q, ICT,NZ, Z, CHI )

SURROUTINE DIFFUSF PERFORM.S DIFFUSION COMPUTATIONS USING A SECTOR AVERAGFD GAUSSIAN PLUME MODEL WITH COMPLETE REFLECTION AT GROUND LEVEL. A REFLECTING LID IS OPTIONAL. THE SOURCE MAY BE ELEVATED OR AT GROUND LEVEL. THE RELEASE HEIGHT IS ASSUMED TO BE BELOW THE LID. ALL REFLECTION TERMS CONTRIBUTING LESS THAN . 25 PERCENT OF THE DOMINANT TERM TO CHI/Q ARE NFGLECTED. WHEN ZLID/SIGMAZ IS LESS THAN I.5, A UNIFORM VERTICAL CONCENTRATION IS ASSUMED. TEN LEVELS CAN BE TREATED, IF A LEVFL IS ABOVE THE LID THE CONCENTRATION IS 2.ERO. THE BASIC SECTOR AVERAGF MODEL IS DESCRIBE IN SECTION 3-3 OF $M+A E-1968$. TREATMENT OF REFLECTION IS BASED ON SECTION 6.6 OF TEXT RY CSANADY, 1973

DIMFNSION Z(10), CHI (1O)

ORTAIN SIGMAZ ESTIMATF

10000 FORMAT $111 \mathrm{X}$, STAB.CLASS, WIND SPEED, RELEASE HEIGHT, ICT, DISTANCE, AND

+ SIGMAZ ARE*,I5,F6.2,F5.0,I5,F7.0,F6.2I

$D N M=-2 * S Z 2$

COEF $=(.0635 * N S) /(D R * S Z * U B A R)$

$C$ IS THERE A LID, IF SO GO TO 30

IF (ZLID) $10,10,30$

C NO LID

C FlFVATED RELEASE, IF SO GO TO 20

10 IF (H) $11,11,20$

COMPUTE CHI/O FOR GRROUND LFVFL SOURCF WITHOUT LID

11 DO $15 \quad \mathrm{I}=1, \mathrm{NZ}$

IF $(Z(1)) 12,12,13$

$12 \mathrm{CHI}(\mathrm{I})=2 * \mathrm{COEF}$

GO TO 15

$13 \mathrm{CHI}(I)=2 * \operatorname{COFF} * \operatorname{EXP}(Z(1) * Z(1) / D N M)$

15 CONTINUE

C GO TO 300 to COMPUTE CHI

GO TO 300 
Figure A4 (continued)

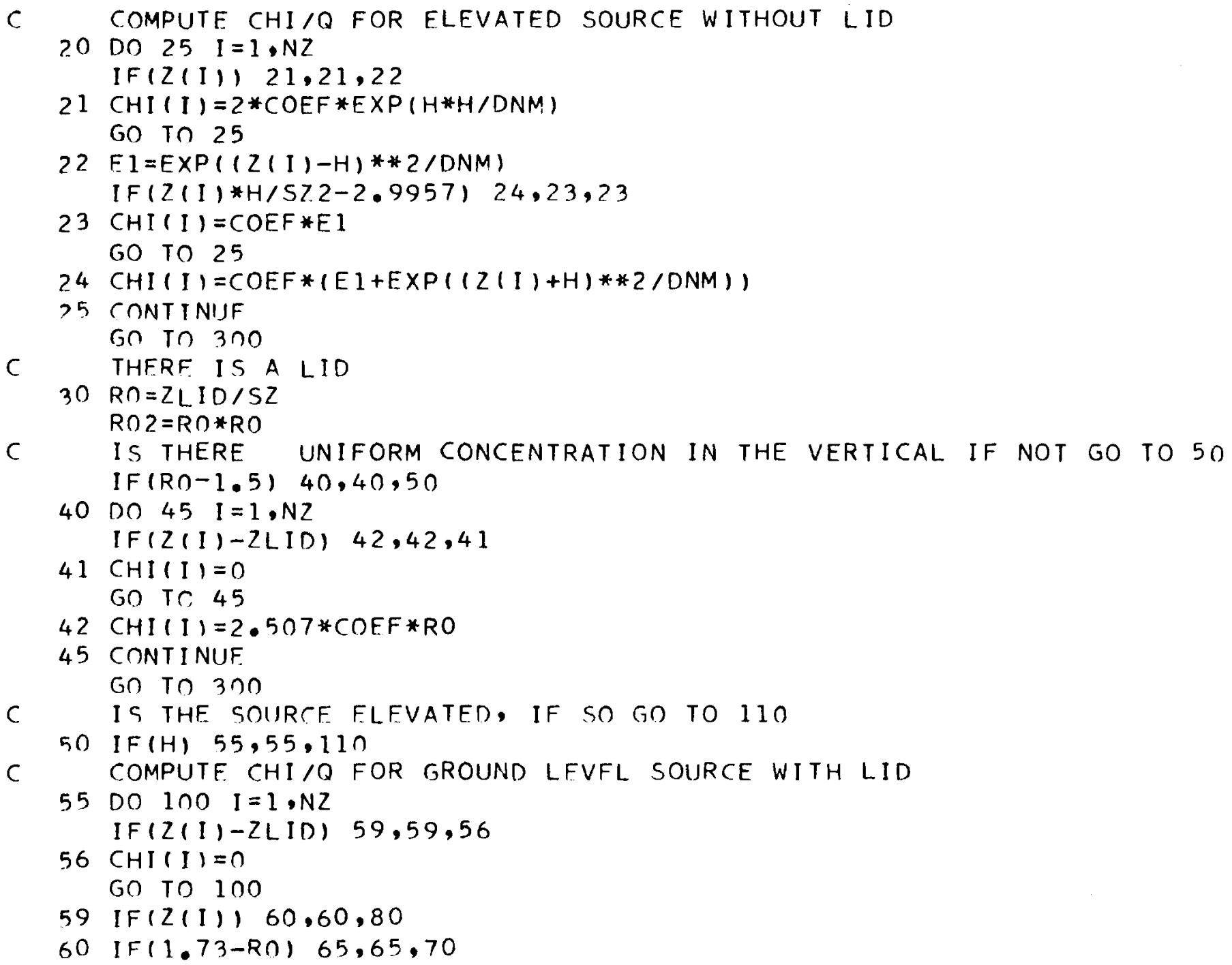




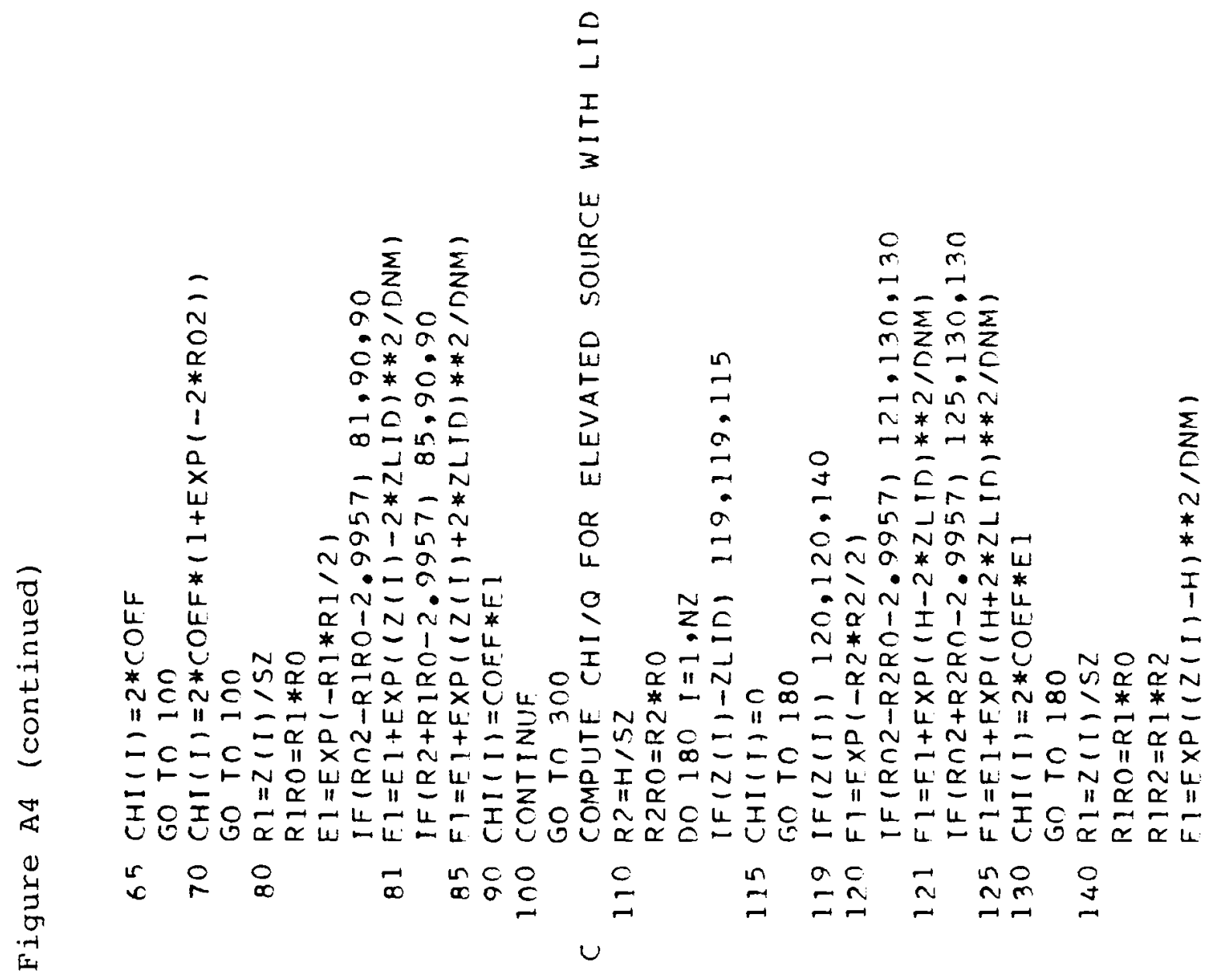




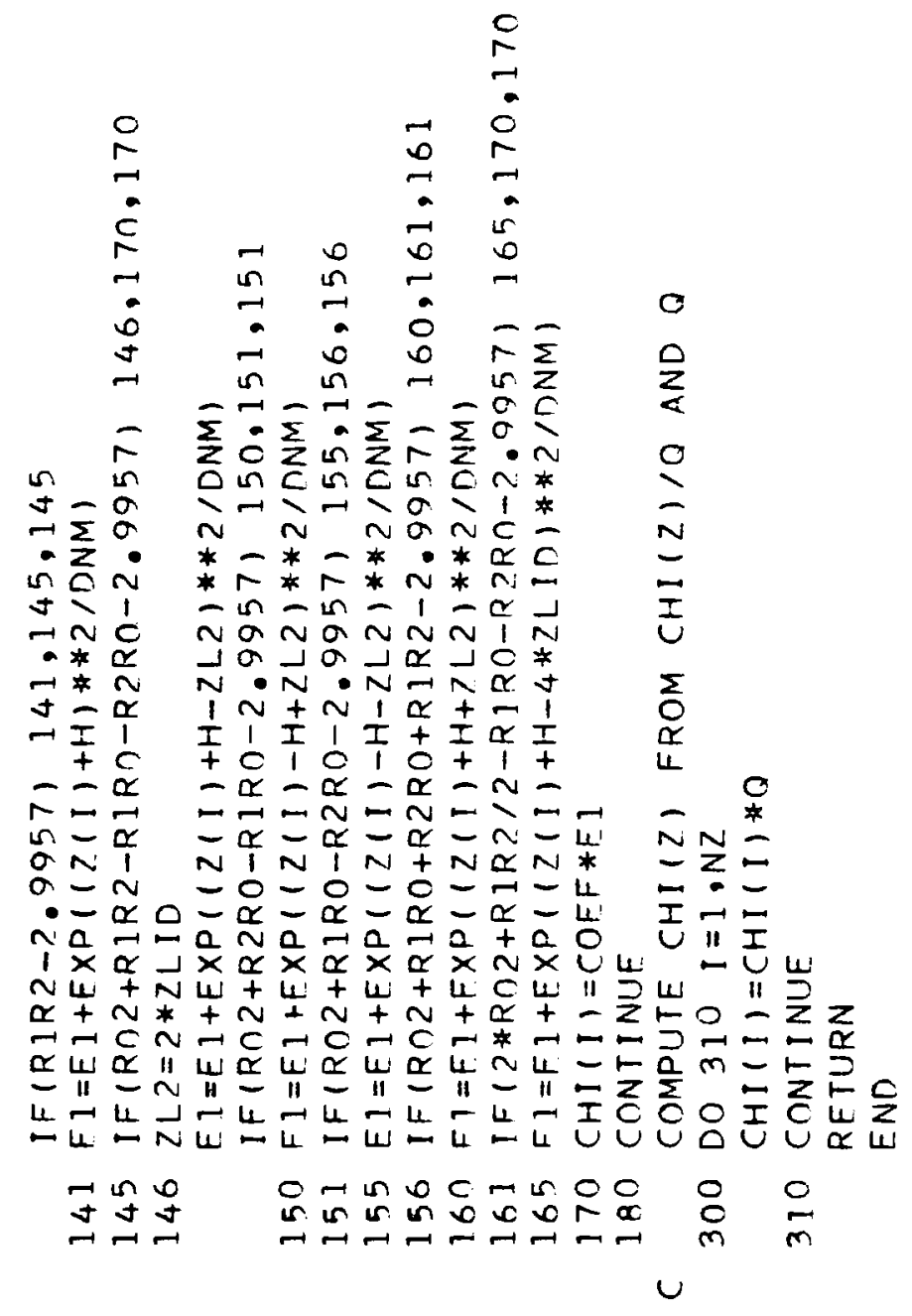


Figure A4 (continued)

SURROUTINF. SIGMAZIKSTR, UIRAR,URC,H,ICT,DR, SZ,SZ2)

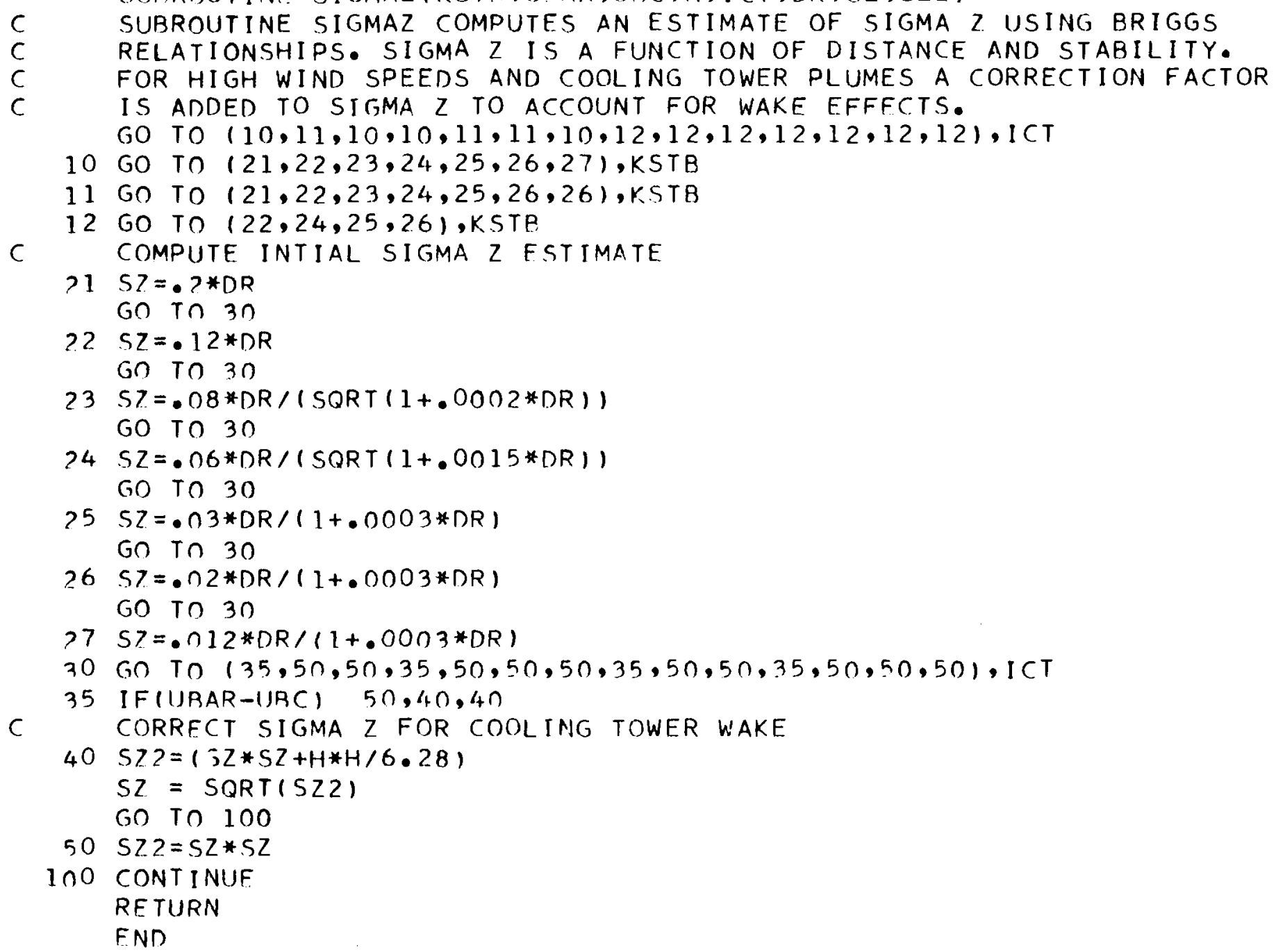




\section{DISTRIBUTION}

No. of

Copies

\section{OFFSITE}

1 ERDA Chicago Patent Group

A. A. Churm

1 Aluminum Company of America

Post office Box 120

Vancouver, WA 98660

Lyman J. Harris

Northwest Area Power Manager

1 Benton County Public Utility District

Post Office Box 6270

Kennewick, WA 99336

Robert W. Blodgett, Manager

1 Bonneville Power Administration

Post Office Box 3621

Portland, OR 97208

C. Ray Foleen

Deputy Administrator

1 Culp, Dwyer, Guterson \& Grader

1300 Hoge Building

seattle, WA 98104

Gordon Culp

1 Electric Power Research Institute Post Office Box 10412

Palo Alto, CA 94304

Laura Henning

20 Energy Research and Development Administration Mail stop F-309 Washington, DC 20545

W. F. Savage, Chief

Advanced Concepts Evaluation Branch 
No. of

Copies

27 ERDA Technical Information Center

1 Nuclear Regulatory Commission

Washington, DC 20555

1 Pacific Northwest Utilities Conference

Committee

Post Office Box 1231

Wenatchee, WA 98801

Howard C. Elmore, Chairman

1 Pacific Northwest Utilities Conference

Committee on Engineering and Planning

2730 Northwest 77 th Place

Portland, OR 97213

David J. Lewis, Consultant

1 Portland General Electric Company

621 Southwest Alder street

Portland, OR 97205

A. J. Porter, Vice President

1 Puget Sound Power and Light Company

Puget Power Building

Post office Box 535

Bellevue, WA 98004

John W. Ellis, President

1 Jack Criswell, General Manager

Springfield Utility Board

250 North "A" Street, Box 300

Springfield, OR 97477

1 National Academy of Public Administration

1225 Connecticut Avenue NW

Washington, DC 20036

R. Kloman

2 Washington State Energy Office

1000 south Cherry

Olympia, WA 98504

Larry Bradley 
No. of

Copies

15

Energy Facility Site Evaluation Council

820 East Fifth Avenue

Olympia, WA 98504

Roger Polzin

ONSITE

8

ERDA Richland Operations Office

O. J. Elgert

P. W. Gottschalk

R. H. Lindsey/G. L. Liffick

F. R. Standerfer

M. W. Tiernan

Research and Development Programs Division

W. A. Burns (2)

40

Battelle-Northwest

D. B. Cearlock

R. L. Conley

D. W. Dragnich

R. F. Foster

J. J. Fuquay

H. Harty (10)

J. V. Ramsdell (10)

A. E. Reisenauer

W. H. Rickard

C. L. Simpson

J. K. Soldat

R. W. Wallace

D. G. Watson

Technical Information (5)

Technical Publications (3)

2 Washington Public Power Supply system

Rodger Woodruff

J. R. Young 